\title{
MASTER
}

\section{Oak Ridge TNS Program: Summary of FY 1978 Activities}

D. Steiner

W. R. Becraft

T. G. Brown

W. A. Houlberg

A. T. Mense

Y-K. M. Peng

R. L. Reid
J. A. Rome

C. Sardella

T. E. Shannon

P. T. Spampinato

W. M. Wells

G. W. Wiseman

OAK RIDGE NATIONAL LABORATORY OPERATED BY UNION CARBIDE CORPORATION - FOR THE DEPARTMENT OF ENERGY 


\section{DISCLAIMER}

This report was prepared as an account of work sponsored by an agency of the United States Government. Neither the United States Government nor any agency Thereof, nor any of their employees, makes any warranty, express or implied, or assumes any legal liability or responsibility for the accuracy, completeness, or usefulness of any information, apparatus, product, or process disclosed, or represents that its use would not infringe privately owned rights. Reference herein to any specific commercial product, process, or service by trade name, trademark, manufacturer, or otherwise does not necessarily constitute or imply its endorsement, recommendation, or favoring by the United States Government or any agency thereof. The views and opinions of authors expressed herein do not necessarily state or reflect those of the United States Government or any agency thereof. 


\section{DISCLAIMER}

Portions of this document may be illegible in electronic image products. Images are produced from the best available original document. 


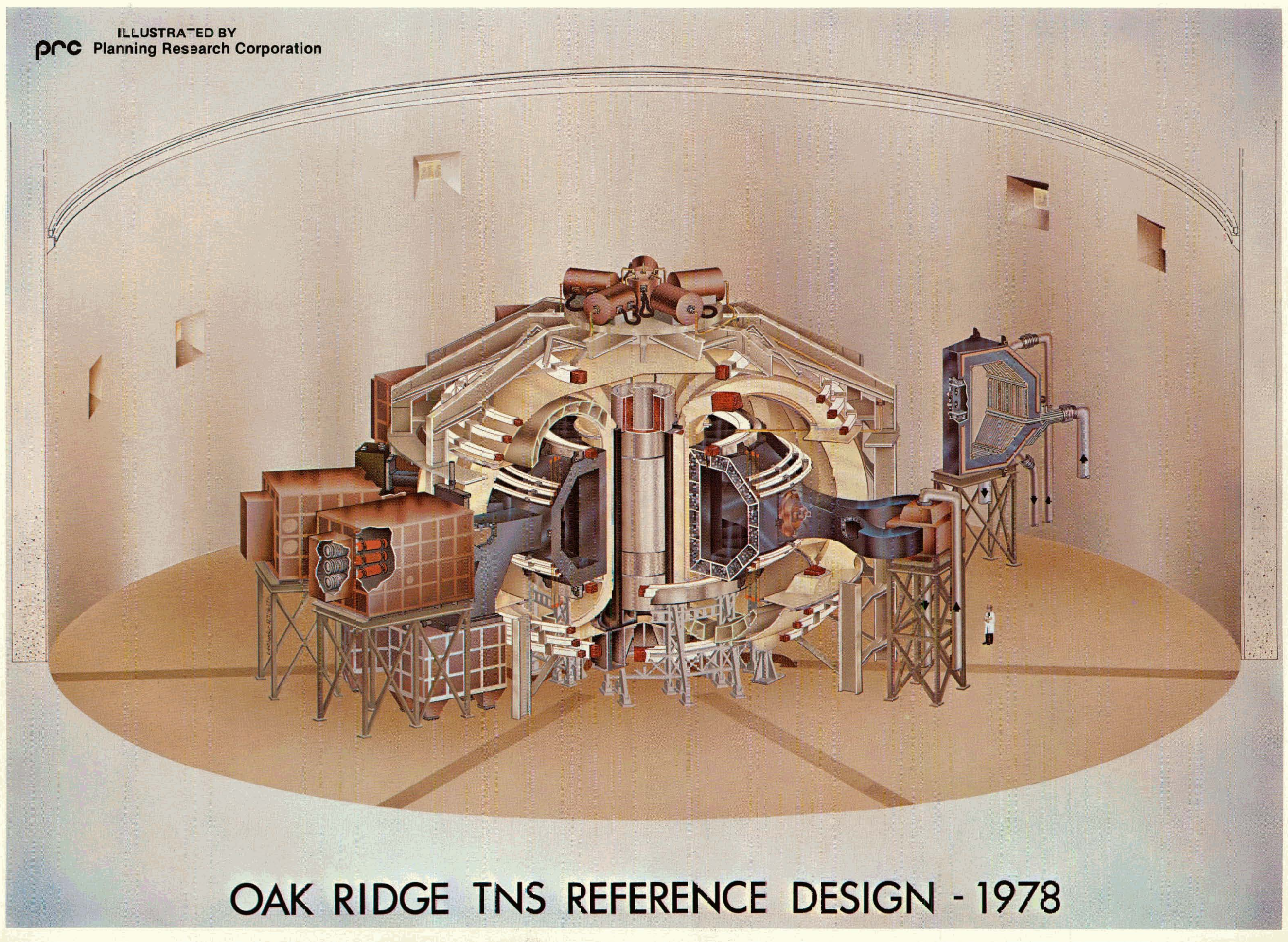


Contract No. $W-7405-$ eng-26

FUSION ENERGYY DIVISION

OAK RIDGE TNS PROGRAM: SUMMARY OF FY 1978: ACTIVITIES
D. Steiner
W. R. Becräft
J. A. Rome
T. G. Brown
C. Sardella
W. A. Houlberg
T. E. Shannon
A. T. Mense
P. T. Spampinato
$\dot{Y}-K$. M. Peng
W. M. We $1 \mathrm{~s}$
R. L. Reid
G. W. Wiseman

Date Públished: July 1979

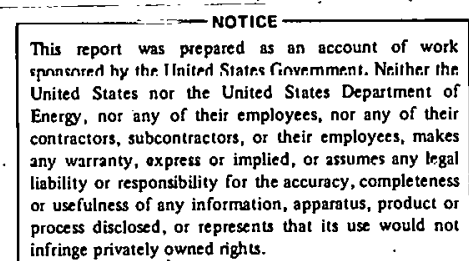

process disclosed, or represents that its use would not

infitinge privately owned rights.

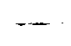

Prepared by the

OAK RIDGE NATIONAL LABORATORY

Oak Ridge, Tennessee 37830

operated by

UNION CARBIDE CORPORATION'

for the

DEPARTMENT OF ENERGY 


\section{Printed in the United States of America. Available from National Technical Information Service \\ U.S. Department of Commerce 5285 Port Royal Road, Springfield, Virginla 22161 \\ Price: Printed Copy $\$ 6.60$; Microfiche $\$ 3.00$}

This report was prepared as an account of work sponsored by an agency of the United States Government. Neither the United States Government nor any agency thereot, nor any of their employees, contractors, subcontractors, or their employees, makes any warranty, express or implied, nor assumes any legal liability or responsibility for any third party's use or the results of such use of any information, apparatus, product or process disclosed in this report, nor represents that its use by such third party would not infringe privately owned rights. 


\section{CONTENTS}

ABSTRACT $\ldots \ldots \ldots \ldots \ldots \ldots \ldots \ldots \ldots \ldots \ldots \ldots \ldots \ldots \ldots \ldots \ldots \ldots \ldots \ldots$

INTRODUCTION $\ldots \ldots \ldots \ldots \ldots \ldots \ldots \ldots \ldots \ldots \ldots \ldots \ldots \ldots \ldots \ldots \ldots \ldots \ldots \ldots \ldots \ldots$

1. ENGINEERING DESCRIPTION $\ldots \ldots \ldots \ldots \ldots \ldots \ldots \ldots \ldots \ldots \ldots \ldots \ldots \ldots \ldots \ldots \ldots \ldots \ldots$

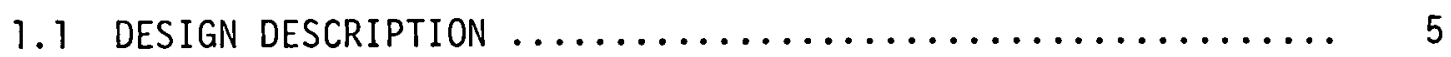

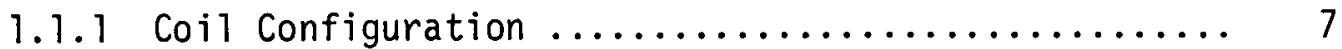

1.1 .2 Assembly and Remote Maintenance ................ 14

1.1.3 Structural Design and Maintenance Features ......... 14

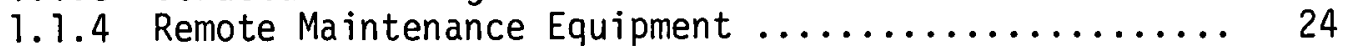

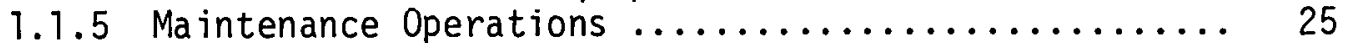

1.1.6 Electrical Power Conversion System ............. 27

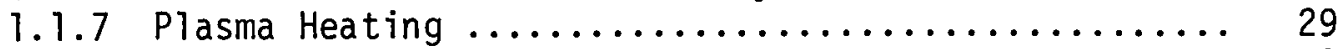

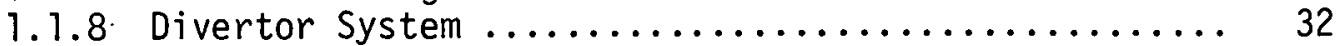

1.1 .9 Secondary Vacuum Enclosure ................. 34

1.2 SYSTEMS DESCRIPTION $\ldots \ldots \ldots \ldots \ldots \ldots \ldots \ldots \ldots \ldots \ldots \ldots \ldots \ldots \ldots \ldots$

2. PROJECTED OPERATING CHARACTERISTICS OF THE PLASMA .......... 45

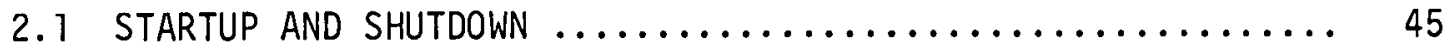

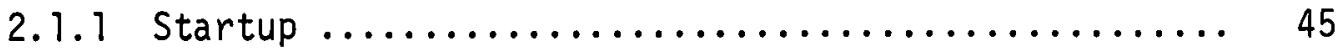

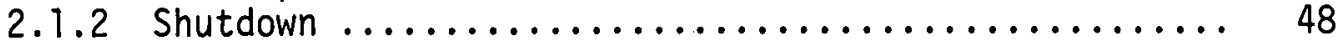

2.2 NEUTRAL BEAM INJECTION HEATING $\ldots \ldots \ldots \ldots \ldots \ldots \ldots \ldots \ldots \ldots$

2.2.1 1-D Transport Model .................... 50

2.2.2 $1 \frac{1}{2}-D$ Transport Model ....................... 53

2.3 MAINTENANCE OF HIGH BETA CONFIGURATION ............ 55

2.3.1 MHD Stability Requirements .................. 56

2.3.2 Poloidal Field and Coil Current Requirements ...... 58

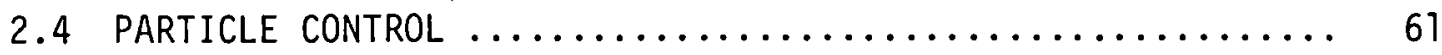

2.4.1 Prefill, Breakdown, and Current Buildup .......... 61

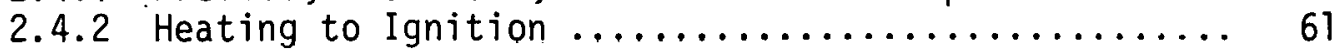

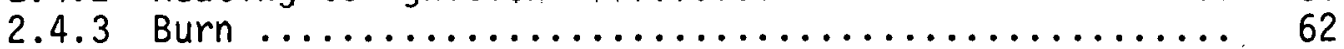

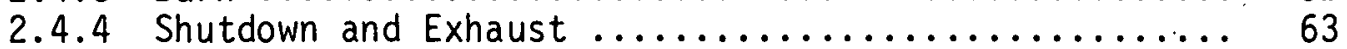

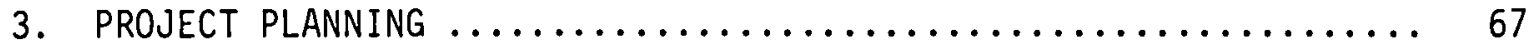

3.1 COST AND SCHEDULE $\ldots \ldots \ldots \ldots \ldots \ldots \ldots \ldots \ldots \ldots \ldots \ldots \ldots \ldots \ldots \ldots \ldots \ldots$

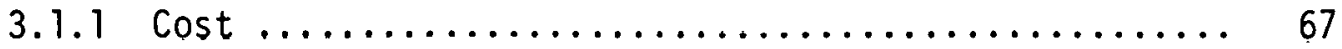

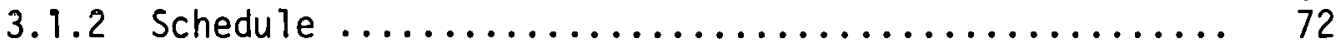

3.2 TECHNICAL NEEDS ASSESSMENT $\ldots \ldots \ldots \ldots \ldots \ldots \ldots \ldots \ldots \ldots \ldots \ldots$

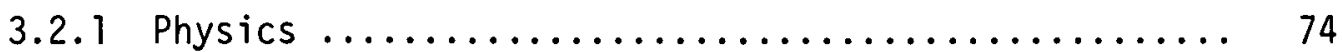

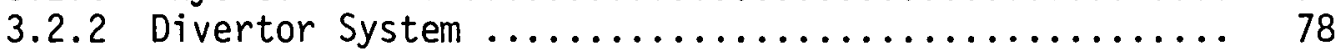

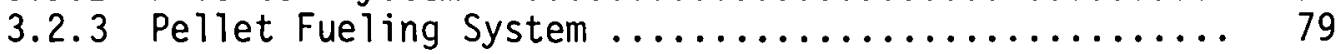

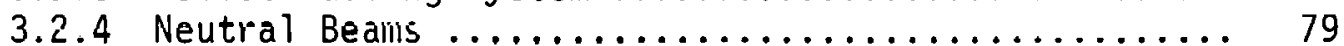


3.2.5 Poloidal Field System ...................... 80

3.2 .6 Mechanical Systems $\ldots \ldots \ldots \ldots \ldots \ldots \ldots \ldots \ldots \ldots, \quad 80$

3.2.7 Blanket $\ldots \ldots \ldots \ldots \ldots \ldots \ldots \ldots \ldots \ldots \ldots \ldots \ldots \ldots \ldots \ldots \ldots, 80$

3.2 .8 Toroidal Field System ...................... 81

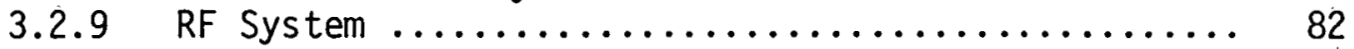

3.2.10 Instrumentation and Controls System $\ldots \ldots \ldots \ldots \ldots .62$

3.3 MISSION DESCRIPTION ............................. 83

3.3 .1 0bjectives $\ldots \ldots \ldots \ldots \ldots \ldots \ldots \ldots \ldots \ldots \ldots \ldots \ldots, 83$

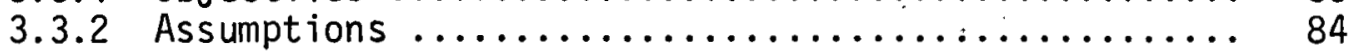

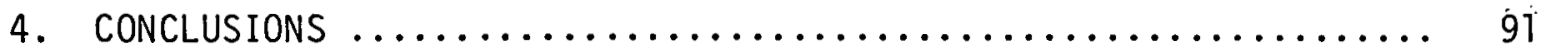

4.1 ENGINEERING FEASIBILITY .......................... 91

4.1.1 Remote Maintenance ........................ 9.1

4.1 .2 Poloidat Field System ........................... 91.

4.1 .3 - Divertor System ............................ 92

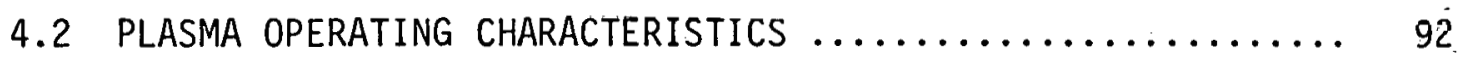

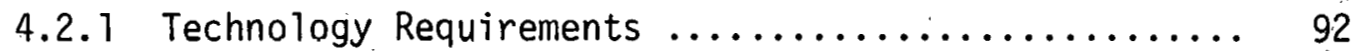

4.2.2 High Beta Maintenance ........................ 93.

4.2 .3 Key Physics Issues $\ldots \ldots \ldots \ldots \ldots \ldots \ldots \ldots \ldots \ldots,{ }_{93}$

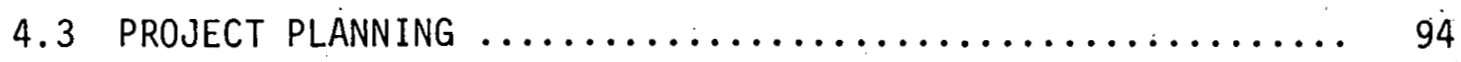

4.3.1 Cost and Schedule ......................... 94

4.3 .2 R\&D Needs Assessment ........................... 94

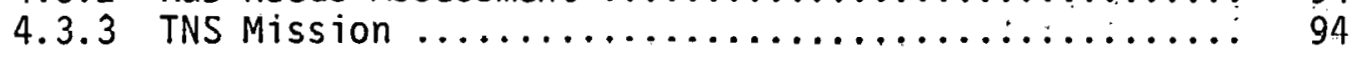




\section{ABSTRACT}

The Next Step (TNS) represents the stage of fusion energy development in which the major emphasis is on engineering testing and demonstration. In this document, the activities of the Oak Ridge TNS Program for FY 1978 are described and summarized. The Reference Design that has evolved from these activities is described, its operating characteristics are examined, and project pianning issues are considered. Major conclusions from the FY 1978 effort are stated.

Further documentation of the FY 1978 Oak Ridge TNS Program activities is contained in ORNL/TM-6721-ORNL/TM-6733. 


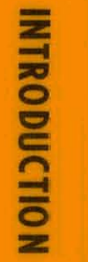

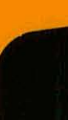




\section{INTRODUCTION}

The Next Step (TNS) represents that stage of fusion energy development in which the major emphasis is directed toward engineering testing and demonstration. Thus, TNS should not be viewed as simply a facility, but rather as a major phase in the development of fusion power. The engineering phase of the magnetic fusion power development effort is beginning with the construction of devices such as the Tokamak Fusion Test Reactor (TFTR) at the Princeton Plasma Physics Laboratory (PPPL) and the Mirror Fusion Test Facility (MFTF) at the Lawrence Livermore Laboratory (LLL). Nevertheless, it is recognized that devices such as TFTR and MFTF are not intended to operate as engineering test facilities. Therefore, the objective of the TNS studies, initiated by the Department of Energy's Office of Fusion Energy, has been to define the characteristics and requirements of a major new facility dedicated to the engineering testing phase of fusion power development. For this reason, TNS has also been identified as an Engineering Test Facility (ETF).

Because the scientific basis required for TNS/ETF will first be available for the tokamak concept, it seems reasonable that the fusion core of the facility should be based on the tokamak concept. The commitment to an ETF with a tokamak reactor core does not represent a commitment to tokamaks as the ultimate power reactor concept. However, if fusion is to develop into an energy option, it is necessary to move into the engineering phase, and it is in this context. that the tokamak concept must be pursued vigorously as the core for TNS.

The TNS studies at Oak Ridge National Laboratory (ORNL) were initiated in FY 1977. During FY 1977, the Oak Ridge effort pursued scoping studies in three broad areas: plasma engineering, systems modeling, and program planning. These activities were carried out in cooperation with the Fusion Power Systems Department of the Westinghouse Electric Corporation. Based upon the findings of the FY 1977 efforts, it was judged that continued activities in the 0ak Ridge TNS program should be directed toward preconceptual design with particular emphasis placed on engineering feasibility. 
As a foint of departure for the FY 1978 activities, a Baseline [esign :vas selected, based on the systems modeling effart of FY 1977. The primary objective of the FY 1978 TNS effort has been to evolve the Baseline Design toward a preconceptual design. However, it is emphasized that because of budget constraints, the FY 1978 effort was not $i_{i}$ tendec to lead to a completed preconceptual design. Therefore, the design resulting from this year's effort is referred to as the Reference Design, rather than as a preconceptual design. The FY 1978 activities were carried out in cooperation with Fusion Energy Department of the Grumman Aerospace Corporation.

In this document we summarize the essential results of the FY 1978 activities of the Oak Ridge TNS Program in the context of the evolved Reference Design. Section 1 is an engineering description of the Reference Design, inclucing a trief systems description, engineering drawings, and a discussion of the key design features. Section 2 examines the projected operating characteristics of the tokamak fusion core, including startup and shutdown, plasma heating, high beta maintenance, anc particle control. Section 3 considers project planning issues, including costs and schedules, technical needs assessments, and mission description. The major conclusions from the FY 1978 effort are stated in Sect. 4.

In addition to this summary document, a number of $0 \div$ her reports are being issued as part of the documentation of the FY 1978 effort (see Tajle I.1). To supplement the brief systems description given in Sect. 1, a systems description mariual is being issued as ORNL/TM-6721. The technical needs assessmert summarized in Sect. 3 is described in more detail in ORIL/TM-6722. The details of the studies which led to the seiection of components and configuration for the Reference Design are reported in 0RNL/TM-6723-ORNL/TM-6733. Included are systems studies of the toroidal field coil configuration, the vacuum topology, the poloidal field system, the bundle divertor concept, the rf system employed in stantup, and the pellet fueling system; descriptions of the mechanical desigr, of the overall system, the startup scenarios, the ieutral beam injection and density buildup options; and the beta maintenance approach. 
Table I.1. Reports dealing with Oak Ridge TNS Program activities during FY 1978

\begin{tabular}{|c|c|c|}
\hline $\begin{array}{l}\text { Report } \\
\text { number }\end{array}$ & Title & First author \\
\hline ORNL/TM-6720 & Summary of FY 1978 Activities & D. Steiner \\
\hline ORNL/TM-6721 & System Description Manual & R. L. Reid \\
\hline ORNL/TM-6722 & Technical Needs Assessment & W. R. Becraft \\
\hline ORNL/TM-6723 & $\begin{array}{l}\text { System Studies of the } \\
\text { Toroidal Field Coils }\end{array}$ & R. L. Reid \\
\hline ORNL/TM-6724 & $\begin{array}{l}\text { Mechanical Design } \\
\text { Considerations }\end{array}$ & P. T. Spampinato \\
\hline ORNL/TM-6725 & Evaluation of Vacuum Topology & C. Sardella \\
\hline ORNL/TM-6726 & $\begin{array}{l}\text { Evaluation of the Poloidal } \\
\text { Field System }\end{array}$ & T. G. Brown \\
\hline ORNL/TM- 6727 & $\begin{array}{l}\text { Evaluation of the Bundle } \\
\text { Divertor }\end{array}$ & W. M. Wells \\
\hline ORNL/TM-6728 & $\begin{array}{l}\text { Evaluation of the ECH Startup } \\
\text { System }\end{array}$ & R. Rosenfeld \\
\hline ORNL/TM-6729 & $\begin{array}{l}\text { Evaluation of the Pellet } \\
\text { Fueling System }\end{array}$ & W. Simpson \\
\hline ORNL/TM-6730 & Plasma Startup Scenarios & W. A. Houlberg \\
\hline ORNL/TM-6731 & $\begin{array}{l}\text { Low Density Neutral Beam } \\
\text { Heating Scenario }\end{array}$ & J. A. Rome \\
\hline ORNL/TM-6732 & Beta Maintenance & Y-K. M. Peng \\
\hline ORNL/TM-6733 & Plasma Particle Control & A. T. Mense \\
\hline
\end{tabular}





\section{ENGINEERING DESCRIPTION}

The engineering description of the Reference Design provided in this section corsists of two parts. The design description (Sect. 1.1) is a summary description of the current Reference Design. Key engineering features of the design are highlighted, and the rationale for the selection of components and configuration is given. The systems description (Sect. 1.2) is an abbreviated description of the major TNS hardware sys tems.

\subsection{DESIGN DESCRIPTION}

The current Reference Design has evolved from the Baseline Designl adopted as a result of the FY 1977 system studies. Table 1.1 lists the major engineering parameters of the Reference Design. The parameters of the Baseline Design are included for comparison.

The Reference Design is an ignited, D-T burning, air core tokamak. The duty cycle is $89 \%$ with a steady-state burn of 500 ser. The plasma radius is $1.2 \mathrm{~m}$, the major radius is $5.0 \mathrm{~m}$, and the plasma elongation is 1.6 (D-shape). The fusion power density is $5.0 \mathrm{MW} / \mathrm{m}^{3}$, which results in $1140 \mathrm{MW}$ of fusion power during the burn. Exothermic reactions in the first wall and shield are assumed to increase the thermal power to $1450 \mathrm{MW}$ (based on an energy release of $22.4 \mathrm{MeV}$ per fusion event).

A water-cooled tubular first wall and a bundle divertor remove the energy associated with the fusion alpha particles. Both the first wall and the bundle divertor are designed to remove all the alpha particle energy; however, the distribution of this energy to each component is presently assumed to be about $50 \%$. A stainless steel shield, cooled by borated water, absorbs the bulk of the energy associated with the fusion neutrons. All the thermal energy, including that deposited at the first wall and in the divertor, is dumped to a cooling tower.

The stainless steel toroidal vessel is composed of 16 bolted segments, and the entire tokamak is situated within an evacuated containment buildirig. A poloidal field (PF) system, consisting of a superconducting ohm: c heating $(\mathrm{OH})$ solenoid and both superconducting and copper 
Table 1.1. Comparison of parameters for the Reference Design and the Baseline Design

\begin{tabular}{|c|c|c|}
\hline & FY 78 Reference Design & FY 77 Baseline Design \\
\hline Plasma major radius, $R$ & $5.0 \mathrm{~m}$ & $5.0 \mathrm{~m}$ \\
\hline Plasma elongation, $\delta$ & 1.6 & 1.6 \\
\hline Flasma minor radius, a & $1.2 \mathrm{~m}$ & $1.2 \mathrm{~m}$ \\
\hline Plasma volume, $V_{p}$ & $230 \mathrm{~m}^{3}$ & $230 \mathrm{~m}^{3}$ \\
\hline Plasma current, $I_{p}$ & $5.0 \mathrm{MA}$ & $5.0 \mathrm{MA}$ \\
\hline Meutron wal1 loading, $\mathrm{L}_{\mathrm{w}}$ & $2.4 \mathrm{MW} / \mathrm{m}^{2}$ & $1.3 \mathrm{MW} / \mathrm{m}^{2}$ \\
\hline Total fusion power, $P_{\text {tot }}$ & $1140 \mathrm{MW}$ & $700 \mathrm{MW}$ \\
\hline Fusion fower density, $n$ & $5.0 \mathrm{MW} / \mathrm{m}^{3}$ & $2.6 \mathrm{MW} / \mathrm{m}^{3}$ \\
\hline Number cf TF coils & 12 & 20 \\
\hline TF coil veriical bore & $9.9 \mathrm{~m}$ & $7.6 \mathrm{~m}$ \\
\hline TF coil horizontal bore & $6.2 \mathrm{~m}$ & $4.9 \mathrm{~m}$ \\
\hline TF coil conductor & $\mathrm{Nb}_{3} \mathrm{Sn}$ & $\mathrm{Nb}_{3} \mathrm{Sn}$ \\
\hline Field at TF coil, $B_{m}$ & $10.9 \mathrm{~T}$ & $10.9 \mathrm{~T}$ \\
\hline Field on axis, $B_{T}$ & $5.3 \mathrm{~T}$ & $5.3 \mathrm{~T}$ \\
\hline S:eady-state burn time & $500 \mathrm{sec}$ & $16 \mathrm{sec}$ \\
\hline Total cycle time & $560 \mathrm{sec}$ & $300 \mathrm{sec}$ \\
\hline Total vo:t-seconds & $83 \mathrm{~V}-\mathrm{sec}$ & $52 \mathrm{~V}-\mathrm{sec}$ \\
\hline Neutral beam power, $P_{i n j}$ & $50 \mathrm{MW}$ & $75 \mathrm{MW}$ \\
\hline $\begin{array}{l}\text { Neutral beam energy, } \\
E_{i n j}\end{array}$ & $150 \mathrm{keV}$ & $150 \mathrm{keV}$ \\
\hline Injectior time, $\tau_{i n j}$ & $6.0 \mathrm{sec}$ & \\
\hline Micrawave power. & $1.0 \mathrm{MW}$ & \\
\hline Micrcwave frequency & $120 \mathrm{GHz}$ & \\
\hline Fueling. & Jellet injection & Pellet injection \\
\hline Impurity controi & 3undle divertor & $\begin{array}{l}\text { Compact poloidal } \\
\text { divertor }\end{array}$ \\
\hline Shielding & $\begin{array}{l}\text { Stainless steel balls } \\
\text { and borated water }\end{array}$ & $\begin{array}{l}\text { Stainless steel balls } \\
\text { and borated water }\end{array}$ \\
\hline Vacuum topology & Vacuum building & Plasma chamber \\
\hline Vacuum punping & Cryopumps & Eryopumps \\
\hline
\end{tabular}


equilibrium field (EF) coils, induces the plasma current and provides plasma position control. Plasma startup is assisted by the injection of $1 \mathrm{MW}$ of $\mathrm{rf}$ power at $120 \mathrm{GHz}$. Bulk heating is accomplished by the injection of $50 \mathrm{MW}$ of $150-\mathrm{keV}$ neutral beams into the plasma. The confining toroidal field is provided by $12 \mathrm{Nb}_{3} \mathrm{Sn}$ superconducting coils (TF coils). Plan and elevation views of the Reference Design are shown in Figs. 1.1 and 1.2 , respectively.

The operating cycle of the Reference Design is shown in Fig. 1.3. The mission objective for the Reference Design covers a 10-year period of operation. Four phases of operation are included in this 10-year period:

Phase I. Systems integration and checkout ( 0.5 year).

Phase II. Hydrogen operation, including long pulse ( 1.5 years).

Phase III. Ignition testing (2.5 years).

Phase IV. Technology and engineering testing ( 5.5 years).

Portions of each phase will operate at a reduced pulse rate, i.e., less than the design value of $\sim 50$ shots per $8-h r$ shift. The total number of cycles for the Reference Design is estimated to be 450,000 over the 10 -year period of operation.

In the evolution of the Reference Design from the Baseline Design, a major emphasis was placed on engineering feasibility. The key design features of the Reference Design are summarized in the context of engineering feasibility issues and their impact on component and configuration selection.

\subsubsection{Coil Configuration}

The configuration of the TF coil system has a significant impact on the mechanical design of the tokamak. In the Reference Design, the overall access around the plasma chamber has been increased by reducing the number of coils from 20 to 12 and substantially increasing their size ( $230 \%$ in bore). A trade study was performed ${ }^{2}$ to evaluate the cost impact of variations in coil size, number of coils, and magnetic field ripple. The Reference Design TF coil system configuration minimizes the 


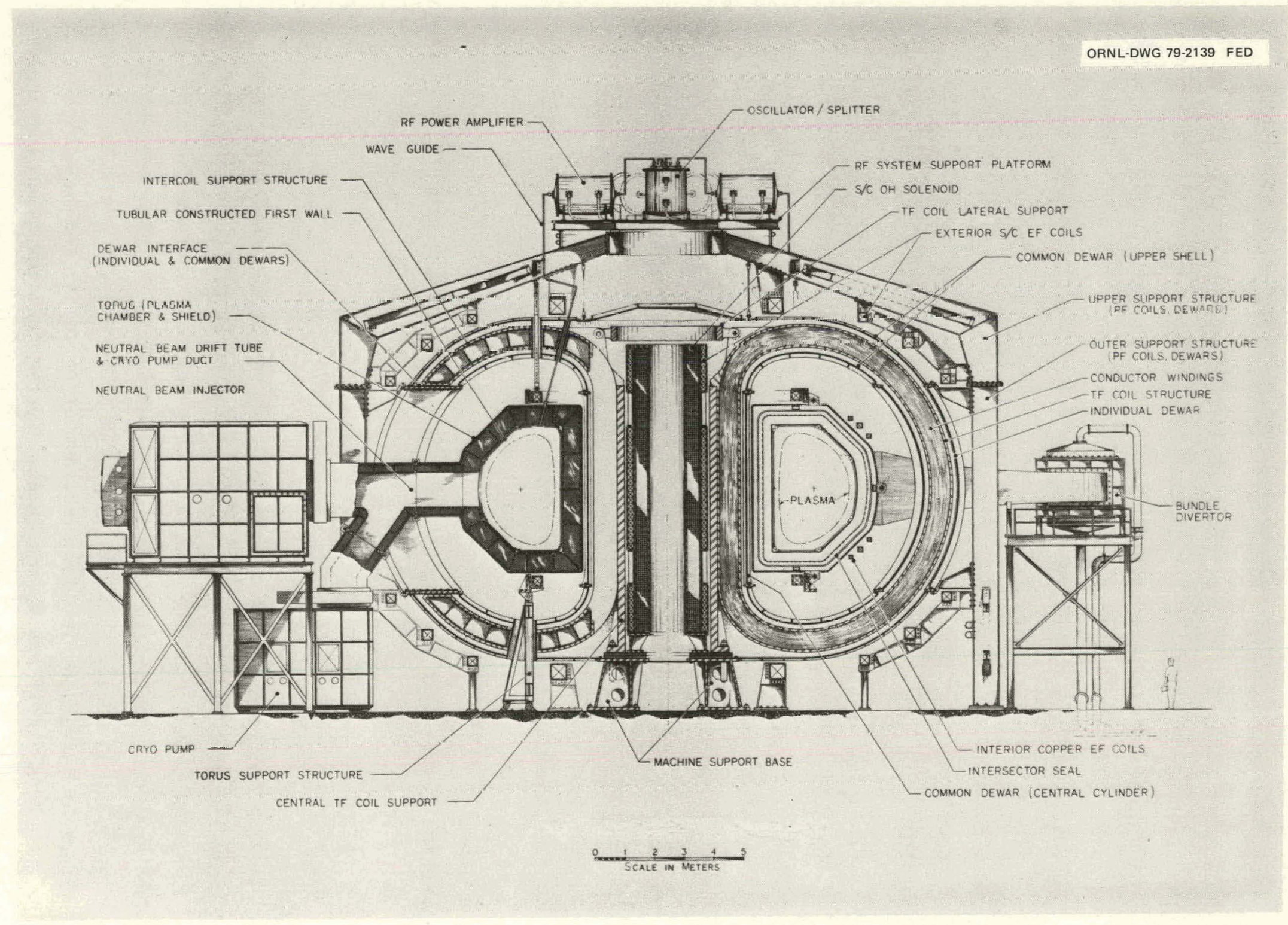

Fig. 1.1, Reference Design elevation view. 


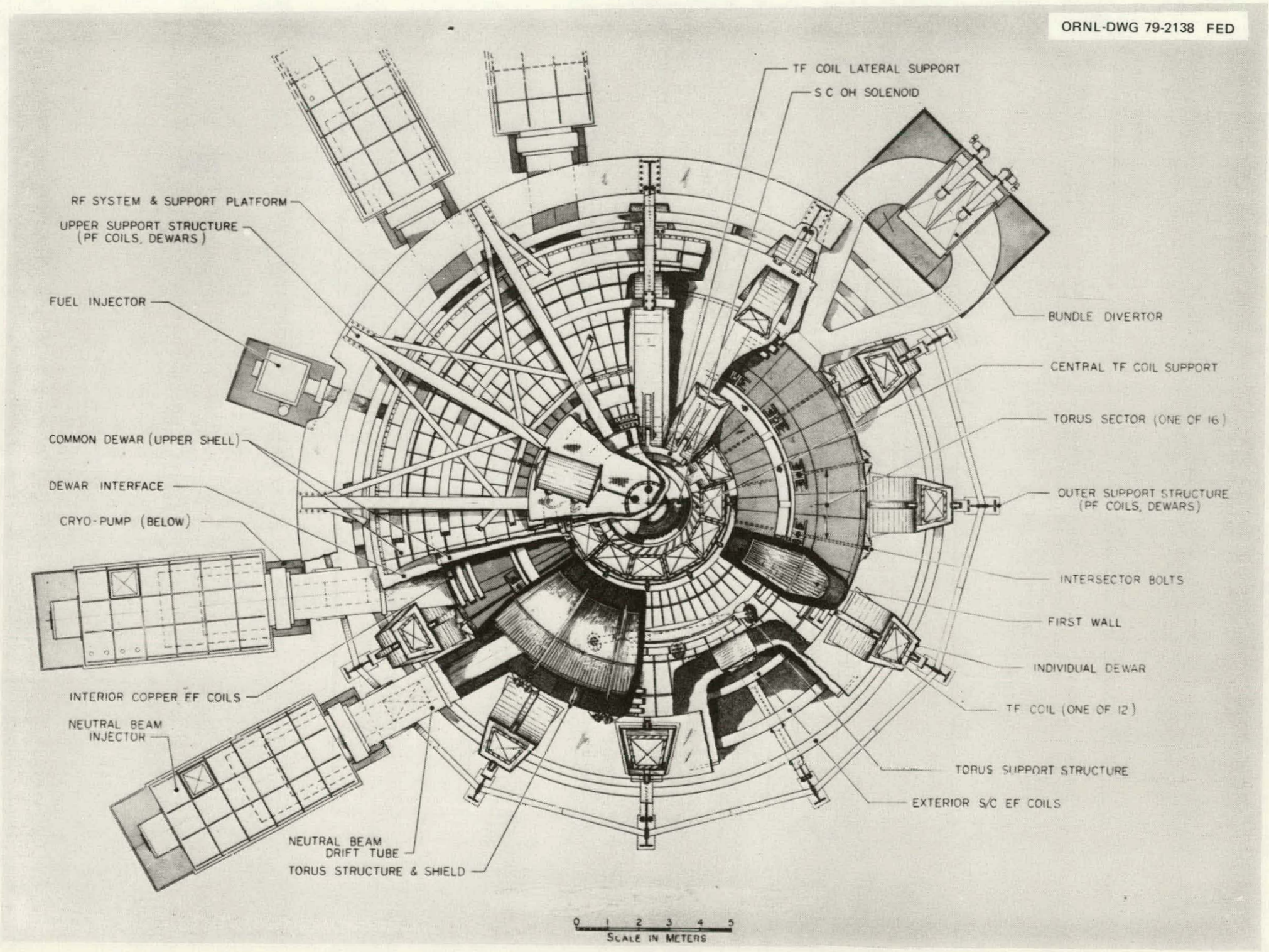

Fig. 1.2. Reference Design plan view. 
ORNL/OWG/FED 78-1176 R
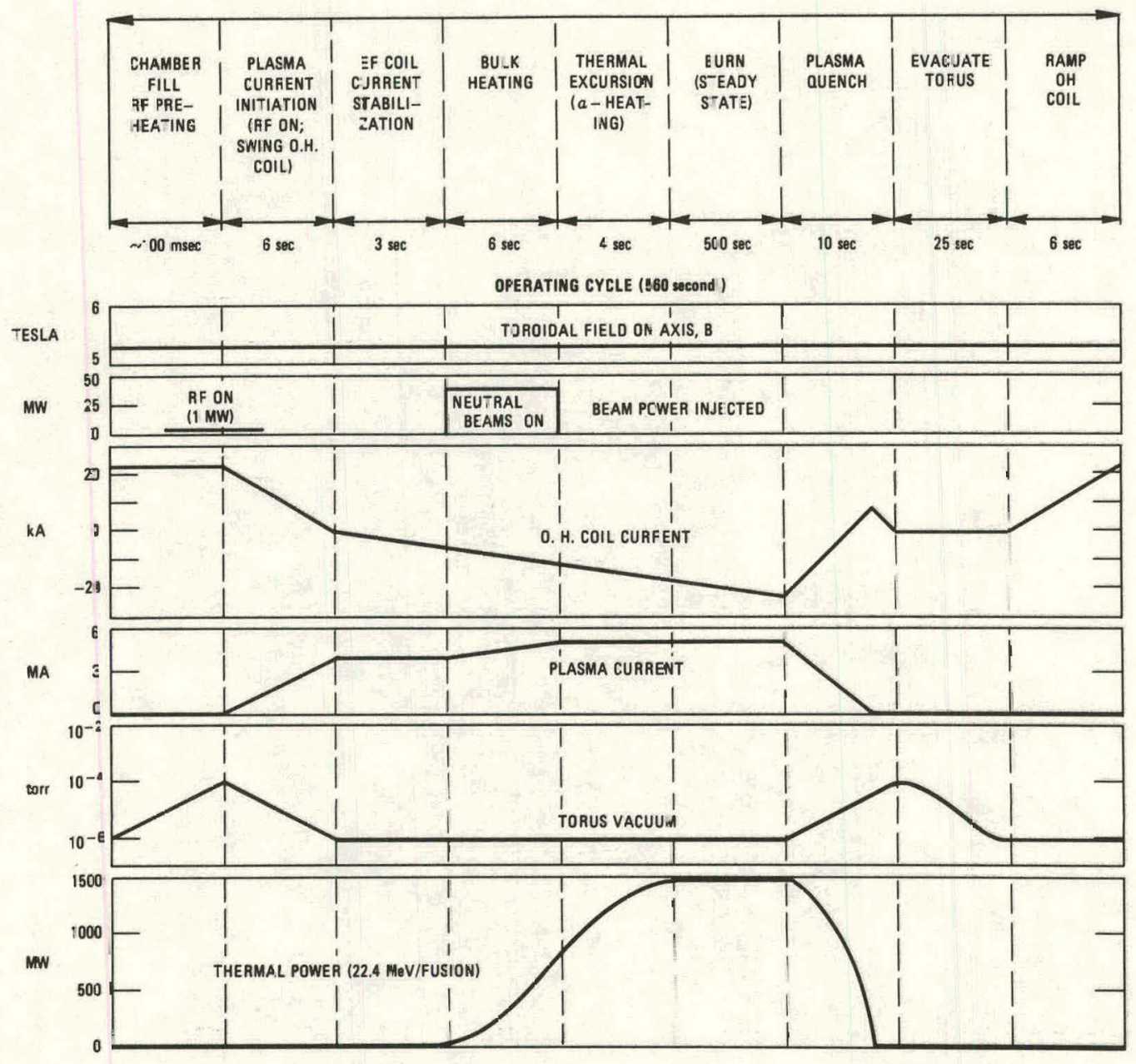

Fig. 1.3. Reference Design operating cycle. 
cost increase while satisfying remote maintenance requirements for access and a field ripple of less than $2 \%$ (peak-to-average) at the plasma edge. The project cost increase over the Baseline Design is $7 \%$.

On the basis of a trade study ${ }^{3}$ that evaluated several design options, an air core, hybrid PF system incorporating rf assisted startup was selected for the Reference Design. The system consists of superconducting $\mathrm{OH}$ coils, interior (inside the TF coil bore) copper EF coils which carry $35 \%$ of the EF current, and exterior (outside the TF coil bore) superconducting EF coils which carry $65 \%$ of the EF current. The name "hybrid" identifies the mix of interior and exterior EF coils. Figure 1.4 depicts the seven separate coil circuits and their time-varying currents.

The choice of the PF coil arrangement, location, and coil material (copper or superconducting) involved trade-offs between capital costs and operating costs for variations in startup and burn time. There is also a considerable cost impact and correlation between initiation rise time, coil location, and inductive power requirements. EF coils located within the TF coil bore have better coupling to the plasma and, assuming short plasma current initiation times $(1-2 \mathrm{sec})$, offer substantial savings in inductive power supply requirements. However, tecause of the need for radiation shielding in this area, copper coils are necessary. This offsets the power supply capital cost advantage with higher resistive power losses during burn. The intrinsic engineering difficulties in assembling and repairing interior coils in the radioactive environment of a D-T tokamak reactor also provide an impetus for reducing the complexity and number of interior coils. Exterior coils alone, aside from power supply costs considerations, are not desirable because of inadequate shape control and response to plasma movements. ${ }^{4}$

Our considerations of this range of possibilities strongly suggested a PF system incorporating a plasma initiation system that maximizes the current rise time in a manner consistent with plasma fhysics and offering a combination of interior and exterior EF coils. The Reference Design hybrid PF system incorporating $r f$ assisted startup does just that. The rf system, as an auxiliary heating source, increases the initiation rise time to $6 \mathrm{sec}$, significantly reducing the cost of power supplies. The split between normal copper interior EF coils and 


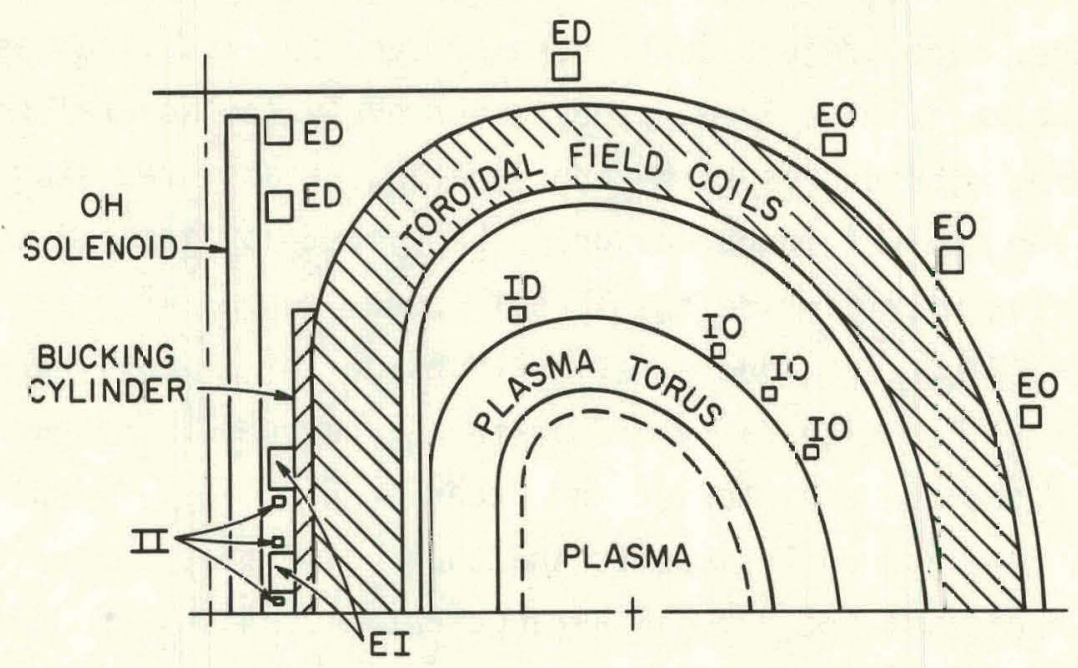

ORNL/DWG/FED 78-1237R

CURRENT WAVE FORMS

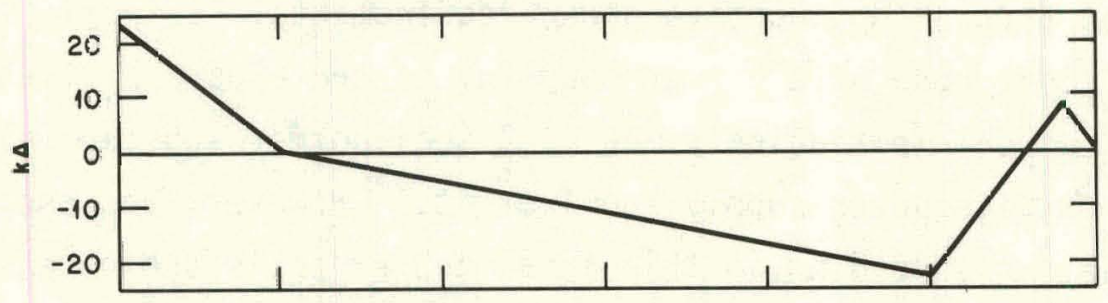

$\mathrm{OH}$

COIL CURRENT

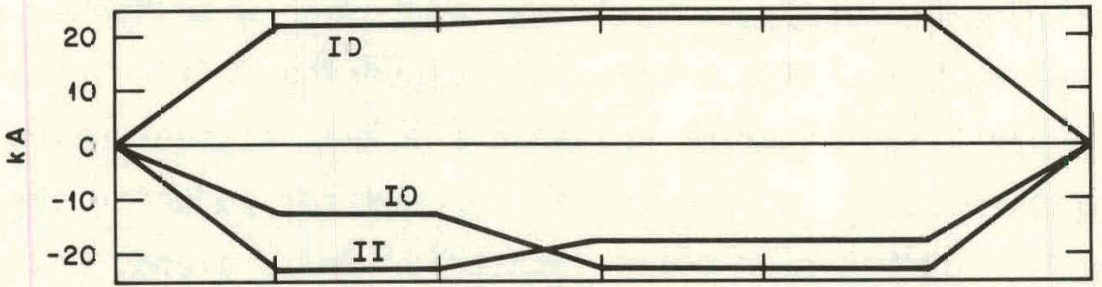

INTERIOR EF

COIL CURRENT

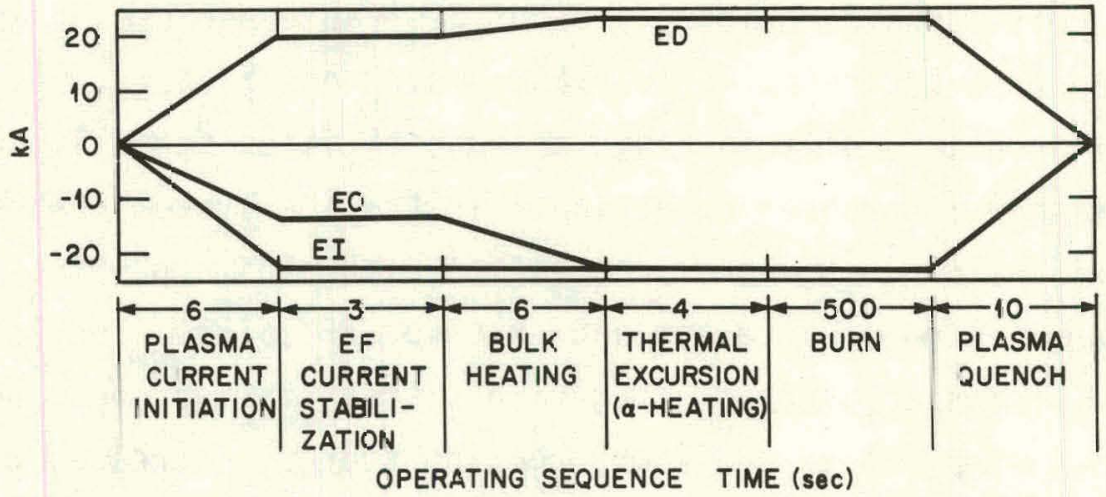

EXTERIOR EF COIL CURRENT

Fig. 1.4. Reference Design PF coil circuits. 
superconducting exterior EF coils offers a reasonable balance between system costs, coil maintenance, and plasma requirements. The use of superconducting coils proved to be a cost-effective approacn in reducing parasitic heatinc losses and MVA demand in the PF system. Interior copper coil resistive losses were minimized by designing the coils for a low current density $\left(450 \mathrm{~A} / \mathrm{cm}^{2}\right)$.

The size of the PF system was based on earlier studies ${ }^{5}$ which identified the geometric characteristics (i.e., plasma size and major radius) for a minimum cost ignited tokamak reactor. The of system was sized for a maximum field of $8 \mathrm{~T}$. The PF system can supply a total of $83 \mathrm{~V}$-sec when swinging the $\mathrm{OH}$ solenoid from $+8 \mathrm{~T}$ to $-8 \mathrm{~T}$.

The time behaviors of the six EF currents and the $\mathrm{OH}$ currents are shown in Fig. 1.7, assuming $r f$ preheating during startup. The $\mathrm{rf}$ power at $120 \mathrm{GHz}$ is produced by five $200-\mathrm{kW}$ gyrokylstrons. It is delivered to the plasma from the high field side in the extraordinary mode to preheat the electrons before the $\mathrm{OH}$ loop voltage is applied. It is presently assumed that low density $\left(\sim 10^{13} \mathrm{~cm}^{-3}\right)$ electrons in a small volume near the upper hybrid resonance can be heated to a temperature around $200 \mathrm{eV}, 6$ allowing the use of a low loop voltage $(\sim 10 \mathrm{~V})$ to initiate the plasma current. Durinc the subsequent current rise, the combined heating from rf, plasma current, and perhaps additional neutral beams can bring the electron temperature to above $3 \mathrm{keV}$. The resistive loss of flux swing during this phase is then relatively small ( $\leqslant 2 \mathrm{~Wb})$. The inductive voltseconds requirement for a plasma current of 5 MA (at $\bar{\beta} \cong i \%$ ) is estimated to be $51 \mathrm{~Wb}$. The PF system is then adequate for sustaining the burn for about $500 \mathrm{sec}$, assuming successful plasma ash removal, impurity control, and beta maintenance.

The air core $\mathrm{OH}$ solenoid was selected over the iron core alternate because of its advantages in total device cost, linearity of control functions, and higher volt-seconds capability for long burn times. The advantage of ar iron core device in improving the $\mathrm{OH}$ coupling to the plasma, and sutsequently reducing power, was found to have greater potential in devices where fewer volt-seconds and short burn times are required. 


\subsubsection{Assembly and Remote Mäintenance}

The cesign feature which most significantly impacts our remote maintelance concept is the use of a secondary vacuum enclosure (SVE) to maintain a vacuum environment external to the reactor. The need for high vacuum joints is thus eliminated throughout the device, and remote maintenance is made easier.

In a commercial power reactor, rapid blanket module replacement is a majo- factor in determining plant availability and hence the cost of electricity. Therefore, an important criterion for maintenance is the ability to replace a torus sector rapidly and reliably. With the design approach adapted in the Reference Design, maintenence of the plasma chamber can be accomplished without removal of either the $T=$ or the PF coil systems.

The remote maintenance features of the Reference Design evolved through the incorporation of three major changes to the Baseline Design:

(1) A reduction in the number of TF coils from $2 C$ to 12 allowed sufficient room between coils to replase a torus sector, which eliminated the need to remove TF coils for sector replacement.

(2) An increase in TF coil bore $(230 \%)$ made it passible to relocate the PF coils inside the TF coils during a sector replacement operation, removing the need for $\mathrm{PF}$ coil segmentation for this operation.

(3) The use of mechanical torus joints, made possible by an evacuated reactor building, el iminated the need for internal cutting and welding to replace a torus sector.

A 1:40 scale model was constructed to help evaluate these concepts. Photographs of the model are oresented in Figs. 1.5-1.8 to illustrate the rerote maintenance features of the Reference Design.

\subsubsection{Structural Design and Ma intenance Features}

Listed below are the major mechanical assemblies of the Reference Design, their functions, and their maintenance requirements (refer to Figs. 1.9 and 1.10). 


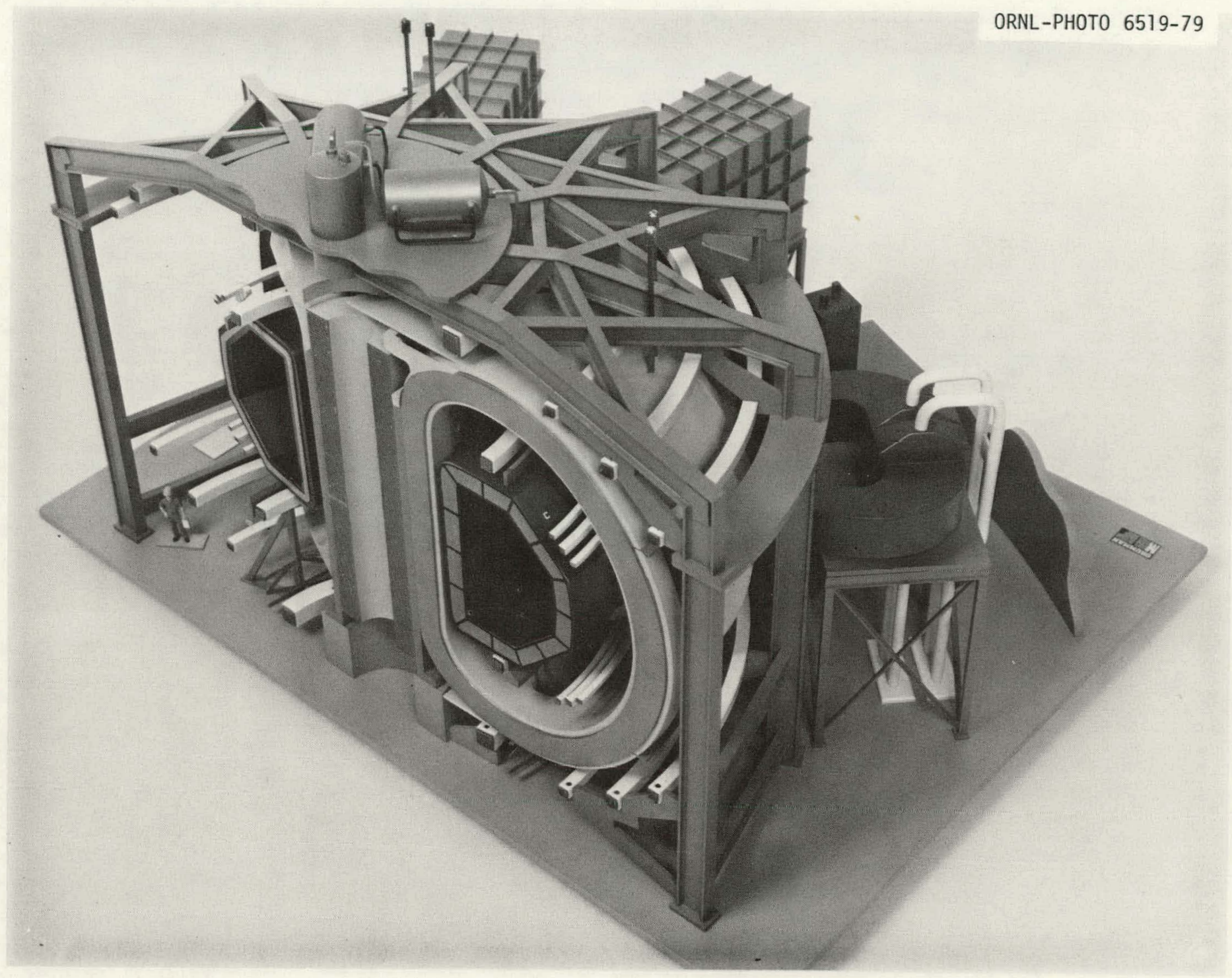

Fig. 1.5. Scale model of Reference Design (scale 1:40). 


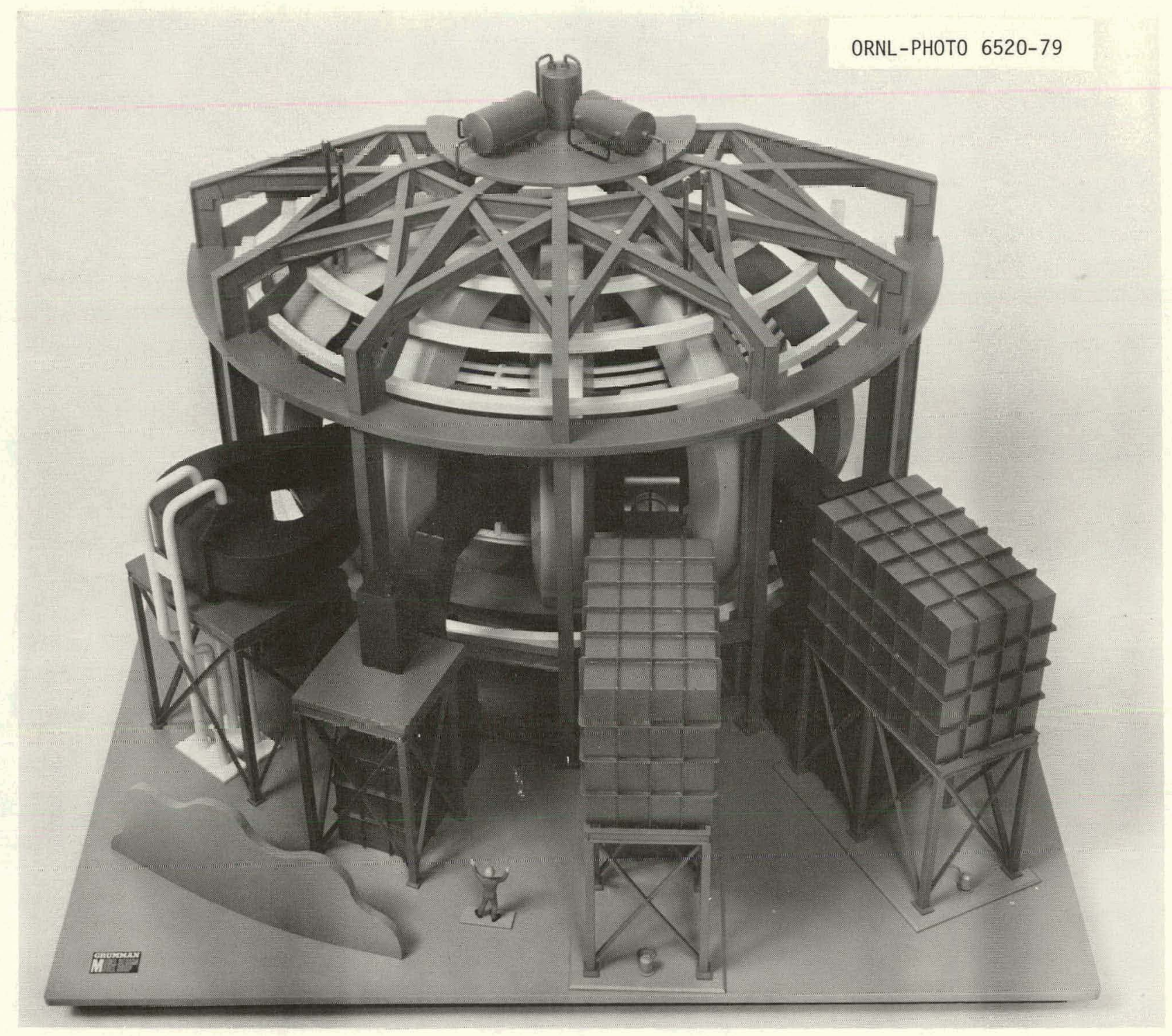

ने

Fig. 1.6. Access between TF coils. 


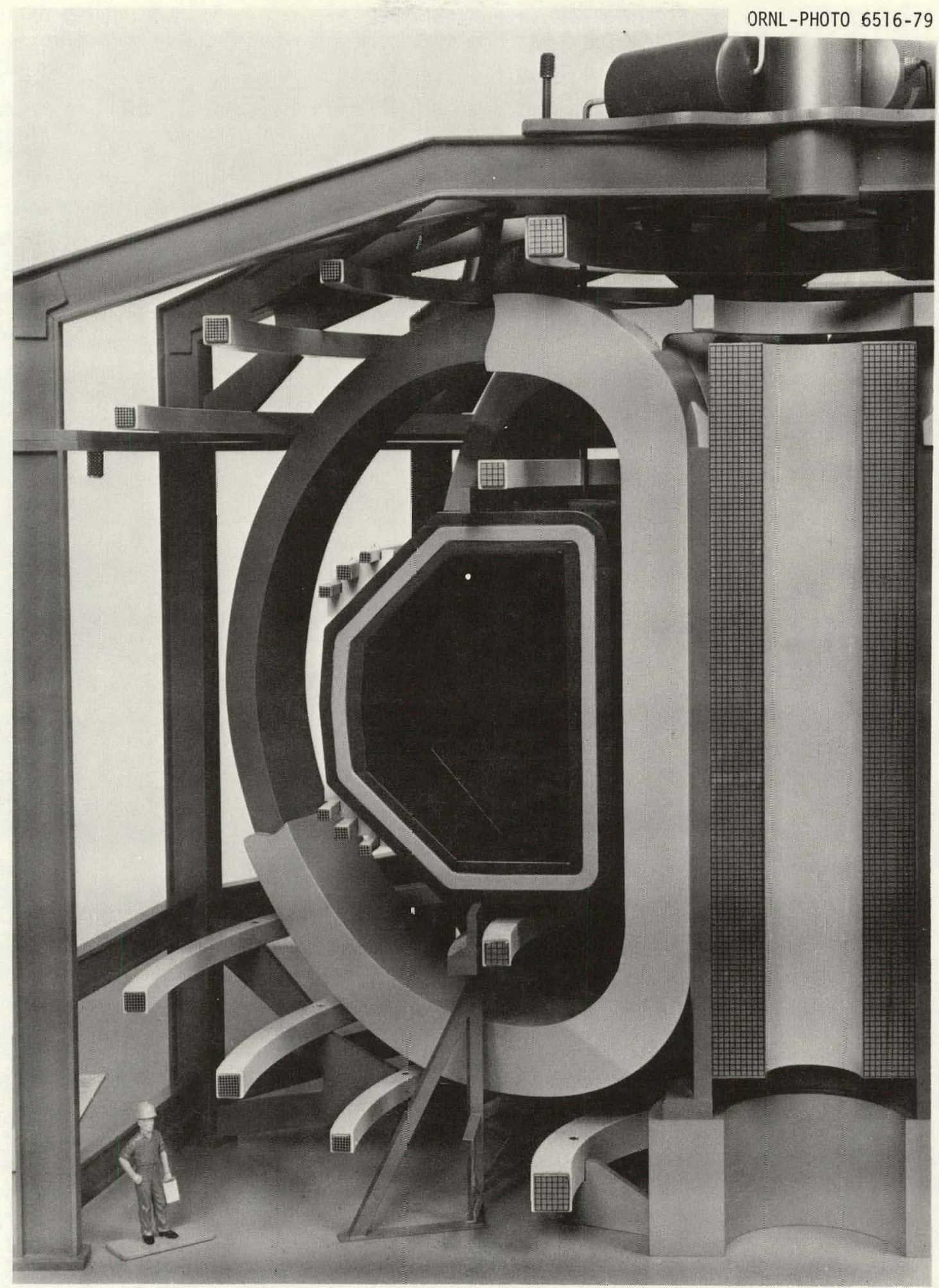

Fig. 1.7. (a) Coil system design approach for shield segment removal, showing coils in operating position. 


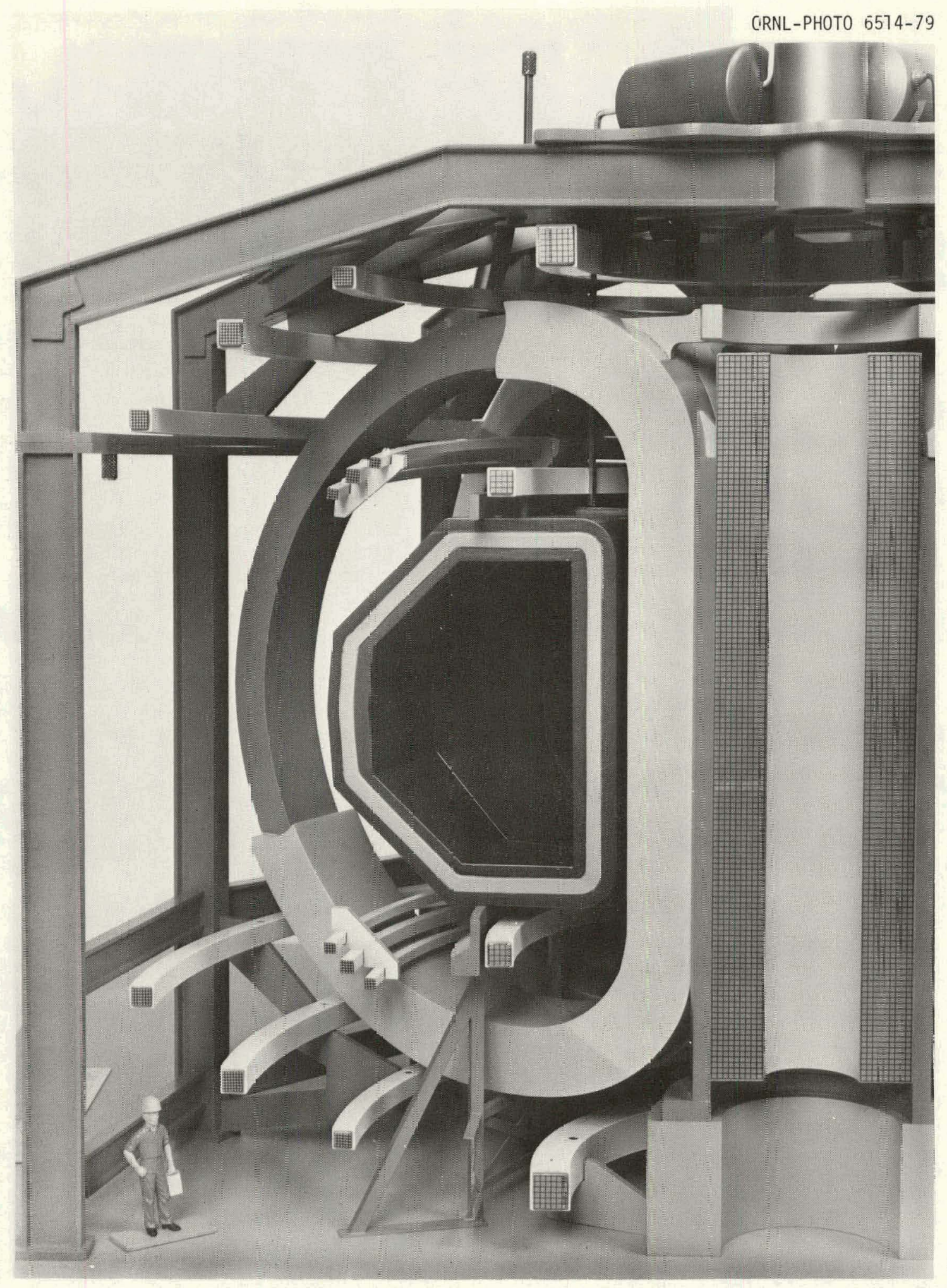

Fig. 1.7. (b) Coil system design approach for shield segment remcval, showing upper PF coils naised and lower PF coils lowered. 


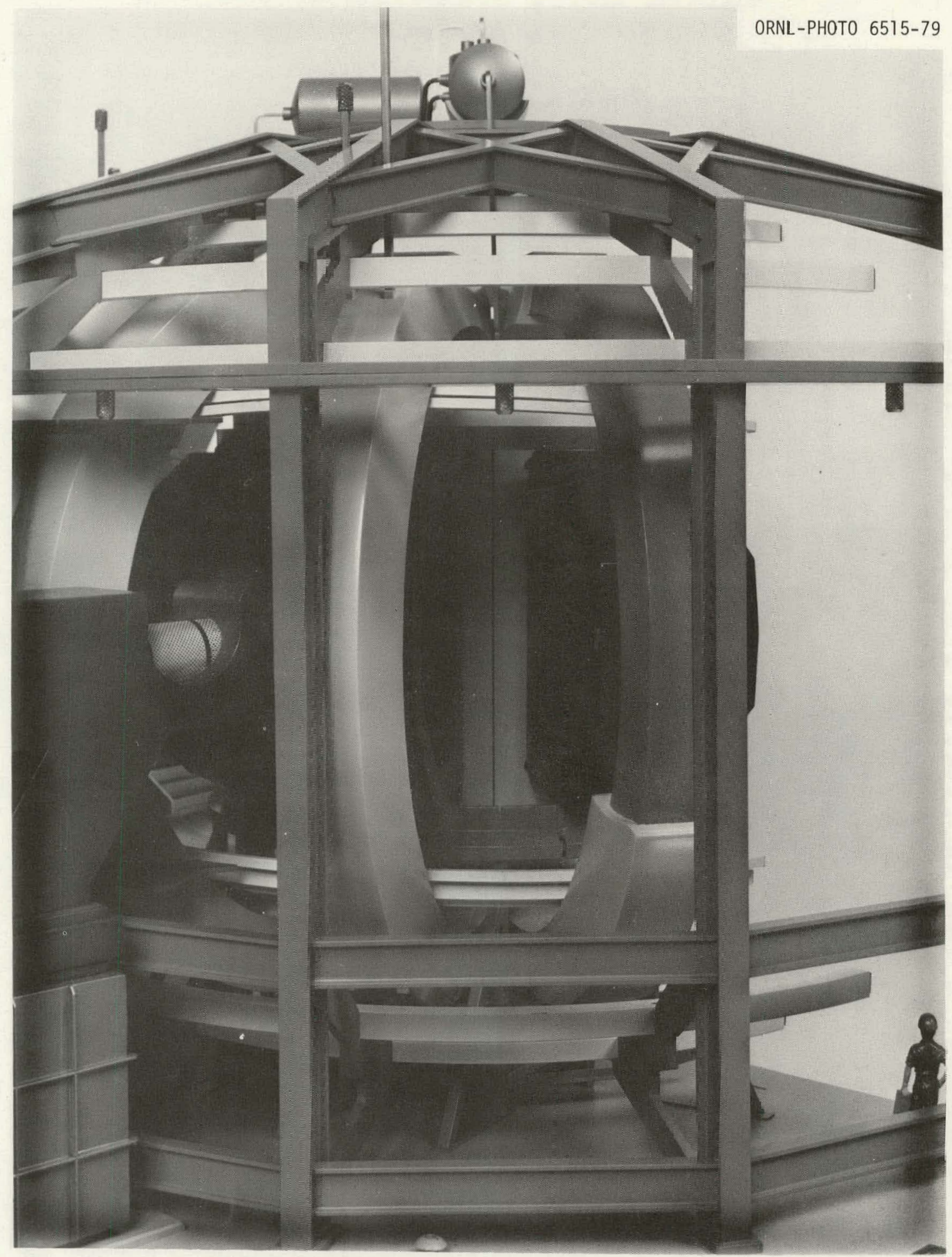

Fig. 1.8. Shield segment removed from torus. 


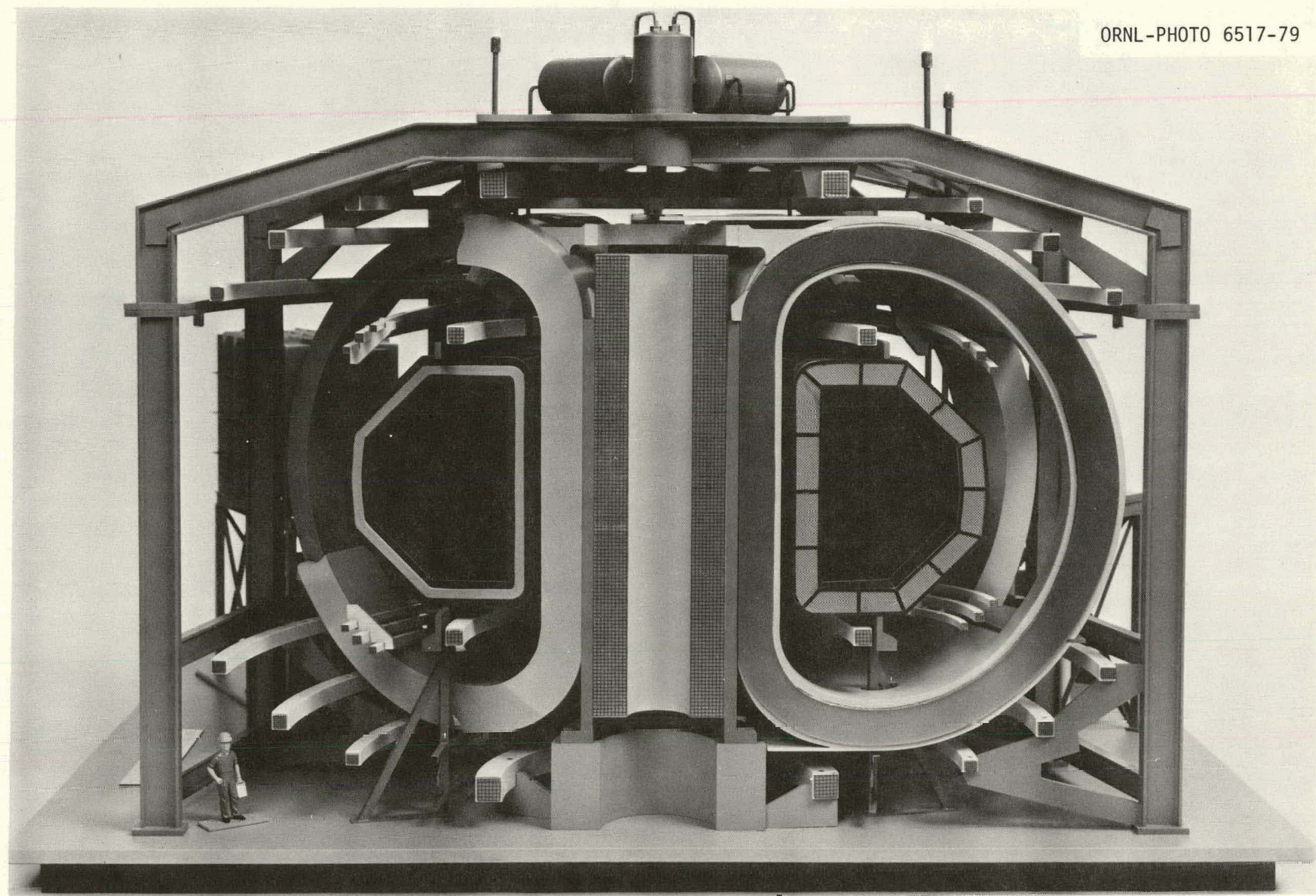

Fig. 1.9. Support structure features. 


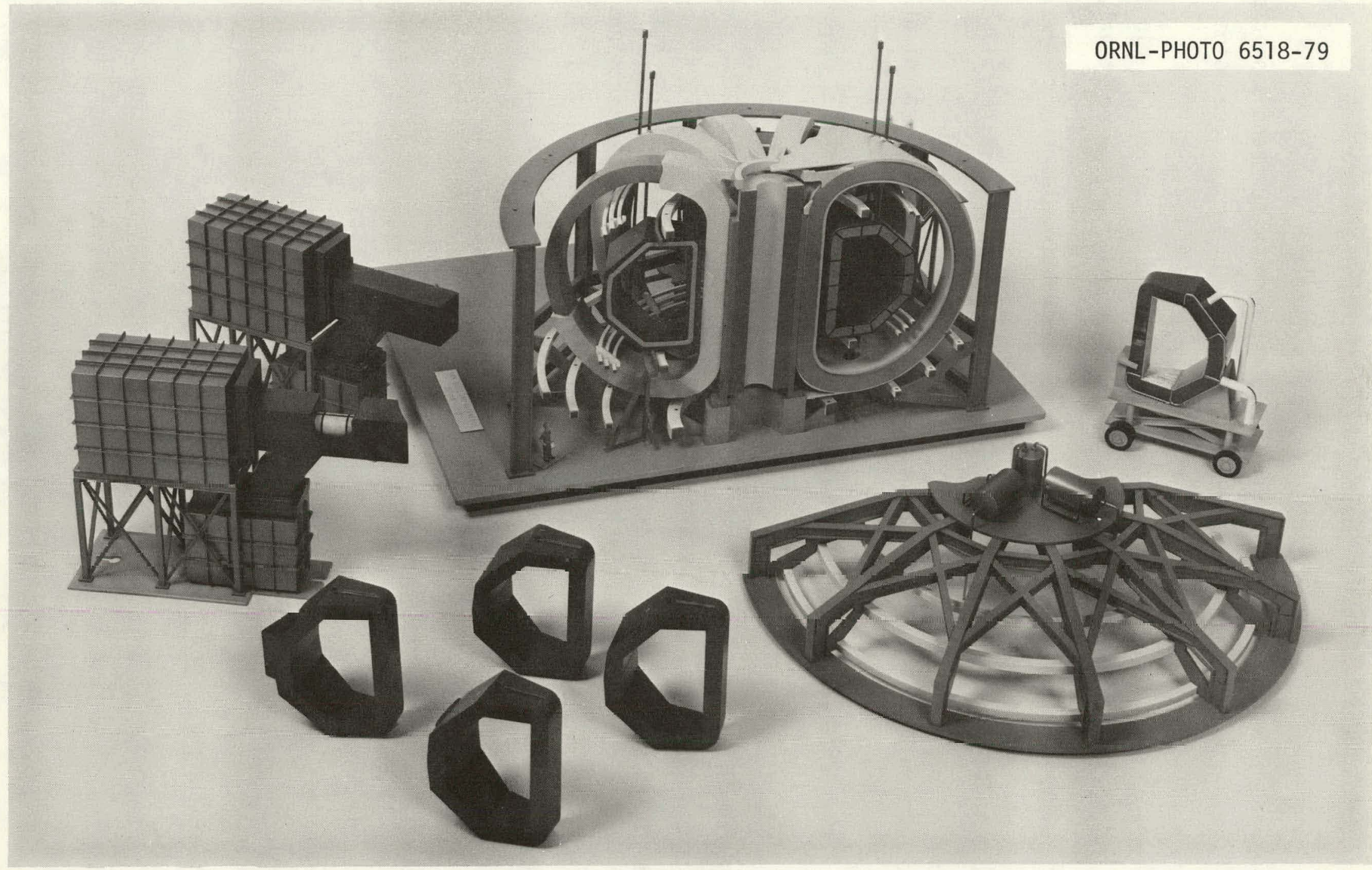

Fig. 1.10. Scale model disassembled to show design features. 


\section{Torus support}

The torus consists of 16 sectors that are bolted togetner and mechanically sealed. Its weight is supported on four quadrant supports independently connected to the ground. When 01116 sectors are joined, they form a rigid structure that encircles a pair of kucking rings. Radial'y inward electromagnetic forces are reacted by tee bıcking rings. Electromagnetic forces in the radially outward direction are relatively small and are reacted by the sector bolts.

Each quadrant suppcrt carries four torus sectors. To remove a sector, one quadrant is moved radially outward a small distance $(210 \mathrm{~cm})$ by releasing a quadrant support lock and renoving the sector tie rods. The horizontal motion of the quadrant is controlled by the arrangement of the support struts.

\section{TF coil support}

Tre $T=$ coils are surported by the central sufport column, the interccil supports, and, during initial assembly, a lateral support member that supports the imbalance in the $T=$ coil gravity loads. A11 coil supports are cryogenically cooled. During maintenance operations, if a ccil is removed, a temporary outboard strut is used to support the remaining coils.

\section{Interior PF coil susport}

The interior PF coils are supported from the outer support structure via the dewar support rings. The six coils closest to the midplane are relocated to a parking position during sector removal. The interior PF coils are segmented for a TF coil replacement.

\section{Exterior PF coil support}

The lower exterior PF coils are superconducting anc are supported from the outer support structure. During a TF coil replacement, they 
are lowered to a parking location below floor level. Replacement of the lower coils requires difficult coil segmentation. Further stuidy is required to identify alternate replacement techiniques.

The upper exterior PF coils are fixed to the upper support structure. To replace the coils, the upper support structure is raised and translated to a storage area.

\section{$\underline{\mathrm{OH} \text { coil support }}$}

The $\mathrm{OH}$ coils are supported on the machine base and constrained lateraliy by the central support column. Replacement of the $\mathrm{OH}$ coils requires removal of the $r f$ units.

\section{Dewar support}

The dewars are supported by the outer and the upper support structures. The individual dewars are accessible from the exterior of the machine. The interior portions of the common dewar are accessible by removal of one or more torus sectors. The upper shell dewar is accessible by relocation of the upper support structure to its storage area. Access to the lower shell dewar requires relocation of the lower exterior PF coils to their subfloor parking location.

\section{Outer support structure}

The outer support structure supports the exterior PF coils, the interior PF coils, the individual dewars, and the outboard part of the common dewar. Removal of one column of the outer support structure is required for a TF coil replacement.

\section{Upper support structure}

The rf unit, the upper exterior PF coils, and the common dewar are supported by the upper support structure. For major maintenance operations, such as a TF coil replacement, the upper support structure is raised and translated to the storage area. 


\subsubsection{Remote Maintenance Equipment}

Radioactivity levels within the reactor cell dictate that all mairitenance operations be performed with remote equipment. Two types of remote maintenance equipinent are used: general purpose equipment is used for nonspecific tasks such as servicing of coolant and electrical connections, and tightening of bolts, and special purpose equipment is used for specific and complex: tasks such as torus sector replacement or TF coil transport.

\section{General purpose equipment}

Bridce mounted manifulator system. Thə bridçe mounted manipulator system (BMMS) is a shielded, manned unit with a pair of servomanipulators; it services equipment above tine torus midptane.

Floor mounted manipulator system. The floor mounted manipulator systen (FMMS) is a shielded, manned unit with a pair of servomanipulators; it services equipment bel ow the torus midplene.

Floor mounted module. The floor maunted module is an unmanned unit with small servomanipulators for use in flocr areas that are inaccessible with the FMMS, for example, the area beneath the torus.

Po:ar crane. The palar crane provides nobility for the BMMS. It is also used during replacement of $\mathrm{OH}$ coils, rf units, and exterior PF coils.

\section{Special parpose equipment}

Sector replacement module. The sector replacenent module (SRM) provides all the functions necessary for replacement of a torus sector, including transportation between hot celli anc reaction cell. When the SFM is positioned at the torus, it is latched to the outer support structdre. Two rails extend from the SRM and latch to the quadrant suppor:. A rail mounted unit translates the torus sectors radially into the SRM after first removing the sector tie rods. Where a sector requires lateraj notion prior to racial removal between the coils, an $X-Y$ table mounted an the SRM rails is used. 
IF Coil transport module. The TF coil transport module jacks up the $T F$ coil, removes the lateral support connection and the intercoil connections, and transports the coil to the hot cell.

Toroidal bore unit. The toroidal bore unit is carrieo by the BMMS and extends a boom into the $\mathrm{OH}$ bore unit to service $\mathrm{OH}$ coil connections.

Injector transport module. The injector transport module (ITM) transports neutral beam injectors and fuel injectors between the hot cell and the reactor cell. It is used in conjunction with the BMMS to make and break service lines and duct connections.

\subsubsection{Maintenance Operations}

The replacement of a torus sector and the replacemen: of a TF coil represent two of the most difficult maintenance operations in the lifetime of the device. Procedures for these two operations have been developed in conjunction with the Reference Design.

\section{Sector replacement procedure}

The sector replacement procedure is shown in Fig. 1.11. To remove a sector, an entire quadrant is first moved radially outward to provide intersector clearance. Sector $A$ is aligned between two TF coils and thus may be moved directly out. Removal of sectors $B, C$, and $D$ requires prior removal of sector $A$.

The procedure for removal of sector $A$ of quadrant $\bar{i}$ is as follows.

(1) Remove injector units and cryopumps in quadrant I.

(2) Disconnect service 1 ines to quadrant 1 .

(3) Relocate interior PF coils to their parking position.

(4) Transport SRM to sector A.

(5) Latch SRM to the outer structural support.

(6) Extend two lower rails from SRM and latch to the quadrant support rail.

(7) Latch SRM to sector A.

(8) Disconnect torus sector joints $A D$ and $D A$.

(9) Remove quadrant lock and move quadrant I radially outward. 


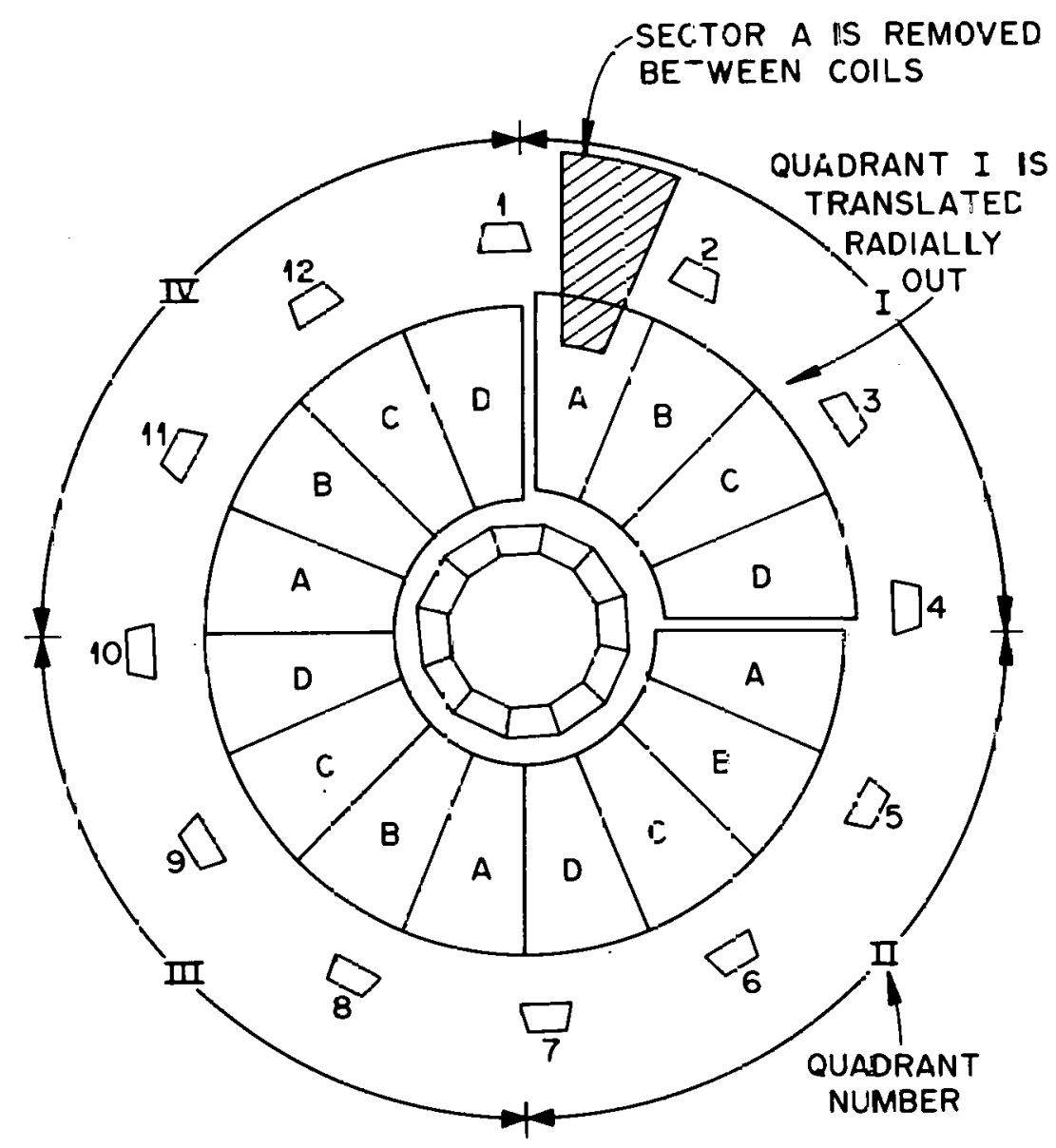

SECTOR

A

B

$c$

D
REMOVAL PROCEDURE

P.EMOVE BETWEEN COILS 182

REMOVE. SECTOR A, THEN REMOVE

E BETWEEN COILS 1 \& 2

FEMOVE SECTOR A; ROTATE B INTO

SPACE VACATED BY A; REMOVE $C$ BETWEEN COILS $2 \& 3$

REMOVE SECTOR A, OF QUADFANT II REMOVE $D$ BETWEEN ZOILS 4 \& 5

Fig. 1.11. Sector replacement procedure. 
(10) Disconnect torus sector joint $A B$.

(11) Jack up sector $A$ to remove weight from quadrant support rail.

(12) Translate sector A radially outward.

(13) Release SRM latches and retract SRM rails.

(14) Transport SRM (with sector A) to the hot cell.

(15) Install a replacement sector, reversing this procedure.

\section{IF Coil replacement procedure}

The TF coil replacement procedure is as follows.

(1) Remove the three torus sectors closest to the damaged TF coil.

(2) Remove the upper support structure complete with rf heating unit and PF coils; place in storage area.

(3) Install an outboard strut on the TF coil that is diametrically opposite the damaged TF coil.

(4) Place lower exterior PF coils in their parking location.

(5) Remove the outer support column behind damaged TF coil.

(6) Remove the individual dewar and a $30^{\circ}$ sector of the common dewar.

(7) Remove a segment of each internal PF coil, the sector support rails, and the bucking rings.

(8) Remove the intercoil support structure.

(9) Position the coil transport module (CTM) at the damaged TF coil.

(10) Latch the TF coil to the CTM.

(11) Jack up the TF coil to remove its weight from the central support column.

(12) Remove the lateral supports.

(13) Transport TF coil to the hot cell.

(14) Install a replacement TF coil, essentially reversing this procedure.

\subsubsection{Electrical Power Conversion System}

The electrical power conversion system consists of an energy storage system, a power convertor system, and primary and secondary distribution systems. A number of power conversion configurations were considered, 
including a combination of notor-generator flywheel (MGF) sets, transformers, and thyristors; homopolar generators; dc generators; and a superzonducting coil energy storage system. The MGF-transformer-thyristor combination was selected on the basis of cost, technical feasibility, machine integration, and compatibility with an extenced burn device.

The technical details associated with the configuration of a series or parallel power supply; and coil section interconnection were considered. The series configuration, involving the alternate interleaving of an equal number of power supplias and PF coil sections, was chosen on the basis of EF-DH coupling and its impact on device implementation, compatibility with superconducting coils, energy transfer efficiency, circulating current problems, short-circuit protection and current clearing modes, and stray capacitance.

The energy storage system is required to act as a buffer between the utility grid and the high peak power and energy demands of the pulsed PF coils. It sufplies PF pulsed loads from two vertical shaft MGF sets having a combined rated capability of 600 MVA at a lagging power factor of 0.7 and a combined deliverable energy of 4.3 GJ over a 35-sec interval for plasma startup and shutdown every $560 \mathrm{sec}$. The electrical load demand during the $500-\mathrm{sec}$ burn is taken directly from The utility gin. The MGF sets are also capable of accepting the stored energy from the PF coils at the end of the power discharge cycle.

A sower convertor system, based on a 12-pulse thyristor bridge in a modular design, was selec:ed for its coil wave shape control, accuracy in plasma positioning, flexibility, commonality, fast response, recovery of energy, anc cost. The power convertor converts variable frequency ac power to dc and inverts dc to ac.

The primary distribution system consists of the electrical buswork between the utility interface at the substation level and the MGF sets, with its associated equiprent (e.g., short-circuit current limiting reactors, circuit breakers, monitoring devices, lightning arrestors, transient suppression circuits, and controls). The secondary distribution system consists of the electrical buswork between the power convertors and the serialiy interieaved coil sections for each of the seven PF coil circuits. The power convertors are built up in 2-kV units to meet the individial voltages required by each P.F circuit. 
The PF coil circuit schematic is shown in Fig. 1.12. Table 1.2 lists the PF system considerations and the design alternatives considered.

\subsubsection{Plasma Heating}

The Reference Design specifies neutral beams of deuterium for plasma bulk heating. The beam power is $50 \mathrm{MW}$ and the particle energy is $150 \mathrm{keV}$. The required pulse length for neutral beam injection is $6 \mathrm{sec}$. Comprehensive experiments such as the Oak Ridge Tokamak (ORMAK), the Impurity Study Experiment (ISX-B), and the Princeton Large Torus (PLT) have provided a sound basis for the choice of neutral beam systems to supplement ohmic heating.

Early calculations show that the beam systems successfilly operated to date are those using positive ions. During the required neutralizing action, these systems are subject to much lower efficiencies at energy levels over $150 \mathrm{keV}$ than those expected from beam injectors using negative ions. However, the development of negative ion approaches is lagging considerably ( 25 years) behind that of the positive ion types. The incompatibility of these developments with the TNS/ETF schedule, as well as the uncertainties in predicting the operating characteristics of negative ion systems, provided a strong impetus to reassess ways of using the more readily available and acceptably efficient positive ion based beam lines.

A startup scenario has been established and studied; it shows promise of being quite compatible with neutral beam auxiliary heating systems with moderate energy levels. The Reference Design uses a full bore, low density fusion startup approach (see Sect. 2.2). The startup sequence requires the injection of $50 \mathrm{MW}$ of $150 \mathrm{-keV}$ particles into the plasma for $6 \mathrm{sec}$. The maximum feasible equivalent particle current was selected as $300 \mathrm{~A}$ per beam line (three sources at $100 \mathrm{~A}$ ). Four beam lines are required to provide the necessary $50 \mathrm{MW}$. The dimensions of the torus penetrations were maximized $(0.4 \times 1.2 \mathrm{~m})$ to reduce potential drift tube choking (experienced in some earlier beam injection tests). 


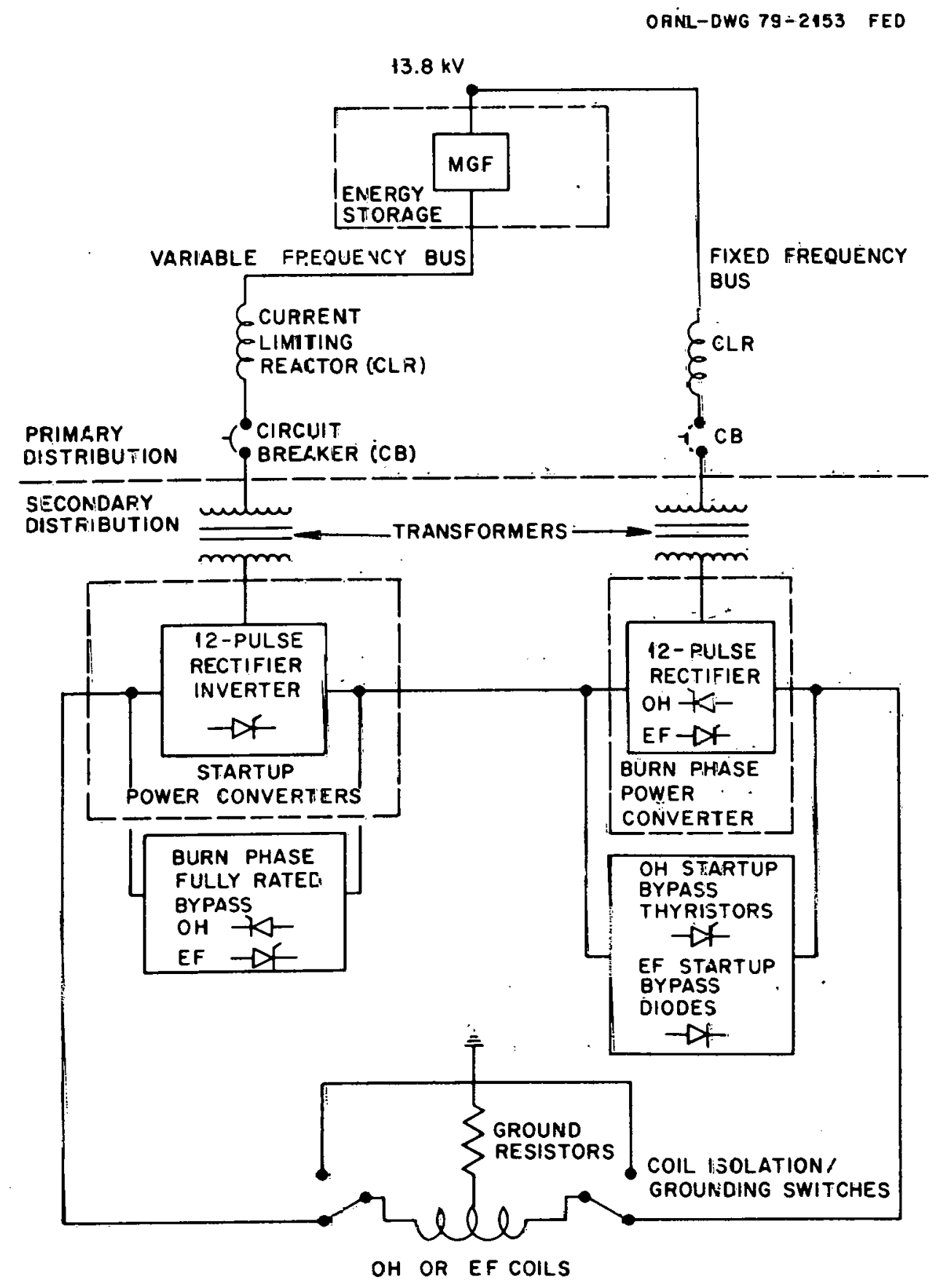

Fig. 1.12. Electrical energy conversion system (simplified block ciagram). 
Table 1.2. PF system trade study alternatives

\begin{tabular}{ll}
\hline PF system considerations & \multicolumn{1}{c}{ Design alternatives } \\
\hline PF coil arrangement & $\begin{array}{l}\text { Hybrid } \\
\text { Mixed } \\
\text { Conventional }\end{array}$ \\
PF coil locations & Air \\
Type of OH solenoid & Iron \\
& \\
Remote maintenance relevance & Copper \\
Conductor type & Superconducting \\
& rf \\
Initiation method & OH current interruption \\
& Interior "blip" coils \\
& Neutral beam driven plasma current \\
& Auxiliary transformers \\
EF and OH decoupling & Matching mutual inductances \\
methods & Power supply voltage control \\
& ac motor-generator set \\
& Homopolar generators \\
& Superconducting energy storage \\
& Shunt connected dc generator system \\
& \\
&
\end{tabular}


The neutralizing efficiency referred to above indicates the ratio of particles that are neutralized to those that remain unneutralized. Recent dejelopments in techniques for the direct recovery. of the power in the unneutralized pontion have supported the selection of direct power recovery as an iniegral part of the Reference Design beam 1 ines. The resultant overall e ectrical efficiency of the Reference Design beam line system is $\sim 50 \%$.

RF heating has beer chosen to aid the preionization during startup (see Sect. 2.1). This choice has support in physics calculations and will be soon tested experimentally. The use of microwave energy is expected to substantially reduce the plasma loop voltage requirements and this permit a much less expensive PF system power supply. The system specified couples 1 MW of power at a frequency of $\sim 120 \mathrm{GHz}$ to the plasma for approximately 2 sec at the beginning of the startip scenario.

\subsubsection{Divertor System}

We have adopted a bundle divertor for impurity control in the Reference Design, instead of the compact poloidal divertor in the BaseTine Design. The primary reason for this change was to move the divertor system outside the TF coil bore to improve overall access and provide more space for particle and energy collection.

The bundle divertor ${ }^{7}$ is shown schematically in Fig. 1.13. It is composed of two coils, side by side, with opposite current flows that provide $a$ strong short-range magnetic field, which is superimposed on the toroidal field in the plasma to produce zero field close to the external surface of the plasma. The resulting field distortion allows a bundle 0 : field lines to te extracted and form a loop external to the piasma aiong which charged particles trapped on the lines can travel.

Plasma physics, magnetics, and economic considerations strongly favor smell divertor coils placed as close as possible to the plasma ecige. However, in a reactor enitronment, the divertor coils will require shielding from radiation damage and heating. These shielding requirements impact both the diameter of the coils and their placement relative to the plasma. On the basis of our trade studies, we have selected 


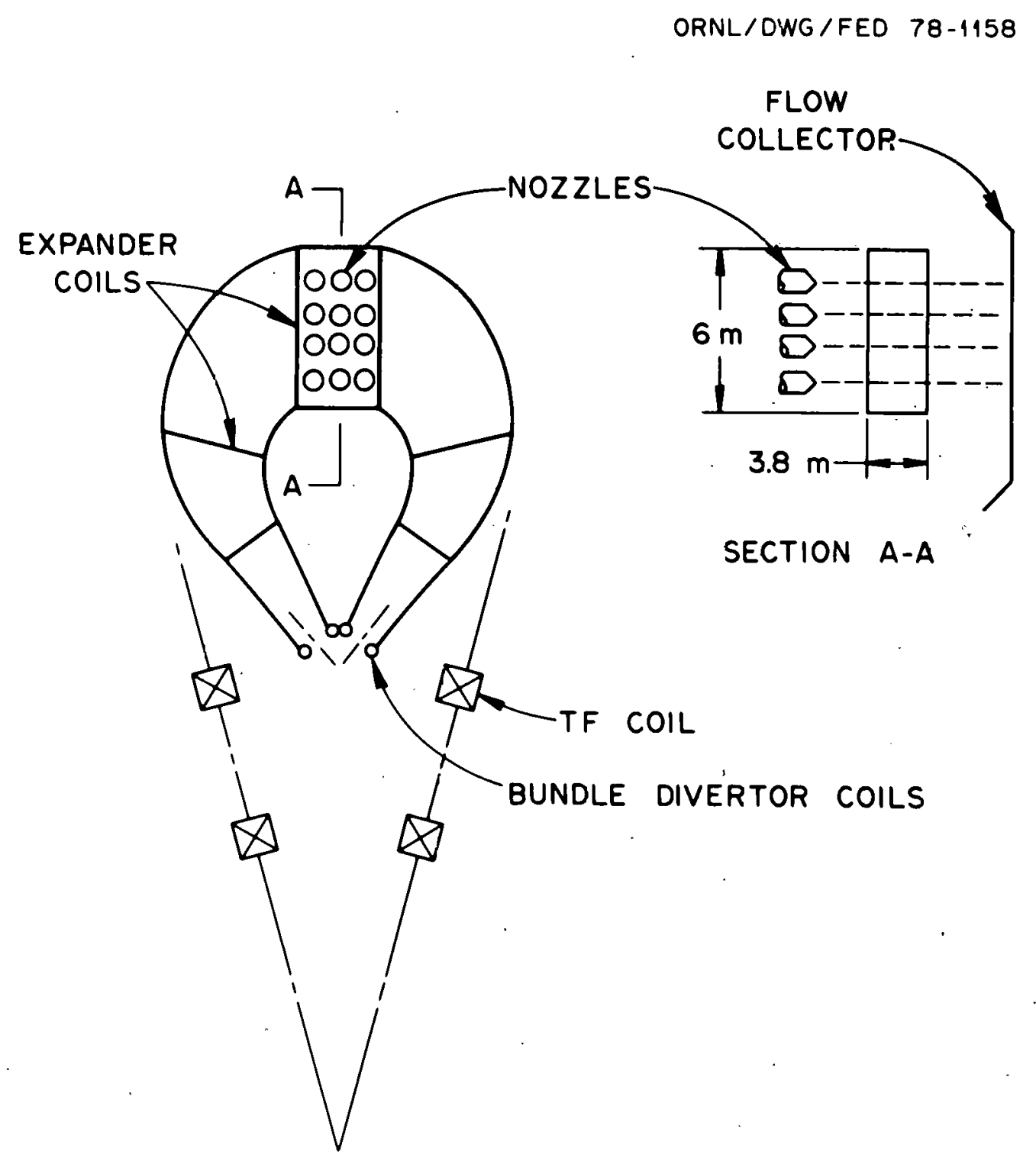

Fig. 1.13. Reference Design bundle divertor schematic. 
water-ccoled copper coils rather than superconducting or cryogenically cooled coils to minimize the snielding requirement. The shield thickness is then $0.4 \mathrm{~m}$, rather than up to twice as much if supercoriducting or cryogenic coils were used.

The divertor will expand the diverted magnetic ield to reduce particle and energy flux. For design purfoses, it is assumed that the divertor must absorb $226 \mathrm{MW}$ and $3 \times 10^{23}$ ions/sec (mostly deuterium and tritium). If a solid absorter is used, the getter material must either constitute or be part of a heat exchanger, which requires material having good strength and thermal conductivity, since it must be subjected tc at least $10^{5}$ cycles of absorption and desorption. Consideration of data on hydrogen embrittlement of structural materials ifor one atsorption cycle) suggests tinat this will seriously degrade the material. Also, the times and temperatures for regeneration of getters $\left(700-1000^{\circ} \mathrm{C}\right.$ for sever $\equiv 1$ hours) tend to indicate infeas-bility for solics. It is therefore proposed that these functions be accomplished by an array of lithium jets, shown schematically in Fig. 1.13. If it is assumed that a heat flux of $10 \mathrm{MW} / \mathrm{m}^{2}$ can be absorbed, there must be $22.6 \mathrm{~m}^{2}$ on which the exfanded, diverted magnetic field impinges. The expansion requirenent leads to a system that has much in comnon with direct conversion approaches proposed for advanced fuel concepts. 8

\subsubsection{Secondary Vacuum Enclosure}

The Reference Design specifies an evacuated reactor cell or "vacuum building" to house the tokamak device. The maintenance of a vacuum environment within the cell means that the vacuum integrity requirements for the plasma chamber are relaxed sufficiertly to permit use of a kolted rather than a welced tcrus assembly. This leads to a substantial reduction in the plant dicwntime required to remove and replace a torus sector and consequently to a substantial increase in plant availability. The vacuum building is one of several secondary vacuum enclosure (SVE) configurations studied (see Fig. 1.14). 0thers include a dual-wall torus with an evacuated interspace, a toroidal enciosure around the TF coils, and jwo bell jar configurations. Although the vacuum building is 
$\because$

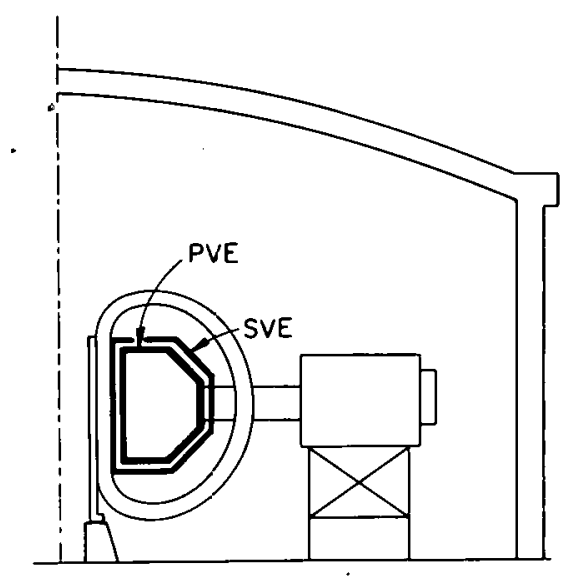

DUAL WALL TORUS

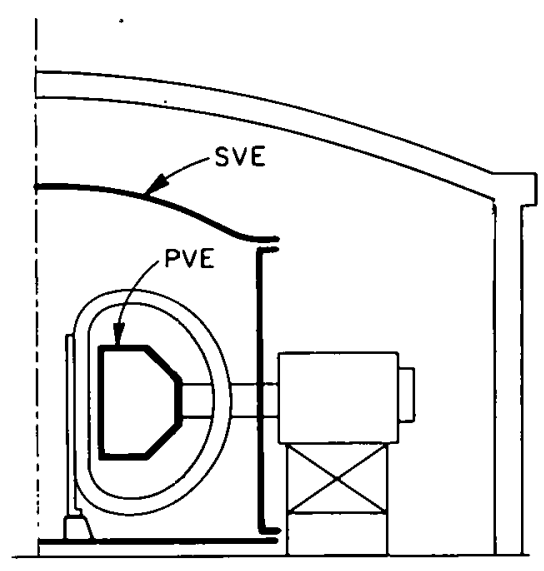

BELLJAR

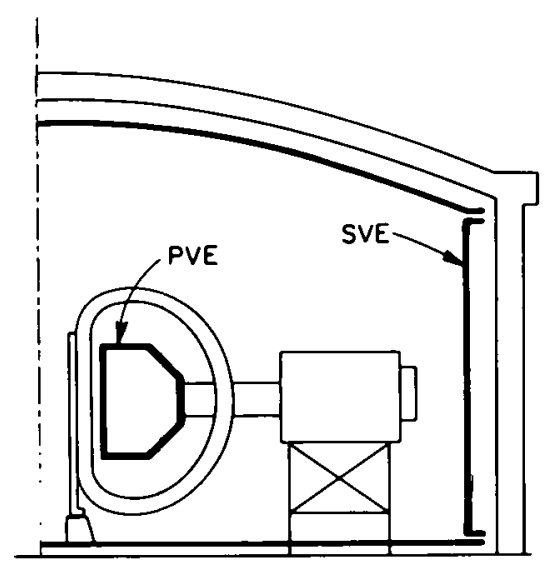

VACUUM BUILDING

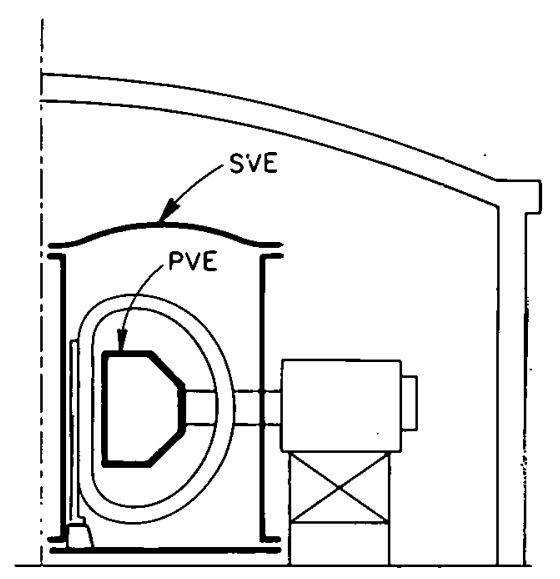

TOROIDAL ENCLOSURE

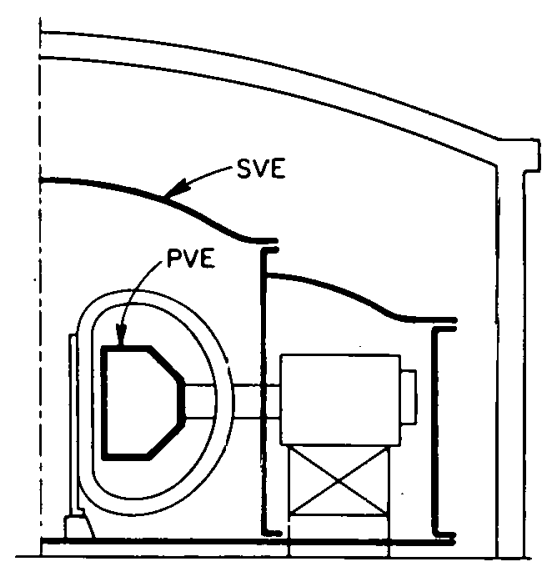

EXTENDED BELLJAR

PVE = PRIMARY VACUUM ENCLOSURE . SVE = SECONDARY VACUUM ENCLOSURE

Fig. 1.14. Secondary vacuum enclosure alternatives. PVE indicates primary vacuum enclosure; SVE indicates secondary vacuum enclosure. 
the largest and most expensive SVE consideræd, it was selected as the preferred concept because of the relative ease of penetration for maintenance oprations and the unrestricted access for insjection and adjustment during normal operations. Also, technical feasibility for a similar structure has been established at the NASA facility in Plumbrook. ${ }^{9}$ By comfarison, both the toroidal enclosure and the bell jar require extensive dismantling to gain access to the torus, and they severely restrict the ability to monitor operations with remote television cameras. The dual-wall torus was deemed infeasibie because of critical seal clamping requirements, which necessitated the placemen: of tolts in highly inaccessible areas. 10

Since the maximum benefit derived from the SVE is ease of access to the plasma chamber, its economic benefits for TNS cannot be quantified secause routine maintenance operations within the TNS plasma chamber are not required. However, in a commercial power reactor (CPR) where periodic replacement of the blanket may be required, the economic benefits of rapid and reliable access to the plasma chamber are quite apparent. Comparison of two similarly configured CPRs shows that plant availability is $50 \%$ for a CPR with a veldec torus and $82 \%$ for a CPR with a mechanically assembled tarls made pcssible by use of a SVE. Furthermore, the potential or catastropric failure due to high risk internal operations is largely el iminated with a SVE. Justification for using a SVE configuration for TNS is the desirability of developing a design with reactor relevance. on a program basis, the cost factor for using a SVE can be either positive or negative, depending on the number of unscheduled maintenance operations during its sperational 1 ife whicin require replacement of a torus sector. The breckeven point is two, based on a SVE cost penalty of $\$ 20.5$ million, a time saving of 2.7 months per sector replacement, and a loss of revenue because of plant unavailability of $\$ 4$ million per month.

A base operating pressure of $10^{-4}$ torr was selected for the vacuum building. Selection was based on permissible torus leak rate and electrical systems requirements to prevent arcing and corona discharge. Although serious consideration was given to el imination of dewars within the vacuum building, our study concludes that dewars should be retained. The main reasons are (1) the excessive downtime required for 
thermal cycling of coils during maintenance operations, (2) the undesirable effects of cold-trapping, i.e., high tritium and hydrogen gas accumulations, and (3) the possibility of quenching the TF coils as a result of a temporary loss of vacuum due to a coolant line leakage.

The vacuum building (Fig. 1.15) is a cylindrical concrete structure with a spherical dome. Its external dimensions are a 56-m diameter and a 40-m maximum height. A metal1ic inner she11, $48 \mathrm{~m}$ in diameter and 33 $\mathrm{m}$ high, houses the tokamak, and the space between the inner and outer shells is maintained at 20 torr to prevent outgassing of the concrete.

The outer structure has a dual function; it supports the atmospheric pressure load and serves as the biological shield. The inner chamber is the high vacuum barrier and is designed for an internal pressure of $0.1 \mathrm{~atm}$, which occurs during a leak checking operation.

Initial pumpdown of the vacuum building is by a combination of mechanical pumps and Roots blowers. High vacuum pumping is by ten oil diffusion pumps having a combined pumping speed of $2.0 \times 10^{5}$ 1iters $/ \mathrm{sec}$. Pumpdown time from atmospheric to base pressure is $6 \mathrm{hr}$.

\subsection{SYSTEMS DESCRIPTION}

A Work Breakdown Structure (WBS) has been used as the basic management tool to identify and control the elements of the TNS Program (see Fig. 1.16). The WBS has been used as a basic framework on which a major design and construction project can later be established. As part of this year's activities, a System Description Manual, ORNL/TM-6721, has been prepared to describe the hardware systems included in the reactor and facilities WBS. ${ }^{11}$ A brief overview of each of the Reference Design systems covered in ORNL/TM-6721 is given in Table 1.3. 
OMNL / UWG/KED 70 - 11774

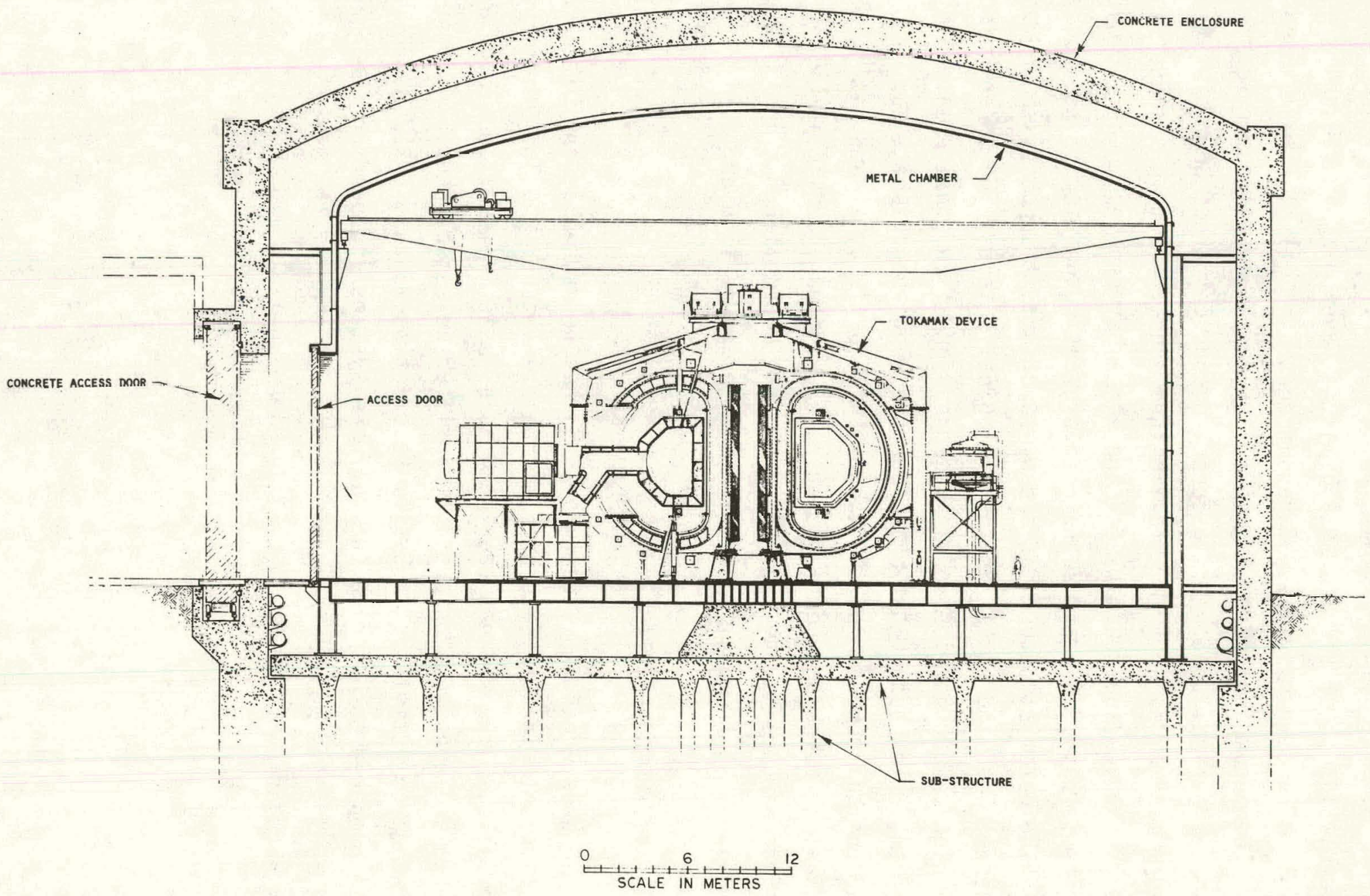

Fig. 1.15. Reactor cell cross section. 
ORNL/DWG/FED 78-45A

WORK BREAKDOWN STRUCTURE (WBS)

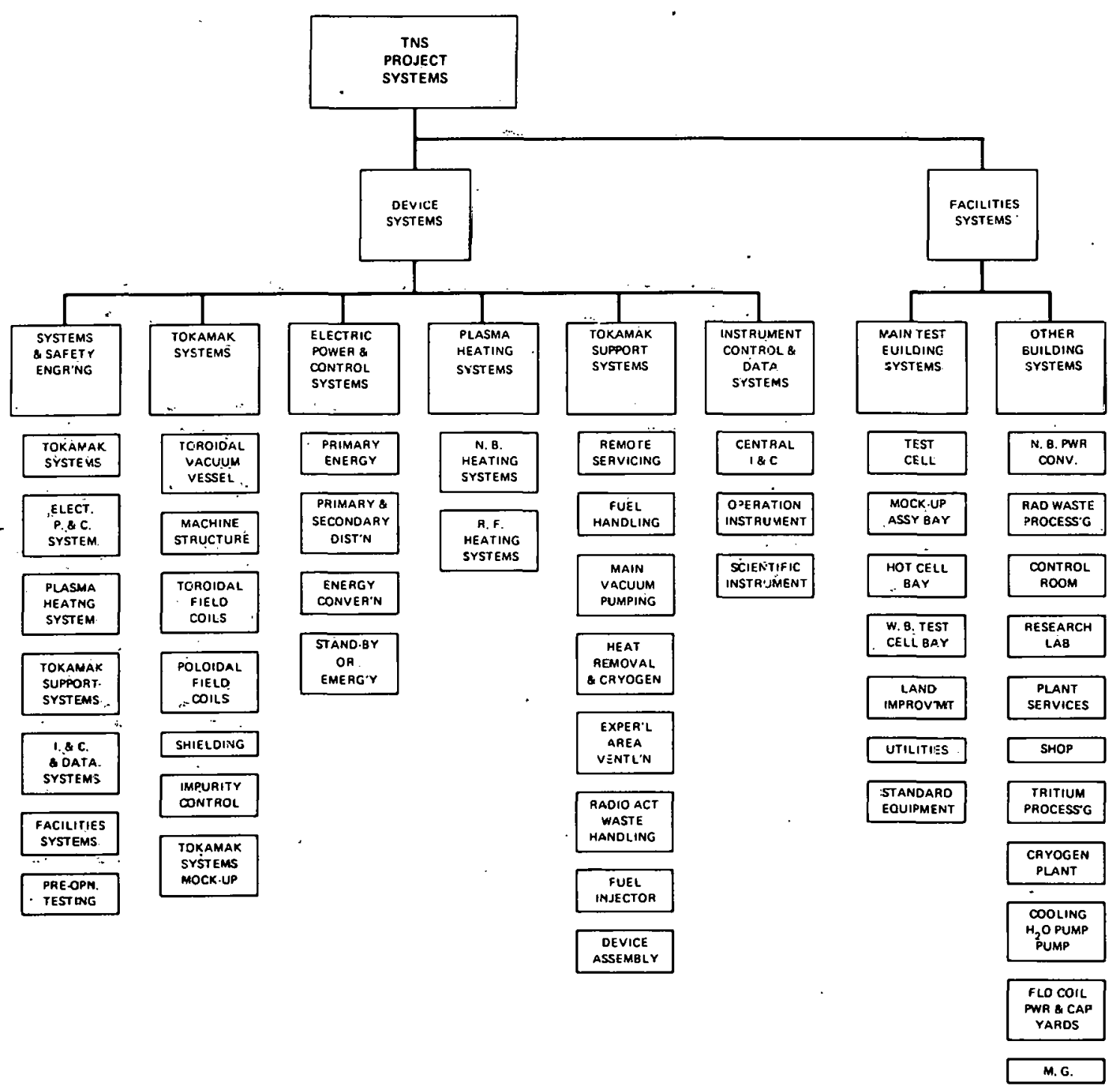

Fig. 1.16. Work Breakdown Structure for TNS. 
Table 1:3. Summary system description

Plasma

Limiter

First wall

Shield

Machine structure

PF system
Expected to achieve an average power density of $5 \mathrm{MW} / \mathrm{m}^{3}$ and operate with $\bar{\beta}=7 \%$. Temperature and density during the steady-state burn are taken to bc $12 \mathrm{kcV}$ and $2 \times 10^{20} \mathrm{iii}^{-3}$, respeclively. Plasima impurity control is provided by a bundle divertor. A 500-ser. hurn out of a 560-sec tokamak operating cycle yields a duty cycle of $89 \%$. Plasma radius is $1.2 \mathrm{~m}$ with an elongation of 1.6 (D-shape); major radius is $5.0 \mathrm{~m}$. An average neutron wall loading of $2.4 \mathrm{MW} / \mathrm{m}^{2}$ results.

Two poloidal graphite limiters, assumed to be passively cooled, are user to protect the tirst.wall.

The first wall and divertor are each designed to handle all the energy associated with the alpha particles. However, the energy to the first wall is estimated to be only $50 \%$ of the alpha particle energy. The water-cooled first wall is composed of stainless steel tubes and divided into 96 modular panels.

Composed of stainless steel balls and borated water, divided into 16 removable modules, and sized to adequately attenuate neutrons in order to protect the superconducting coils.

Includes the bucking cylinder, all TF coil supports, the PF coil supports, the dewar structure, and the torus plasma chamber; designed to react all operational mechanical loads as well as seismic load conditions; constructed of austenitic stainless steel. The intercoil support structure for the TF coil is designed for a single coil fault condition; all TF coil support structure is cryogenically cooled.

Consists of a superconducting $\mathrm{OH}$ solenoid, normal copper EF coils located inside the TF coil bore, and superconducting EF coils located outside the TF coil bore. The PF system will supply 83 $\mathrm{V}$-sec while operating with a half-biased $\mathrm{OH}$ system swinging from +8 $\mathrm{T}$ to $-8 \mathrm{~T}$, adequate for startup and a 500-sec burn. 
Table 1.3 (continued)

TF system

Dewars

Divertor

Bulk heating system

rf heating system

Electrical energy storage system
Composed of 12 forced-flow superconducting $\left(\mathrm{Nb}_{3} \mathrm{Sn}\right)$ coils which produce a field on axis of $5.3 \mathrm{~T}$ and a maximum field at the coil of $10.9 \mathrm{~T}$, sized for a magnetic field ripple of $1.5 \%$ at the plasma edge.

Mechanically joined dewars enclose the superconducting coils, the central supporting column, and the intercoil support members; they provide a vacuum barrier to reduce convection heat loads and a cryogenically cooled thermal shield to reduce radiation heat loads.

The divertor and first wall are each designed to handle all the energy associated with the alpha particles. However, the actual energy to the divertor is estimated to be only $50 \%$ of the alpha particle energy. The bundle divertor transports charged particles away from the first wall by diverting magnetic field lines outside the plasma chamber. Flowing lithium is used to collect the diverted particles and absorb their energy.

Four beam lines with three positive ion sources per line inject $50 \mathrm{MW}$ of 150-keV deuterium neutral beams into the plasma for up to $6 \mathrm{sec}$ to achieve required plasma temperatures. A direct recovery system to collect the energy of the unneutralized particles is a component of the beam line. An overall beam line efficiency of approximately $50 \%$ is estimated.

A rf assisted startup is accomplished by injecting 1 MW of $120-\mathrm{GHz}$ microwaves into the plasma from the high field side for approximately 2 sec during startup, using five injectors.

Provided by two motor-generator flywheel (MGF) sets having a combined rated capacity of 600 MVA and a deliverable energy of 3.7 GJ over $19 \mathrm{sec}$. Electrical energy during most of the burn is supplied directiy from the utility grid. 
Electrical energy conversion system

Electrical distribution systems

Emergency standby power. system

Torus vacuum pumping

Heat transport

Fuel injector

Fuel handling system
Receives ac power from the MGF sets and converts it to dc for each coil set. Transformers and solid state rectifiers are used.

The primary system receives ac power from the utility grid at $138 \mathrm{kV}$ and transforms 600 MVA to a $13.8-\mathrm{kV}$ load bus. The secondary system transfers power from the electrical energy conversion system to the coil sets.

Consists of batteries that store sufficient energy to controllably terminate the plasma discharge in the event of loss of power from the utility grid or the primary MGF sets.

During the initial pumpdown and after the plasma burn cycles, accomplished by mechanical vacuum pumps and cryosorption pumps. During the burn, provided primarily by the divertor system.

Water cooling systems remove heat from the first wall, shield, copper coils, and portions of the neutral beam lines. Cryogenic cooling systems remove heat from the superconducting coils and high vacuum cryosorption pumps. The heat removed by these systems is rejected to the environment by a water cooling tower.

Delivers solid D-T pellets to the plasma at velocities of $1000-2000$ $\mathrm{mi} / \mathrm{sec}$.

Provides for removing tritium, deuterium, and helium from the spent plasilia, the divertor, and the vacuum pumps. Processing and purification are accomplished by combinations of mechanical filtration, gettering, cryugenic trapping, cryogenfc distillation, permeationdiffusion, and sorption. 
Table 1.3 (continued)

\begin{tabular}{|c|c|}
\hline Radwaste & $\begin{array}{l}\text { Will consist of portions of the tokamak itself and those components } \\
\text { which become contaminated through contact with the coolant. Dis- } \\
\text { posal is expected to be performed using techniques established in } \\
\text { fission programs. }\end{array}$ \\
\hline Ventilation system & $\begin{array}{l}\text { Major functions include containment of activated air and tritium } \\
\text { leaks. The use of a vacuum building diminishes the activated air } \\
\text { problem and is compatible with a tritium cleanup system. }\end{array}$ \\
\hline $\begin{array}{l}\text { Instrumentation, control, and } \\
\text { data handling system }\end{array}$ & $\begin{array}{l}\text { Automatically controls the tokamak plasma and systems through all } \\
\text { the phases of operation. Controls are centralized and are under the } \\
\text { command of one operation station. }\end{array}$ \\
\hline Assembly and maintenance & $\begin{array}{l}\text { The torus is divided into } 16 \text { mechanically assembled sectors, each } \\
\text { replaceable as a unit with integrally mounted portions of the first } \\
\text { wall and shield. Bolted rather than welded assembly is possible } \\
\text { since vacuum-tightness requirements are relaxed by the use of an } \\
\text { evacuated reactor building. The TF coil bore is enlarged to allow } \\
\text { relocation of PF coils to a parking position during sector replace- } \\
\text { ment. Disassembly is done remotely. }\end{array}$ \\
\hline Facilities & $\begin{array}{l}\text { The tokamak containment building is an evacuated structure with a base } \\
\text { pressure of } 10^{-4} \text { torr. The remaining facilities are conventional } \\
\text { atmospheric buildings. }\end{array}$ \\
\hline
\end{tabular}




\section{REFERENCES}

1. [. Steiner et a1., Oak Ridge TNS Program: Context, Scope and Easeine Design of the Fy 1978 Activities, ORNL/TM-6201, Oak Ridge, Tennessee (May 1978).

2. F. L. Reị, Oak Ridge TNS Program: System Studies of the Toroidal Field Coils, ORNL/TM-6723, Oak Ridge, Tennessee (to be published).

3. T. G. Brown and G.W. Wiseman, Oai Ridge TNS Program: Evaluation of the Poloidal Field System, ORNL/TM-6276, Oak Ridge, Tennessee (to be published).

4. Y-K. M. Peng, D. J. Strickler, and R. A. Dory, "Hybrid Equilibrium Field Coils for the ORN TNS," Proc. 7th Symp. on Engineering Problems of Fusion Research, p. 136 (1978); J. Brocks et al., "The EF CDil System for the Argonne EPR Design," Proc. ith Symp. on Engineering Problems of Fusion Research, p. 118 (1978).

5. -NS Engineering Staff, Four Ignition TNS Tokamak Reactor Systems Design Study, WFPS-TME-071, Westinghouse Electric Corporation, Pittsburgh, Pennsyivania (October 1977).

5. Y-K. M. Peng, S. K. Borowski, and T. Kammash, Nuci. Fusion 18, 1489 (1978).

7. W. M. Wells, Oak Ridge TNS Program: Evaluation of the Bundle Divertor Study, OF.NL/TM-6727, Oak Ridge, Tennessee (to be published).

8. D. K. Choi, G. A. Gerdin, G. H. Niley et a1., Exploratory Studies of :igh-Efficiency Advanced-Fuel Fusion Reactors, Annual Report, EPR]-ER-581, El ectric Power Research Institute (November 1977).

9. R. W. Werner, ORNL Fusion Power Demonstration Study: Arguments for a Vacuum Building in which to Enclose a Fusion Reactar, ORNL/TM-5664, Dak Ridge, Tennessee i December 1976).

10. C. Sardella, Oak Ridge TNS Program: Evaluation of Vacuum Topology, ORNL/TM-6725, Oak Ridge, Tennessee (to be published).

11. R. L. Reid et al., Oak Ridge TNS Program: System Description Manual, ORNL/TM-6721, Oak Ridge, Tennessee (to be putitished). 


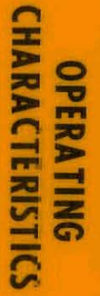




\section{PROJECTED OPERATING CHARACTERISTICS OF THE PLASMA}

This section summarizes the projected operating characteristics of the plasma. The plasma of the Reference Design is assumed to operate in an ignited mode. A nominal set of plasma parameters for the Reference Design is shown in Table 2.1. These parameters represent reasonable estimates and extrapolations based on our current understanding of plasma physics. It is emphasized that the operating parame ters listed in Table 2.1 are to be viewed as plausible, not definitive. More refined physics considerations are discussed in four general areas: startup and shutdown, neutral beam heating, maintenance of high beta configurations, and particle control. The area of long pulse burn dynamics was not addressed in this year's activities.

\subsection{STARTUP AND SHUTDOWN}

\section{1 .1 Startup}

Both the startup and shutdown phases of the plasma present many complex problems arising from the dynamics of the system. Startup scenarios have been examined to determine whether innovative variations in the procedure can reduce or eliminate major technological constraints associated with traditional procedures. The traditional startup scenario for a tokamak involves the application of a large voltage spike to achieve breakdown in the plasma and to burn through the radiation barriers of hydrogen and small quantities of low-Z impurities. Extrapolation to reactor grade plasmas leads to estimates of several hundred volts for the pulsed voltage and a few thousand megavolt-amperes for the peak power in the ohmic heating system. ${ }^{1}$

Experimental evidence ${ }^{2}$ and theoretical estimates ${ }^{3}$ indicate that launching microwaves from the high field side of the torus at a frequency near the electron cyclotron resonance ( $120 \mathrm{GHz}$ for the Reference Design) may result in plasma breakdown and heating of the electrons by the extraordinary wave. This heating occurs in a small volume near the upper hybrid resonance. The dominant energy loss is due to magnetic 
Tatle 2.1. Flasma parameters for the reference design

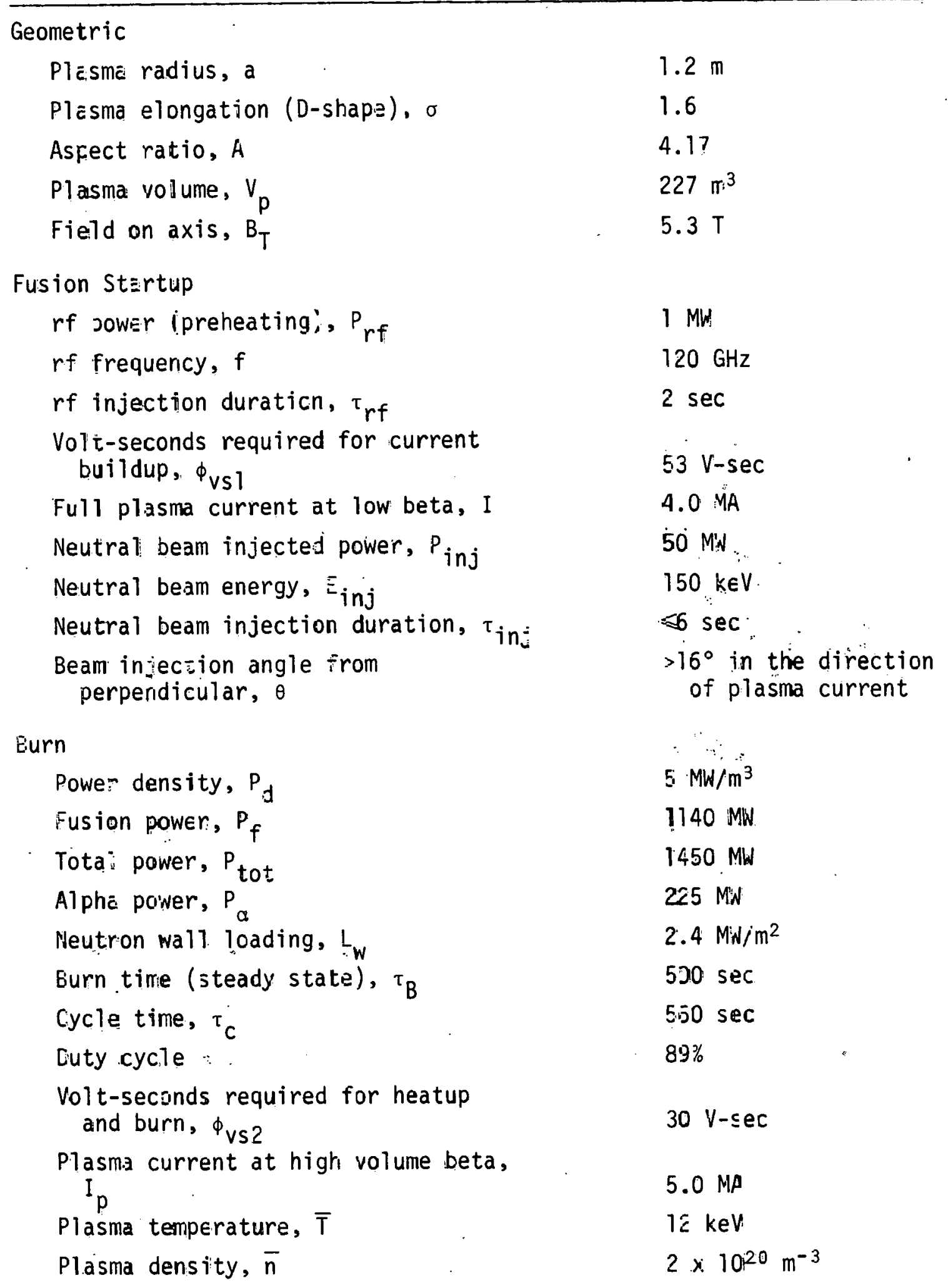


Table 2.1 (continued)

\begin{tabular}{ll}
\hline Burn (continued) & \\
Volume beta, $\bar{\beta}$ & $7.0 \%$ \\
Volume-averaged energy confinement & $1.2 \mathrm{sec}$ \\
time, $\bar{\tau}_{E}$ & $3 \times 10^{23}$ particles/ \\
Plasma edge particle loss rate & $\mathrm{sec}$ \\
& $85 \%$ \\
Plasma fraction recycled at edge & $4.6 \times 10^{22}$ particles/ \\
as neutrals & $\mathrm{sec}$ \\
Pellet fueling rate & $<1.5$ \\
& 3.8 \\
Impurity indicator, $Z_{\text {eff }}$ & $1.5 \%$ \\
Safety factor, $q$ & $0.1 \%$ \\
TF ripple at plasma edge, $\delta_{a}$ & \\
TF ripple at plasma center, $\delta_{0}$ & \\
\hline
\end{tabular}


field curvature and parallel drifts of the electrons. The ions remain cold tecause of charge exchange loss with the neutrals. A stable, currentless plasma maj be established due to the ambipolar potential resulting from unequal electron and ion drifts. Stability is enhanced with the use of a conducting wall which linits the buildup of the vertical electric 'ol tage to less than $1 \mathrm{~V}$ (Ref. 4). It is estinated that roughly $1 \mathrm{MW}$ of $\mathrm{rf}$ power is needed to preheat the electrons to a temperature of $200 \mathrm{eV}$. The peak voltage may then be reduced by rougrly an order of magnitude from estimates for startup without microwave brea<down and preheazing, leading tc a significant decrease in resistive $101 \mathrm{t}$-seconds during startup. ${ }^{3}$ The PF coil flux swing requirement for current startup is then largely due to the plasma inductance and amounts to roughly $51 \mathrm{~Wb}$. (These values are listed under fusion startup in Table 2.1.)

Câlculations of the current rise phase in full bore plasmas indicate that a skin current will form, and experimental observations indicate that MLD disruptions redistribute this skin current in the $\mathrm{plasma}$ and create an influx of impurities from the limiter and/or walls. 5 A model has been developed for transport simulation of the skin current redistribution Jue to internal MHD disruptiors. ${ }^{6-8}$ Comparison of this model with exjerimental data shows good agreement. ${ }^{6}$ Expandir.g radius startup scenarios have been excmined ${ }^{9}$ as a means of reducing the skin current effect and avoiding the introduction of impurities during startup. The use of neutral beam heating with expanding radius is discussed in Sect. 2.2. $\therefore$ The expanding radius scenario also follows naturally from the microwave breakdown and preheating shase, which creates the plasma in a small volume due to the localized $r f$ heating. More detailed studies are needed to quantify the plasma operation during this phase.

\subsubsection{Shutdown}

There are two general categories of shutdown for a large tokamak: controlled or soft shutdown and abort or hard shutdown. The features of the two types of shutdown are discussed in qualitative terms in Ref. 10, but little guantitative analysis has been dore. In general, controlled stutdown would require a programmed decrease of particle fueling and of 
the currents in the PF coils. The vertical field (VF) systen would be required to maintain the plasma position as the plasma pressure decreases. The magnetic configuration of the divertor would also have to be maintained. In many respects, a controlled shutdown requires a reversal of the processes considered during startup.

A hard shutdown due to a major plasma disruption places much greater demands on the design of a power producing tokamak and has therefore received more attention than soft shutdown. A theoretical model for the MHD processes responsible for major disruptions ${ }^{11}$ leads to an estimate of about $24 \mathrm{msec}$ for the disruption time in the Reference Design, as shown in Fig. 2.1. Previous estimates of $100 \mu \mathrm{sec}$ were based on observed times in machines like ST, T-4, and Alcator, with no extrapolation because of the lack of a theoretical model; based on the new information, the impact of major disruptions on the Reference Design has been reexamined. 12

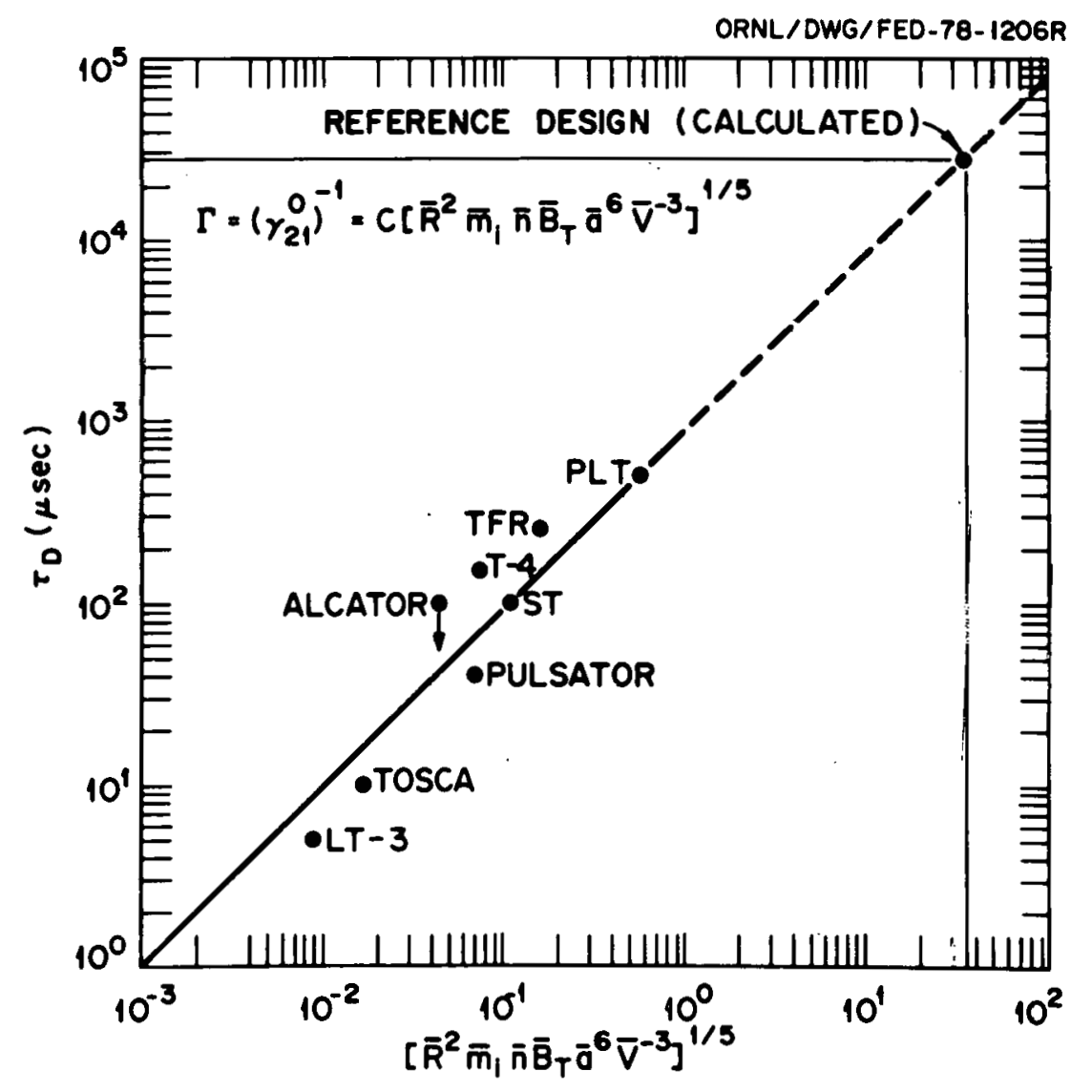

Fig. 2.1. Disruption time as a function of plasma parameters. 
Fcr a disruption time of $100 \mu \mathrm{sec}$ in the Feference Design, it is estimated that 4-5 am of the wall ablate and $\sim 4 \mathrm{C} \mu \mathrm{m}$ melt if the energy is evenly distributed over the entire wall area. 12 For a disruption time of $24 \mathrm{msec}$, it is estimated that no meltirg or ablation of the wall occurs if the energy is evenly distributed. If the latter case proves to be valid, an estimate can be made for the maximum number of aborts whicn can be tolerated due to thermal fatigue. The maximum temperature rise is estimated to te $406^{\circ} \mathrm{C}$ for uniform: energy defosition on the stainless steel first wall. About 460 aborts can be tolerated if thermal fatigue is solely due to disruptions. ${ }^{2}$ Further analysis should provide valuable information for the engineering design requirements of the first wa11.

\subsection{NEUTRAL BEAM INJECTION HEATING}

Mani factors influence the assessment of ne:ltrai beam energy and power requirements for reaching ignition in the Reference Design. A one-dimensicinal (1-D) transfort code was used for a frarameter study which exanined the impact of variations of beam heating time, beam energy, plasma density, and the semiempirical transport model on neutral beam fower requirements. 9 In a companion study, a simplified 1-D transport code was coupled to a 2-D flux conserving equilibrium code to study the full bore, low density heating scenario and the evolution of the MHD equi ibrium with intense neutral beam heating. 13 The results of these studies are summarized below.

\subsubsection{1-B Transport Model}

The impact of variations of neutral beam heating time, beam energy, plasma derisity, and uncertainties in the particle and energy transport models has been examined for the Reference Design for both full bore and expanding radius startup scenarios. In a full bore scenario, the plasma size and current are brought to final values before the neutral beams are turned on. The density is increased to the desired value before injection $\left(\bar{n} \cong 8-12 \times 10^{13} \mathrm{~cm}^{-3}\right)$ and maintained constant during injection. 
After ignition, the density can be increased or decreased to the operating density of the burn phase by a combination of pellet injection, gas puffing, and pumping. In an expanding radius scenario, a plasma with one-half the final minor radius and one-fourth the final current is initiated. The density is raised to the startup density as in the full bore scenario. The neutral beams are then turned on while the plasma size and current are increased to the final full bore values. Neutral beam penetration is improved during the early part of the startup because of the smaller plasma size.

The most dramatic reduction in neutral beam injection power comes from increasing the injection time to several energy confinement times $\left(\tau_{E} \sim 1 \mathrm{sec}\right)$, as shown in Fig. 2.2. Lower energy beams cán be used for

ORNL / DWG / FED-78-1056R

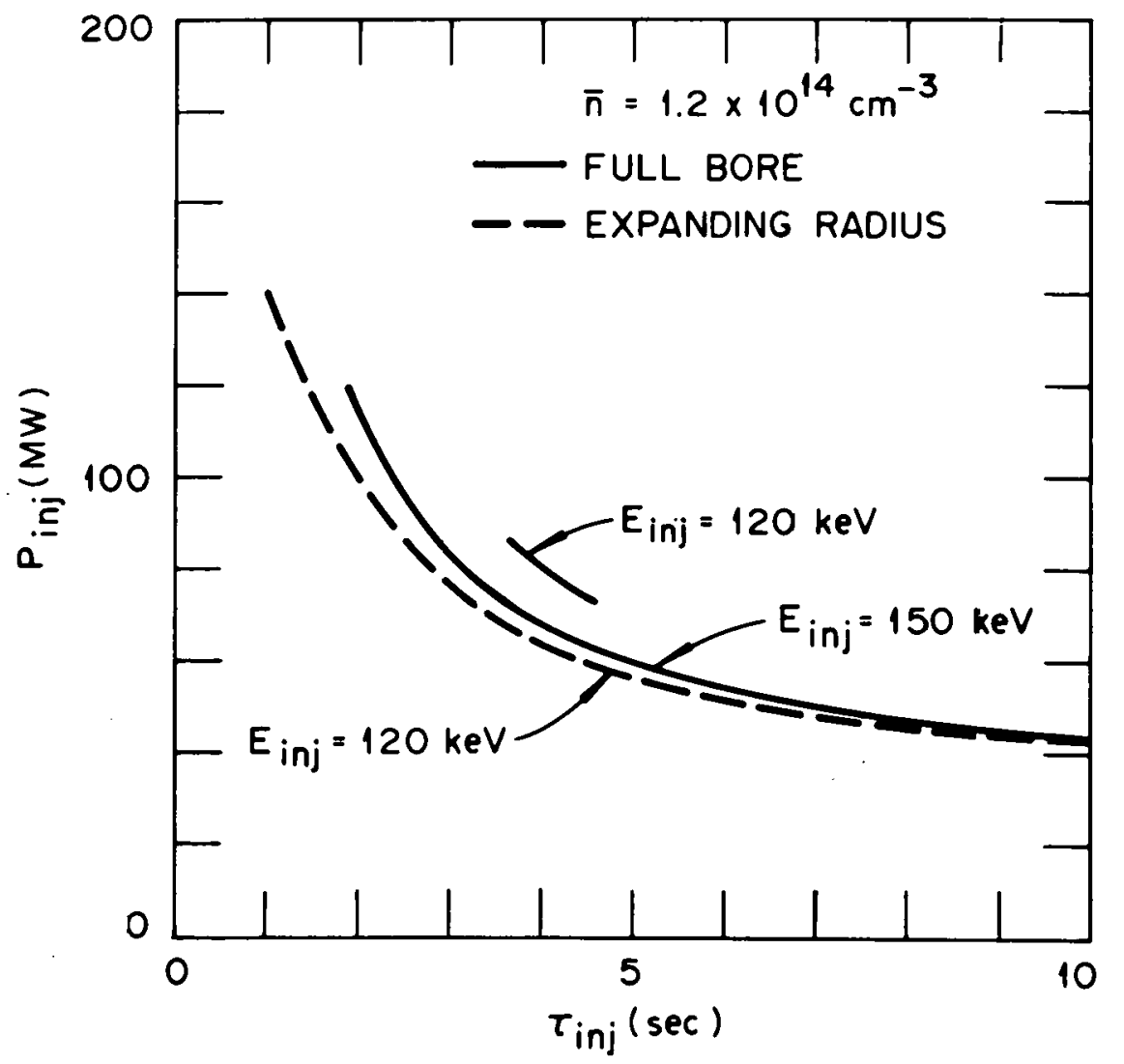

Fig. 2.2. Neutral beam power required for ignition as a function of beam heating time, $\tau_{i n j}$. The expanding radius scenario with $120-\mathrm{keV}$ $D^{0}$ beams and the full bore scenario with $150-k e V$ De beams require essentially the same beam power, $P_{\text {inj }}$. Decreasing the beam energy in the full bore scenario by $20 \%$ requires a $20 \%$ increase in beam power. 
the expanding radius scenario because of the reduced penetration requirements. Lowering the neutral team energy by 220\% (From 150 to $120 \mathrm{keV}$ ) in the =ull bore startuf leads to an increase of $\sim 20 \%$ in the neutral beam power required for ignition. This observation is further reinforced by calculations reported in Sect. 2.2.2.

The impact of plasma density on neutral beam power requ: rements is shown in Fig. 2.3. There is a broad minimum in the curve around $\bar{n}=10^{14}$ $\mathrm{cm}^{-3}$. Eelciw $\bar{n}=8 \times 10^{13} \mathrm{~cm}^{-3}$, ignition becomes difficult because of the lcw fusion power density. This cutoif is sensitive to tre transport

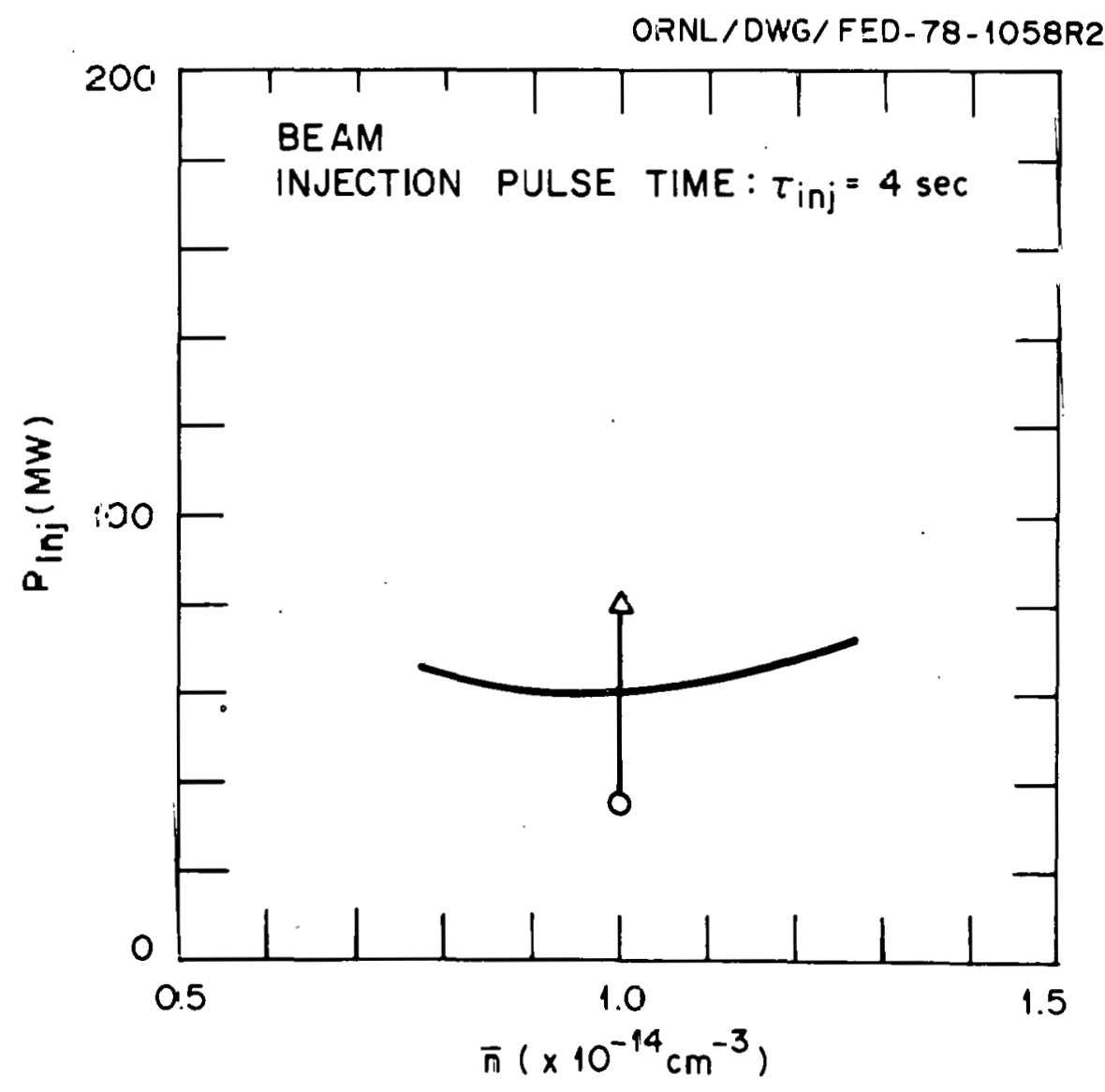

Fig. 2.3. Neutra beam power required for ignition as a function of plasma density, $\bar{n}$. 
model used. In these cases, electron conduction increases as the density is lowered and exceeds the energy input from fusion alpha particles when $\bar{n} \leqslant 7 \times 10^{13} \mathrm{~cm}^{-3}$. At high densities $\left(\bar{n} \geqslant 1.2 \times 10^{14} \mathrm{~cm}^{-3}\right)$, the decreasec neutral beam penetration begins to take its toll on the power required. The transport model was varied over a range consistent with empirical models for ohmic discharges in existing experiments. For a startup density of $\bar{n}=10^{14} \mathrm{~cm}^{-3}$, the neutral beam power requiremen $\bar{s}$ range from 30 to $80 \mathrm{MW}$ for a $4-\mathrm{sec}$ beam pulse, as shown in Fig. 2.3. Startup densities in the range $\bar{n}=8-12 \times 10^{13} \mathrm{~cm}^{-3}$ are indicated, with the largest impact on power requirements due to uncertainties in extrapolation of transport models.

\subsection{2 $73 \frac{3}{2}-D$ Transport Model}

The effectiveness of neutral beam heating to ignition depends strongly on whether the plasma center can be heated enough at low density so that significant local alpha particle heating occurs. ${ }^{14}$ The effectiveness is also influenced by the plasma cross section, the shift of the magnetic axis as beta changes, and the energy spectrum of the beams. A simplified transport model was coupled to a fixed boundary MHD equilibrium code to follow the evolution of the plasma through a sequence of flux conserving equilibria in the presence of large heating and fueling sources. ${ }^{3}$ The transport model assumes a single fluid $\left(T_{e}=T_{j}\right)$ with density and pressure subject to flux-surface-averaged radial transport. Empirical confinement laws consistent with 1-D considerations are used. The Monte Carlo neutral beam deposition code, which includes multiple energy species, was incorporated for the beam heating calculations. This code was developed at PPPL 15 but has been substantially modified at ORNL to account for noncircular, shifted flux surfaces.

Neutral heating with 120-keV beams having a energy mix of $85: 10: 5$ (full:one-half:one-third energy) in the range of $68 \mathrm{MW}$ for $6 \mathrm{sec}$ is shown to ignite the plasma, consistent with the 1-D calculations. The evolution of the plasma density, temperature, beam deposition profile, and alpha particle heating profile for this case is shown in Fig. 2.4. Several beam energies have been studied to determine the required power 

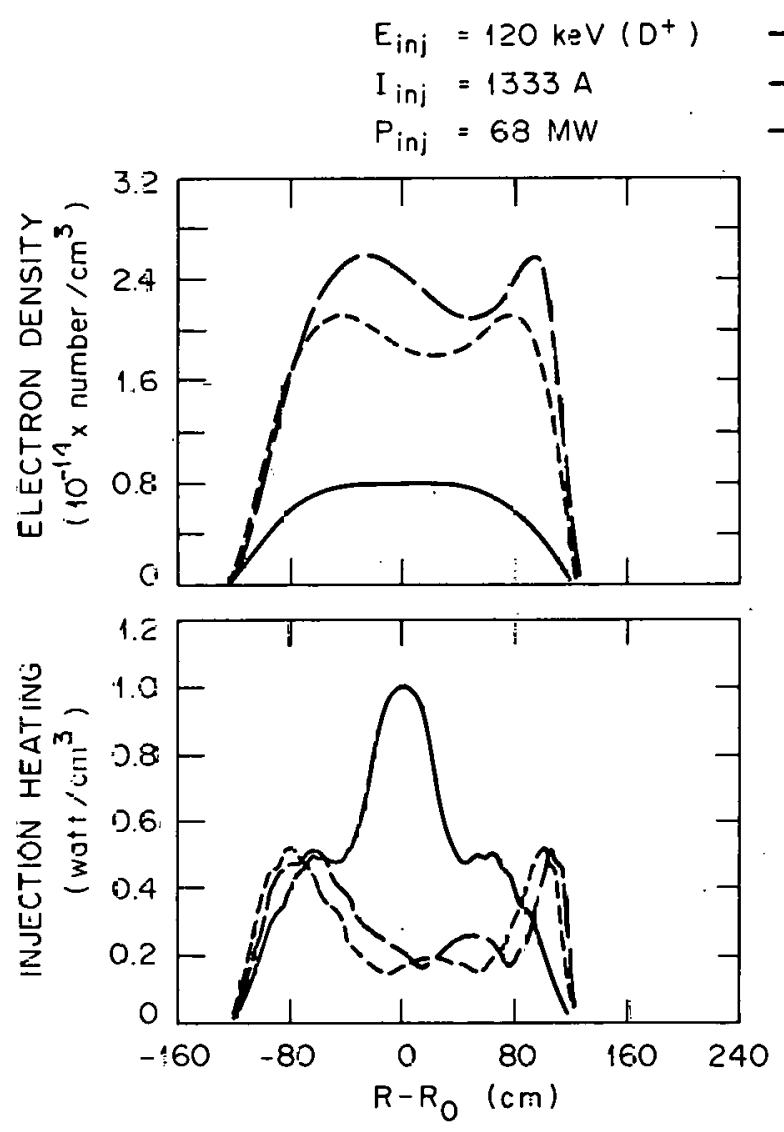
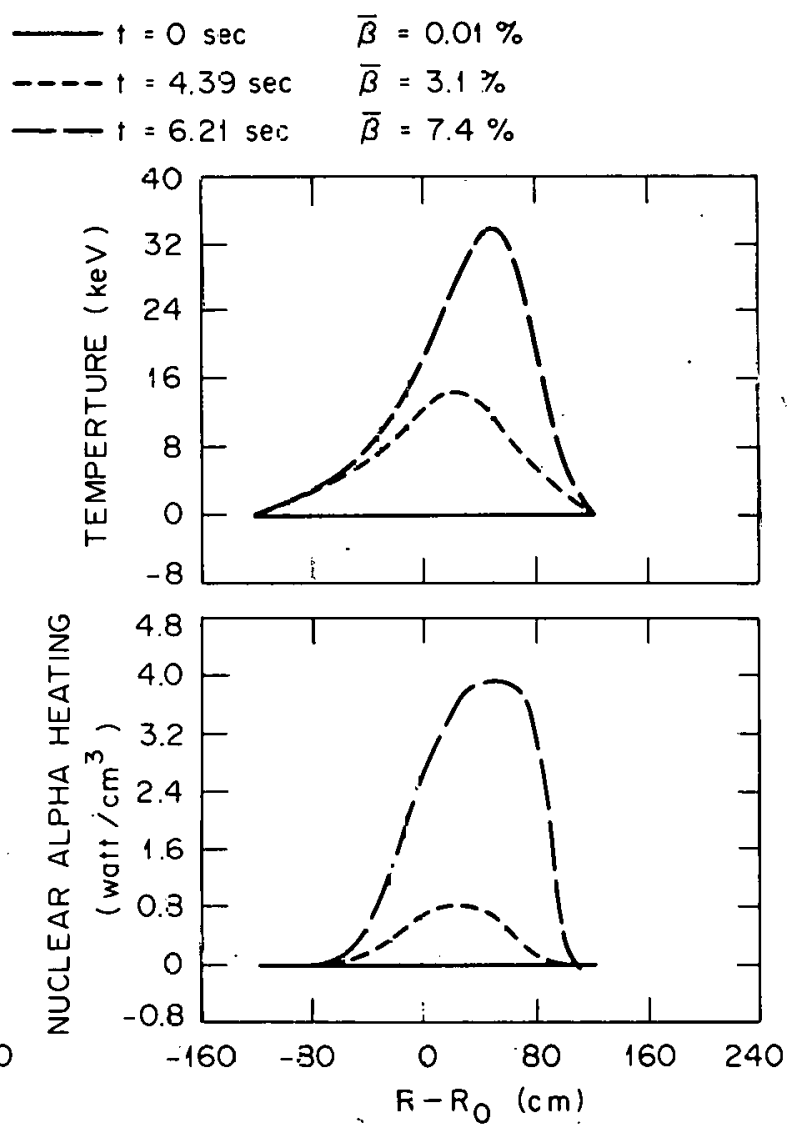

Fig. 2.4. The evoluticn of electron density, plasma temperature, injection heating, and alpha heating along the midplane during a low density, full bore heating scenario with $120-\mathrm{keV}$ beams.

for ignition with a similar final density. The results are summarized in Fig. 2.5. It is seen that, as in the 1-D calculation, the required neutral beam power increases as the beam energy is decreased to $100 \mathrm{keV}$. However, taking the neutralization efficiency into account, the extracted ion powar is seen to remain roughly independent of beam energy. ${ }^{13}$ These calculations $\bar{c}$ ls so show that the plasma can ignite near the center when The 'volume-averaged beta exceeds $\sim 4 \%$ and the density afproacies $\sim 10^{20} \mathrm{~m}^{-3}$. the plasma is assumed to burn at $\bar{\beta} \cong 7 \%$, a critical beta value limited by pressure driven MHD instabilities (sea Sect. 2.3).

Our extensive calculations for the ignition of a clean plasma. ( $z_{\text {eff }} \sim 1$ with only light impurities) in the Refererce Cesign have suggested tinat a deuterium beam energy above $200 \mathrm{k \in V}$ is unnecessary if our present assumptions of the plasma confinement froperties are reasonable. They also show that a steady-state beam pulse in the range of 


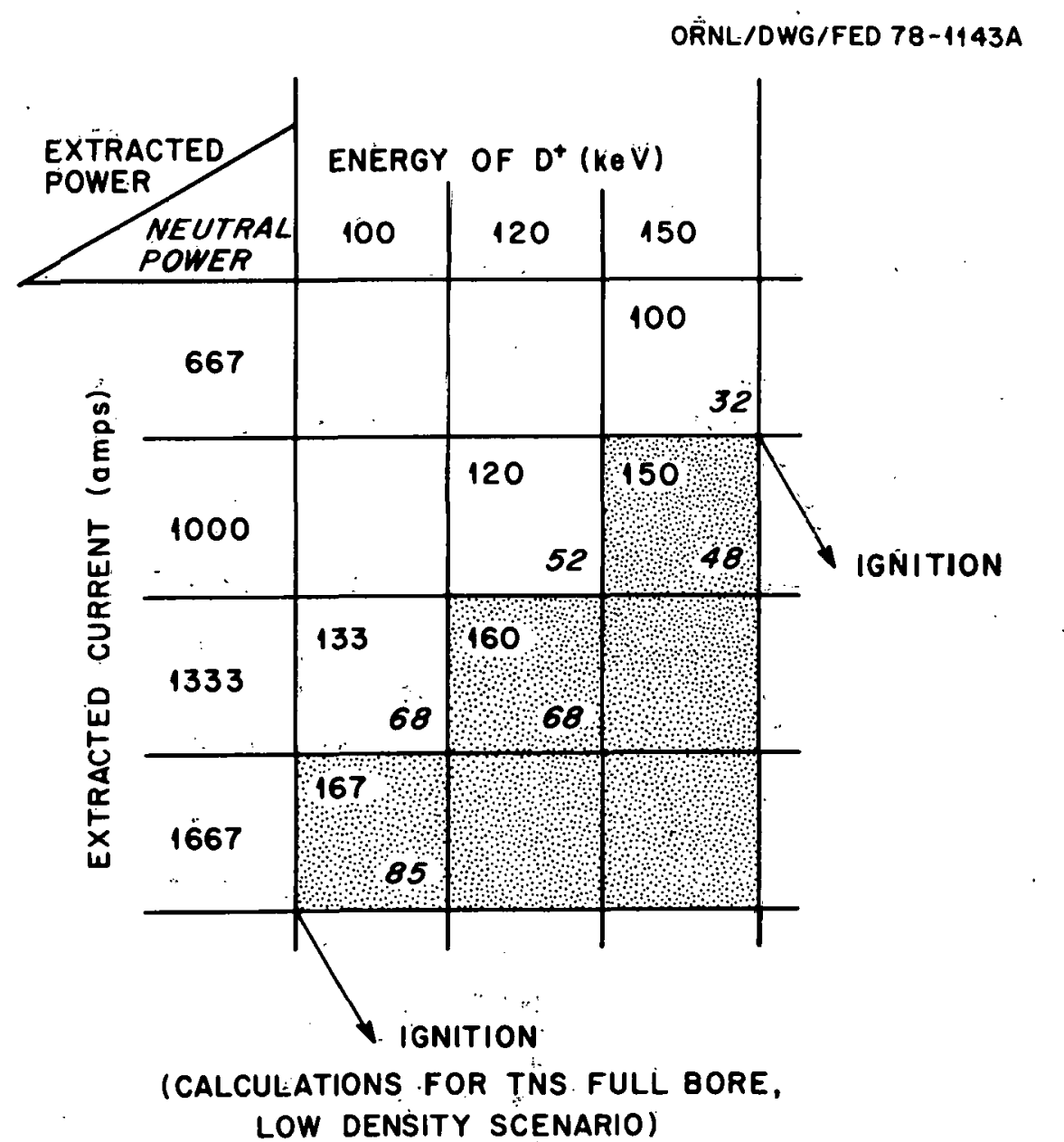

Fi.g. 2:5. To obtain ignition; à trade-off must be made between beam energy and extracted current, but extracted power is about the same at all energies.

4-6 sec is needed. Both scenarios for heating to ignition seem to allow for sufficient margin in energy and power requirements. Since the - plasma control requirements of expanding radius startup require further analysis, the full bore, low density heating scenario witn $150 \mathrm{keV}$ and $50 \mathrm{MW}$ for 4-6 sec has been chosen for the Reference Design.

\subsection{MAINTENANCE OF HIGH BETA CONFIGURATION}

The high beta ( $4-7 \%)$ plasma obtained at the end of the ignition phase is to be maintained over a pulse length of $500 \mathrm{sec}$ in the Reference Design. This requires an understanding of the plasma energy, particle, and impurity balances over a time scale longer than the equilibration 
times between the plasma and the surrounding surfaces (assumed to be tens of seconds) and nuch longer than the plasma and impurity transport times in the plasma and divertor regions (a few seconds). This also requires knowledge of the evolution of hich beta equil ibrium configurations and fusion plisma profiles over a time scale comparable to or longer than the magnetic flux diffusion times (hundreds of seconds). Our present understanding of the energy, particle, and impurity balances is quite limited. For example, the interazting processes of plasma transport and impurity production at the first wall and at the divertor collector under intense thernal power loads are largely unknown. Some initial assumptions and estimates of particle handling requirements are summarized in Sect. 2.4.

The magnetic flux diffusion process in high beta plasmas heated by beams and alpha particles over long time scales is alsc not understood. Therefore: this discussion is concerned with the presently more amenable studies of maintaining the high beta equilibrium configuration during the heating, ignition, and eacrly burn phases before significant magnetic flux diffusion sets $i r$. As shown by the results of the $1-D$ and $1 \frac{1}{2}-D$

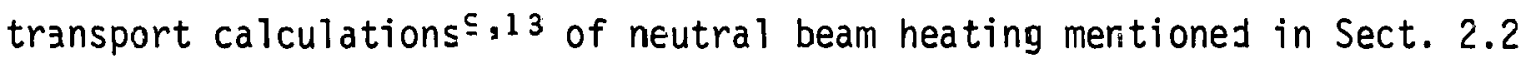
and by the transport simulations carried out by Hogan ${ }^{16}$ and others, 17 significant variations in the plasma current and pressure profiles can result during these phases when varying sources of power and fuel are applied. The estimated requirements for maintainirg the high beta plasma configuration in terms of stability, poloidal field, and coil currents are summarized.

\subsubsection{MHD Stability Requirements}

Assuming that the MHD instabilities degrade plasma confinement and derress plasma beta, it is necessary to estimate ways to improve plasma stability. In ideal MHD, significant theoretical understanding has Elready been obtained. It has been shown ${ }^{18,19}$ that the stability of linearized modes depends strongly on plasma cross section, aspect ratio $(A)$, pressure and currert profiles, and $\beta_{p}$. There is row rather wide acceptance of the potential acivantages for stability at high beta of the Q-shaped cross section with elongations of around $\$ .6$ at a modest aspect ratio $(3 \leqslant A \leqslant 5)$. 
The effects of the plasma profiles and $\beta_{p}$ on the ideal MHD stability are less well understood. Earlier calculations of the Mercier criterion and the high mode number ballooning instabilities have indicated that beta is maximized when $\beta_{p} \sim A / 2$ (Refs. 18 and 19) and for broad current profiles with low $q_{a} \cdot{ }^{18-20}$ It has been shown ${ }^{21}$ that a separation between the plasma and the conducting wall of $\leqslant 0.2 a$ will be sufficient to stabilize the low mode number instabilities. A systematic study of stability on flux conserving equilibria 22 for the Reference Design plasma has been carried out to analyze the effects of profiles and $\beta_{p}$. The results indicate that the critical beta value for stability follows the approximate formula

$$
\bar{\beta}_{C} \cong C\left(\frac{q_{0}}{q_{a}}\right)^{2} \frac{1}{\bar{A}}\left(\frac{\beta_{p}}{A}\right)^{1.5}\left(1-\frac{\beta_{p}}{A}\right),
$$

where $C$ is estimated to be around 9 . For $A \cong 4, q_{0} \cong 1.5, q_{a} \cong 3.8$, and $\beta_{p} \cong 2.4$ it follows that $\bar{\beta}_{c} \cong 7 \%$, which is the value assumed for the Reference Design.

Significant advances ${ }^{23}$ have been made in the past several years in understanding the role of resistive MHD tearing modes in plasma internal ${ }^{24}$ and major disruptions ${ }^{11}$ and in the Mirnov oscillations ${ }^{25}$ observed in existing tokamaks. If we assume that the ideal MHD instabilities would limit $q_{0}$ to 21.5 , internal disruptions may be absent in a high beta plasma. The major disruptions observed have been successfully modeled to include nonlinear interaction and overlapping of tearing modes, which become severe (as do Mirnov oscillations) when the q prozile is relatively flat.

Present understanding of MHD stability seems to indicate the need to maintain the proper plasma cross section, profiles, and $\xi_{p}$ values in order to sustain high beta in the fusion plasma. Many more experimental and theoretical studies are needed to understand the MHD stability properties of high beta plasmas to further quantify the requirements. Since there are significant uncertainties in the profile evolutions of the plasma during the ignition and burn phases, it is important to ensure that the desirable plasma cross section can be maintained by the $\mathrm{PF}$ system despite large changes in plasma profiles and $\beta_{p}$. 


\subsubsection{Poioidal Field and Coil Current Requirements}

A set of MHD equil bria with $q_{a}=2.0-5.4\left(q_{0}=i\right)$ and $\beta_{p}=0.4-3.5$ has been zalculated to determirie the poloidai fields and coil currents requir $ə$ to maintain a $D$-shaped plasma with $\bar{\beta}$ values ranging from 1 and $15 \%$. From these equilibria the dependence of the desirable poloidal field on $q_{a}$ and $E_{p}$ is determined. Our previous studies have resulted in the choice of the hybric PF coils ${ }^{26}$ shown in Fig. 2.6. The dependence of the currents in the inside (I), outside ( 0$)$, and D-shape (D) coils on $q_{a}$ and $\beta_{p}$ can then be determined. Our results are summarized in Figs. 2.7 and 2.8, under the assumptions that $\Sigma I_{\text {coil }}=-I_{p}$ and the split of the produced poloidal field between the coils interior and exterior to the TF coi is is $35 / 65 \%$. For the interior coils, Fig. 2.7(a) shows that the absolute value of $I_{I I}$ and $I_{I D}$ increases mildly with increasing $q_{a}$ (increasing peakedness of profile) while $I_{\text {IO }}$ remains essentially unchanged. Figure $2 . \bar{T}(\mathrm{~b})$ shows that as $\beta_{\mathrm{p}}$ is increased, I $\mathrm{I}_{10}$ increases significantly, $I_{\text {II }}$ decreases significantly, and I $I_{\text {ID }}$ decreases mildly in absolute value. For the exterior coils, Fig. 2.8 shows that similar dejendences prevail, except tha: the currents are, on the average, an order of magnitude larger than those in the interior coils.

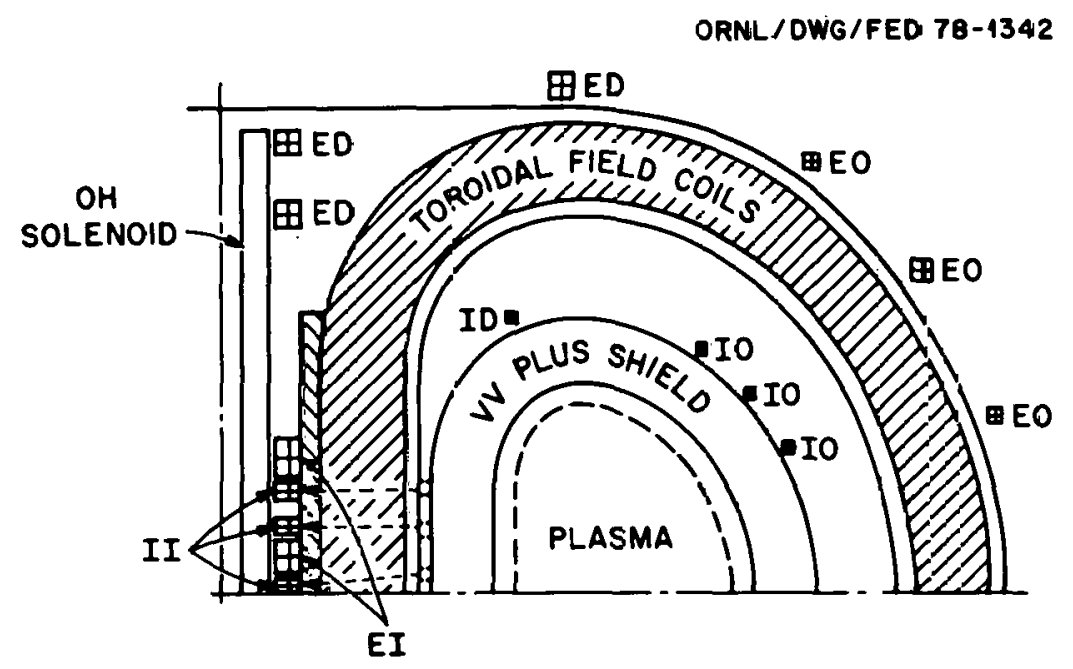

Fig. 2.6. The hybrid PF coil configuration used in the Reference Design. To reduce the engineering difficulties, the II coils have been moved to the vicinity of the EI coils. 

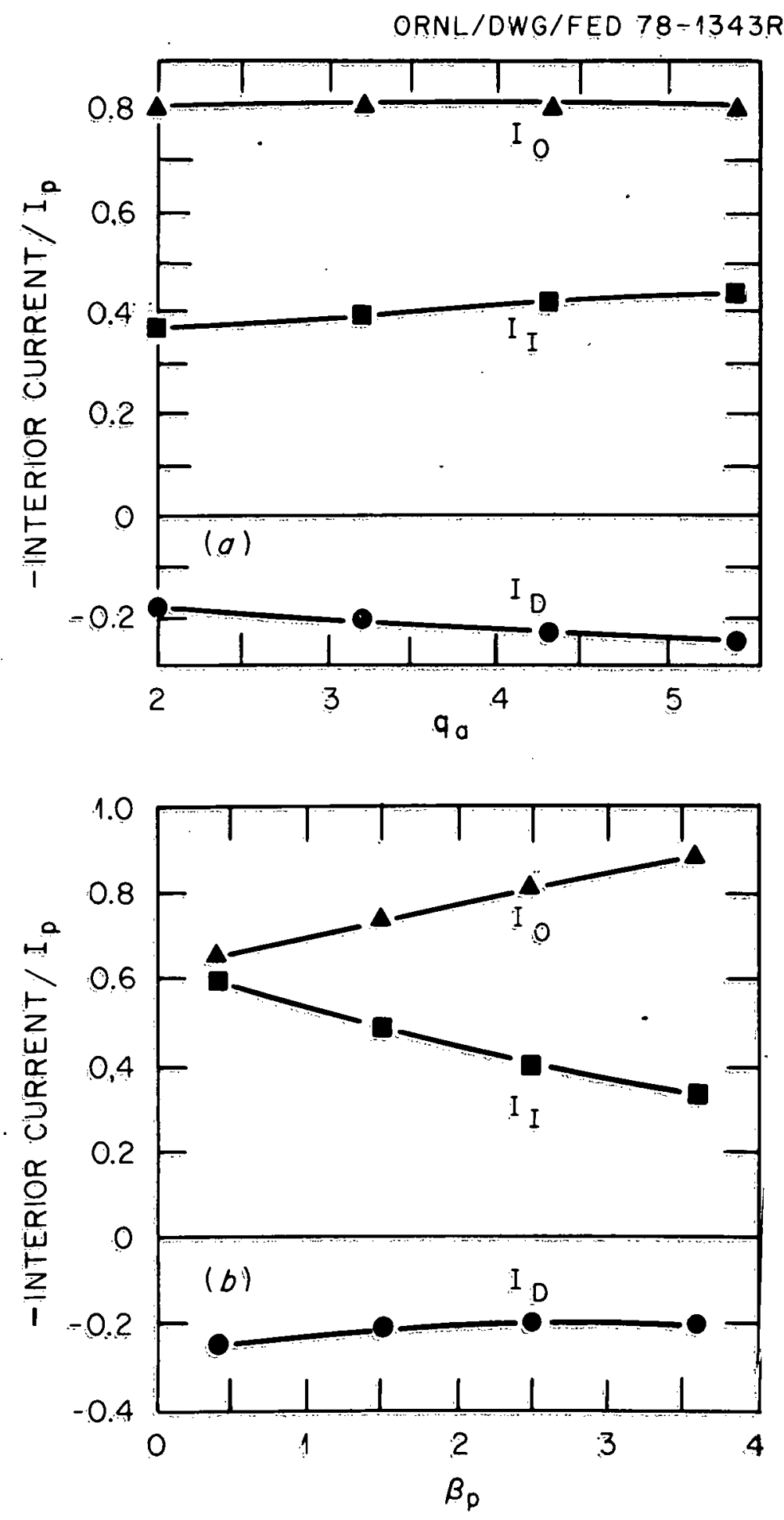

Fig. 2.7. The dependence of $\mathrm{I}_{10}, \mathrm{I}_{\mathrm{II}}$, and $I_{\text {ID }}(a)$ on $q_{a}$ at the plasma surface (with fixed $\beta_{p}=2.5$ ) and $(b)$ on $\beta_{p}$ (with fixed $q_{a}=3.2$ ). 

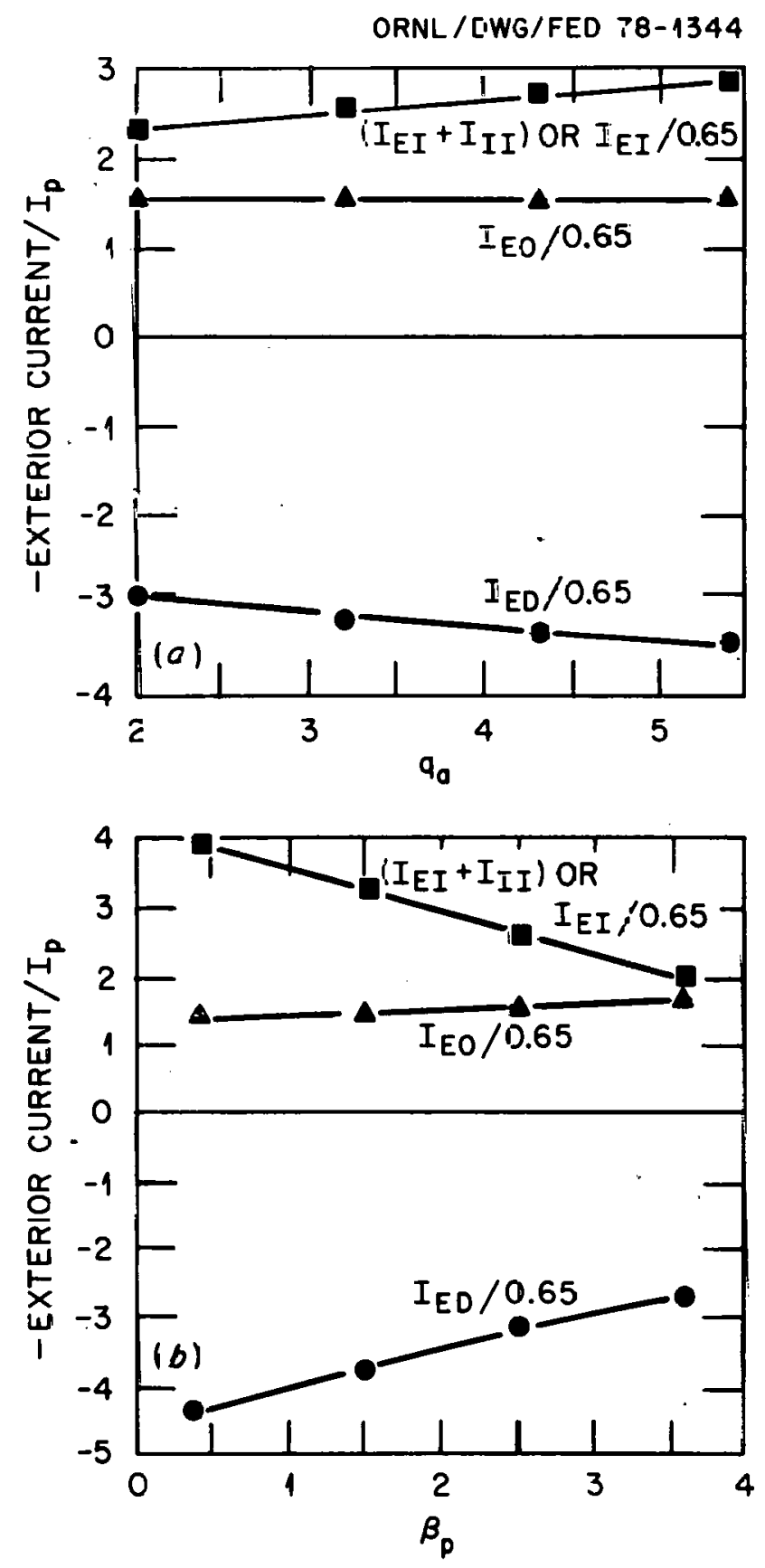

Fig. 2.8. The dependerce of $I_{E I}$, $I_{E O}$, and $I_{E D}(a)$ on $q_{a}$ (witr. fixed $\beta_{p}=$ 2.5) and (b) an $\varepsilon_{p}$ (with fixed $q_{a}=3 . \bar{c}$ ). When the II ccils are moved to the vicinity of the EI coils (se Fig. 2.6), $\left(I_{E I}+I_{I I}\right)$ is plotted. 
These results indicate that the PF system proposed for the Reference Design will allow us to control the D-shaped plasma cross seztion despite possible large changes in plasma profile and beta. Similar studies based on realistic plasma profiles, obtained through $1 \frac{1}{2}-D$ transport calculations, are needed for better quantification of the needed poloidal fields and coil currents. A similiar PF coil system 27 will be tested in ISX-B during experiments on noncircular, high beta plasmas.

\subsection{PARTICLE CONTROL}

Particle control in the Reference Design should involve all assumed fueling and exhausting mechanisms and can be discussed in terms of the phases of the discharge cycle: prefill, breakdown, current buildup, heating to ignition, burn, and shutdown and exhaust. Our knowledge in the area of particle control is presently limited; we preserit a brief discussion of our assumptions, with an emphasis on the phases of heating to ignition and burn.

\subsubsection{Prefi11, Breakdown, and Current Buildup}

A neutral prefill of roughly $5 \times 10^{-4}$ torr is assumed, roughly half of which is ionized and retained in the plasma after breakdown (in accordance with existing tokamak experiments). To control impurity production and migration into the plasma during the current buildup phase, an expanding plasma radius isolated from material surfaces is assumed. Depending on the heating scenario (see Sect. 2.2), gas recycling and/or pellet fueling may be required during current buildup.

\subsubsection{Heating to Ignition}

During this phase, it is expected that fueling by a combination of gas blanket, pellet injection, and neutral injection will be used. For a neutral heating power of $50 \mathrm{MW}$ at $150 \mathrm{keV}$, particles are introduced at a rate in excess of $2 \times 10^{21}$ particles/sec, providing some central fueling. Over $6 \mathrm{sec}$, the neutral beams would contribute substantially to the plasma particles at a density of $10^{14} \mathrm{~cm}^{-3}$, owing to the relatively long confinement time of the particles near the center of the plasma. 
If the neutral beams alone cannot produce the needed density rise during heating (see Sect. 2.2), pellets with at least partial penetration ane needed. Calculations under the neoclassical and trapped ion transport model $\mathrm{s}^{28}$ have indicated volume-averaged particle confinement times around $0.5 \mathrm{sec}$ if no significant gas recycling is present at the plasma edge. Assuming an unload divertor, the average particle temperature at the separatrix would be around $3.4 \mathrm{keV}$, potentially leading to unacceptable rates of impurity production at the wall. Gas recycling from the divertor and the wall is then required to effectively shield the plasma from reentry of sputtered impurities.

The effectiveness of divertors in controlling impurities has been experimentally demonstrated only at low power and for short durations. 29-31 Extrafolation of these results to the Reference Design is presentiy SFeculative. Recent hydrogen recyling measurements in Alcator ${ }^{32}$ have irdicated that the plasma flux at the edge $\left(\dot{\Gamma}_{S}\right)$ lies between $7.5 \times$ $16^{16} / \mathrm{cm}^{2} / \mathrm{sec}$ and $9 \times 10^{-17} / \mathrm{cm}^{2} / \mathrm{sec}$ when the plasma density is between $5 \times 10^{13} \mathrm{~cm}^{-3}$ and $10^{14} \mathrm{~cm}^{-3}$. We have assumed that $\Gamma_{\mathrm{S}}=10^{17} / \mathrm{cm}^{2} / \mathrm{sec}$ in the Reference Design, which leads to a total plasma loss rate around $3 \times 10^{23}$ particles $/ \mathrm{sec}$ and a volume-averaged particle confinement time of $\sim 0.1 \mathrm{sec}$. Because significant gas recycling is assumed, vacuum pumping of only a fraction of this particle rate (say, $3 \times 10^{22} / \mathrm{sec}$ ) is required. It is assumed that this pumping rate at $10^{-4}$ torr is sufficient for adequate impurity control.

\subsubsection{Burn}

Particle and impurity control requirements during this phase differ from those in the previous phase due to the presence of fusion thermal power ( $230 \mathrm{MW})$, the absence of direct fueling to the plasma center (i.e., by neutral beam injection), the depletion of the D-T plasma, and the praduction of aipha particles due to fusion near the plasma center. Assuming the same plasma edge flux of $10^{17}$ particles $/ \mathrm{cm}^{2} / \mathrm{sec}$, the averaged Jarticle efge temperature would be $2.4 \mathrm{keV}$ in the absence of nonconvective neat lisses. To reduce the thermal power handling difficulties at the divertors, it is assumed that more than half of the fusion thermal power 
is deposited on the first wall through cross-field conduction (by instabilities, field ripples, etc.) and charge exchange losses (by gas recycling) in the scrape-off region.

D-T particles are consumed during burn at a rate of $\sim 3 \times 10^{20}$ particles/sec or $2 \% / \mathrm{sec}$ of the total plasma particles. These particles are assumed to be replenished by the inward diffusion of the surrounding plasma, which is fueled by pellets. If a pellet fueling rate of $4.6 \times 10^{22}$ particles/sec is assumed, the required inward diffusion rate is only $2 \%$. The alpha particle confinement time is assumed to be similar to the particle confinement times near the plasma center (which are assumed to be $\sim 4 \mathrm{sec}$ ). This leads to a steady-state alpha particle content of roughly $1.6 \times 10^{21}$ or $4 \%$ of the plasma. Assuming a vacuum pumping requirement of $1.5 \times 10^{22} \mathrm{molecules} / \mathrm{sec}$, the hel ium concentration through the vacuum pump is $\sim 2.7 \%$. These quantitative assumptions need extensive theoretical and experimental corroboration.

\subsubsection{Shutdown and Exhaust}

Fusion shutdown can be achieved by terminating tritium fueling to significantly reduce the tritium content in the plasma in a time scale of the central particle confinement time. The plasma equilibrium is maintained throughout shutdown. Given adequate pumping and various discharge cleaning techniques, exhausting the residual gas in the chamber and on the wall is not expected to be difficult. 


\section{REFERENCES}

1. D. G. McAlees, F. B. Marcus, S. E. Attenbercer, R. N. Cherdack, G. D. Kerbel, J. F. McNally, Jr., Y-K. M. PEng, G. Schilling, D. J. Strickler, and N. A. Uckan, Plasma Ensineering in a DeuteriumTritium: Fueled Tckamak, ORNL/TM-5573, Oak Ridge, Tennessee (1976).

2. A. Anisimov, N. I. Vinogradov, and B. P. Poloskin, Sov. Phys.-Tech. Phys. 18, 459 (1975); 20, 626 (1976); 20, 629 (1976).

3. Y-K. M. Peng, S. K. Borowski, and T. Kammast, Nucl. Fusion 18, 1489 (1978).

4. S. K. Borowski, Y-K. M. Peng, and T. Kammast, "Plasma Confinement in -SX-B Curing UHR Preheating," to be published.

5. D. A. Shcheglọ, Zh. Eksp. Teor. Fiz. Pis'ma Redl. [JETP Lett.] 22, 14 (1975).

6. Yu. N. Dnestrovskij, D. P. Kostomarov, S. E. Lysenko, G. V. Pereverzev, and K. N. Tarasayan, Proc. 7th Int. Conf. or Plasma Physics and Controlled Nuclear Fusion Research, paper F-1-3 (to be published).

7. H. A. Houlberg and J. T. Hogan, Bull. Am. Phys. Soc. 23, 760 (1978).

8. E. Carreras, H. R. Hicks, and E. V. Wadde11, But1. Am. Phys. Soc. 23,331 (1978).

9. H. A. Houlberg, A. T. Mense, and S. E. Attenberger, "Neutral Beam Energy and Power Requirements for Expanding Radius and Ful1 Bore Startup of Tokamak Reactors," to be published.

10. $\therefore$. [. Rogers (compiler), Tivs Doubret Tokamak Ohmic-Heating Power Supp?y Study, LA-7053-Mj, Los Alamos Scientific -aboratory, LoS Alamos, New Mexico (January 1978) (also jssued a.s GAC-ANL TNS scoping Studies, Vol. I, GA-A14614, General Atomic Company, San [iego, Ealifornia).

11. E. Carraras, B. V. Wadde11, and H. R. Hicks, Ana? $y$ itic Model for the Nonlinear Intraction of Tearing Modes of Dijferert Pitch in Cylindrical Geometiy, ORNL/TM-6175, Oak Ridge, Tennessee (1978).

12. F. J. Onega, Major Plasma Disruptions in TNS, ORHL/TM-6616, Cak Ridje, Tennessee (1978).

13. J. A. Holmes, J. A. Rome, Y-K. M. Peng, and 5. J. Lynch, "Low Density Igni亡ion Sceriarios Using Injection Heating," to be putlished. 
14. J. A. Rome, Y-K. M. Peng, and J. A. Holmes, Injection Heating Scenario for TNS, ORNL/TM-5931, Oak Ridge, Tennessee :July 1977).

15. G. G. Lister, D. E. Post, and R. Goldston, Proc. 3rd Symp. on Plasma Heating in Toroidal Devices, p. 303 (1976).

16. J. T. Hogan, The Accessibility of High $\beta$ Tokamak States, ORNL/TM-6049, Oak Ridge, Tennessee (1978).

17. G. Bateman, D. B. Nelson, D. J. Sigmar, and N. A. Uckan, Finite Beta Toroidal Plasmas, ORNL/TM-6273, Oak Ridge, Tennessee (1978).

18. Y-K. M. Peng, R. A. Dory, D. B. Nelson, and R. 0. Sayzr, Phys. Fluids 21, 467 (1978).

19. R. A. Dory et a 1., Tokamaks Heated to High Beta, ORNL/TM-6434, Oak Ridge, Tennessee (July 1978).

20. D. Dobrott et a1., Phys. Rev. Lett. $\underline{38}, 829$ (1977).

21. D. Berger et a1., Proc. 8th European Conf. on Controlled Fusion and Plasma Physics, Vol. 1, p. 69 (1977).

22. L. A. Charlton et al., "Stability Study of High $\beta$.FCT Equilibria," ; to be published.

23. J. D. Callen et al., Proc. Tth Int. Conf. on Plasma Physics and Controlled Fusion Research, paper F-1-7 (to be published).

24. B. V. Waddell et al., Nuct. Fusion 18, 735 (1978).

25. B. Carreras, B. V. Wadde11, and H. R. Hicks, Poloidal Magnetic Field Fluctuations in Tokamaks, ORNL/TM-6403, Oak Ridge, Tennessee (Juiy 1978).

26. Y-K. M. Peng, D. J. Strickler, and R. A. Dory, Proc. 7th Symp. on Engineering Problems of Fusion Research, p. 186 (October 1977).

27. Y-K. M. Peng et a1., Poloidal Field and MHD Equilibrium Considerations for the ISX Tokamak, ORNL/TM-6482 (to be published).

28. A. T. Mense, W. A. Houlberg, S. E. Attenberger, and 5. L. Milora, Eofects of Fueling Profiles on Plasma Transport, ORNL/TM-6026, Oak Ridge, Tennessee (Apri1 1978).

29. P. E: Stott, C. M. Wilson, and A. Gibson, The Bundle Divertor Part 11. Plasma Properties, CLM-P478, Culham Laboratory, Abingdon, England (September 1977).

30. Y. Simomura and H. Meada, J. Nucl. Mater. 76 , 45 (1978). 
31. A. V. Bortnikov et à1., Proc. 7th Symp. on Flasma Physics and Controlled Nuclear Fusion Research, paper T-3-2 (to be published). 3ź. E. S. Marnear, J. Nucl. Maťer. 76, 59 (1978). 


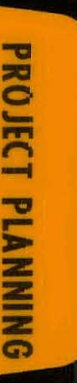




\section{PROJECT PLANNING}

The programmatic issues associated with the implementation of a TNS project are discussed. The major issues include cost and schedule, assessment of technical needs, and the operating plan or mission of the facility.

\subsection{COST AND SCHEDULE}

The cost estimates were calculated with the aid of the COAST code developed in FY 1977, 1 except where more detailed cost analyses were available as a result of the systems cost/performance optimization studies performed this year. A scheduling activity initiated last year has been continued to identify the schedule requirements that must be satisfied in order to implement the TNS project on a timely basis.

\section{1 .1 Cost}

There has been a continuing effort to maintain up-to-date cost estimates for the systems of the evolving TNS design and to use these estimates as a guide in establishing the Reference Design. The FY 1978 activities concentrated on cost/performance trade studies in selected critical system areas in order to arrive at a more cost-effective design. The areas considered included the PF system, the TF coil system configuration, and the vacuum topology.

The cost estimates have been prepared in a format corresponding to the Work Breakdown Structure (WBS) shown in Fig. 1.16. Table 3.1 gives the cost of the facility on the basis of the first level of the WBS. Note that the direct cost of the facility is $2 \$ 500$ million and that the total cost is $2 \$ 1000$ million, excluding escalation and interest during construction. The cost estimate is presented in Fig. 3.1 on the bas is of major functional areas, indicating the large dependence on the TF coil system, followed by the electrical power and controls. Table 3.2 shows the cost estimate carried down to the second level of the WBS. 
Table 3.1. Cost estimate for the THS Reference Design

\begin{tabular}{|c|c|c|}
\hline $\begin{array}{l}\text { Tcp level WBS elements } \\
\text { of facility }\end{array}$ & (in millions of dol ars) & $\begin{array}{l}\text { Percent } \\
\text { of total }\end{array}$ \\
\hline Tokamak systems & 238 & 47 \\
\hline $\begin{array}{l}\text { Electric }{ }^{2} \text { power } \\
\text { and controls }\end{array}$ & 79 & 16 \\
\hline Toka:nak supfort systems & 82 & 16 \\
\hline Structure and site services & 58 & 12 \\
\hline Piasma heating & 45 & $\underline{9}$ \\
\hline Direct facility cost & 502 & 100 \\
\hline \multicolumn{3}{|l|}{ Acditional costs } \\
\hline Shipping and handling ( $27 \%)$ & 5 & \\
\hline Installation $(\sim 15 \%)$ & 75 & \\
\hline E[If. $(\sim 45 \%)$ & 226 & \\
\hline Subtotal & 808 & \\
\hline $\begin{array}{l}\text { Contingency } \\
\quad(30 \% \text { of subtota } 1)\end{array}$ & 242 & \\
\hline $\begin{array}{l}\text { Total cost of TNS } \\
\text { Reference Design }\end{array}$ & 1050 & \\
\hline
\end{tabular}


MILLIONS OF DOLLARS

TF COIL STRUCTURE AND ASSEMBLY

$\$ 168.73$

\begin{tabular}{|c|}
\hline ELECTRIC POWER AND CONTROLS \\
\hline
\end{tabular}

STRUCTUURES AND SITE SERVICES $\$ 58.00$

PLASMA HEATING SYSTEMS

$\$ 45.00$

REFRIGERATION AND COOLING SYSTEMS

$\$ 40.30$

MECHANICAL,

STRUCTURAL SHIELDS

$\$ 36.92$

PULSED COILS

$\$ 32.49$
$\$ 23.78$ FUEL, TRITIUM, PUMPING

$\$ 18.20$ REMOTE SERVICE SYSTEM

Fig. 3.1. Facility cost by functional area. 
Table 3.2. Facility cost by component/elemen

\begin{tabular}{|c|c|c|}
\hline Component/element & $\begin{array}{c}\text { Cost } \\
\text { (in millions of dollars) }\end{array}$ & $\begin{array}{l}\text { Percent } \\
\text { of total }\end{array}$ \\
\hline \multicolumn{3}{|l|}{ Tokamak systems } \\
\hline Vaclium vessel assembly & 9.36 & 1.87 \\
\hline Liner/limiter & 1.79 & 0.36 \\
\hline Machine structure & 7.72 & 1.54 \\
\hline Bucking cylinder & 1.67 & 0.33 \\
\hline \multicolumn{3}{|l|}{ TF coil assembly } \\
\hline Conductor & 63.83 & 12.72 \\
\hline Structure & 73.55 & 14.65 \\
\hline Dewar & 13.35 & 2.66 \\
\hline$\equiv F$ coil assembly & 19.11 & 3.81 \\
\hline $\mathrm{OH}$ coil assembly & 13.38 & 2.67 \\
\hline Winding station & 18.00 & 3.59 \\
\hline Device shielding system & 14.68 & 2.92 \\
\hline Neutral jean duct shielding & 1.70 & 0.34 \\
\hline Subtotal & 238.42 & 47.49 \\
\hline \multicolumn{3}{|l|}{ Electrical power and control systems } \\
\hline PF system MGF sets & 21.22 & 4.23 \\
\hline Neutral beam primary power & 3.12 & 0.62 \\
\hline Primary and secondary distribution & 2.86 & 0.57 \\
\hline TF poiver conversion & 2.41 & 0.48 \\
\hline EF 3-Jhase rectifiers & 9.44 & 1.88 \\
\hline $\mathrm{OH}$ restifiers & 7.73 & 1.54 \\
\hline rf initiation system & 5.00 & 1.00 \\
\hline EF power corversion & 10.05 & 2.00 \\
\hline $\mathrm{OH}$ power conversion & 9.28 & 1.85 \\
\hline Control, handling, safety & 9.49 & 1.89 \\
\hline Plasme diagnostics & 1.80 & 0.36 \\
\hline Standby/emergency system & 0.90 & 0.18 \\
\hline Subitota 1 & 83.30 & 16.60 \\
\hline
\end{tabular}


Table 3.2 (continued)

\begin{tabular}{|c|c|c|}
\hline Component/element & $\begin{array}{l}\text { Cost } \\
\text { (in millions of dollars) }\end{array}$ & $\begin{array}{l}\text { Percent } \\
\text { of total }\end{array}$ \\
\hline \multicolumn{3}{|l|}{ Tokamak support systems } \\
\hline Remote servicing & 18.20 & 3.63 \\
\hline Fuel handling & 11.92 & 2.38 \\
\hline Tritium cleanup & 5.19 & 1.02 \\
\hline Torus vacuum pumps & 4.25 & 0.85 \\
\hline \multicolumn{3}{|l|}{ Refrigeration } \\
\hline $\begin{array}{l}\text { Liquid helium (for super- } \\
\text { conducting coils) }\end{array}$ & $24: 90$ & 4.95 \\
\hline $\begin{array}{l}\text { Liquid nitrogen (for super- } \\
\text { conducting and copper coils) }\end{array}$ & 7.94 & 1.5 .3 \\
\hline Vacuum vessel cooling & 1.51 & 0.30 \\
\hline \multicolumn{3}{|l|}{ Water cooling } \\
\hline PF system & 0.96 & 0.19 \\
\hline Shield & 2.66 & 0.53 \\
\hline Plant circulation & 0.89 & 0.18 \\
\hline Experimental area ventilation & 1.44 & 0.29 \\
\hline Radioactive waste handling & 2.42 & 0.48 \\
\hline Subtotal. & 82.28 & 16.39 \\
\hline \multicolumn{3}{|l|}{ Structures and site services } \\
\hline Vacuum containment building & 40.00 & 7.97 \\
\hline \multirow{2}{*}{$\begin{array}{l}\text { Other structures and site work } \\
\text { Subtotal }\end{array}$} & 18.00 & 3.59 \\
\hline & 58.00 & 11.55 \\
\hline Neutral beam systems & 40.00 & 7.97 \\
\hline Total & 502.00 & 100.00 \\
\hline
\end{tabular}




\subsubsection{Schedule}

A program planning and scheduling activity was initiated during FY 197i.2 A naster program schedule has been developed over the past year that is consistent with the following assumptions:

11) Title I start is restricied unti' after the Tokamak Fusion Test Reactor (TFTR) is operational.

(2) The device is to be operational in the late 1980s.

(3) The development of the facility will be preceded by a site evaluaition and selection process.

(4) The schedule is to be consistent with Department of Energy and Jffice of Management and Budget cycles.

(5) The schedule is to be consistent with the experiences of other najer projects.

(5) The schedule is to be consistent with critical fhysics, zechnology, and cevelopment plans.

Figdre 3.2 deficts the present scheduie for the Reference Design.

Ma-ntaining an up-to-date TNS schedule requires a continuing review in detall of all critical system requirements, the determination of key technical inconsistencies and gaps in present research and development (R\&D) programs, the identification of possible solutions, and the generation of a program schedule with minimum cost impacts. In future studies, all critical systems will continue to be evaluated so that the system schedule can be kept up to date.

As an example of the interfacing between the development schedules and the overall program schedule, Fig. 3.2 shows a preliminary development plan for the electron cyclotron heating (ECH) system. This Reference Design system was not part of the Bcsseline Design and therefore had not been addressed in our previous TNS planning. ${ }^{2}$

\subsection{TECHNICAL NEEDS ASSESSMENT}

The technical needs identified for the key systems of the Reference Design are sumnarized in this section. The goal of this continuing assessne t effort ${ }^{3}$ is the identification of potential barriers and 


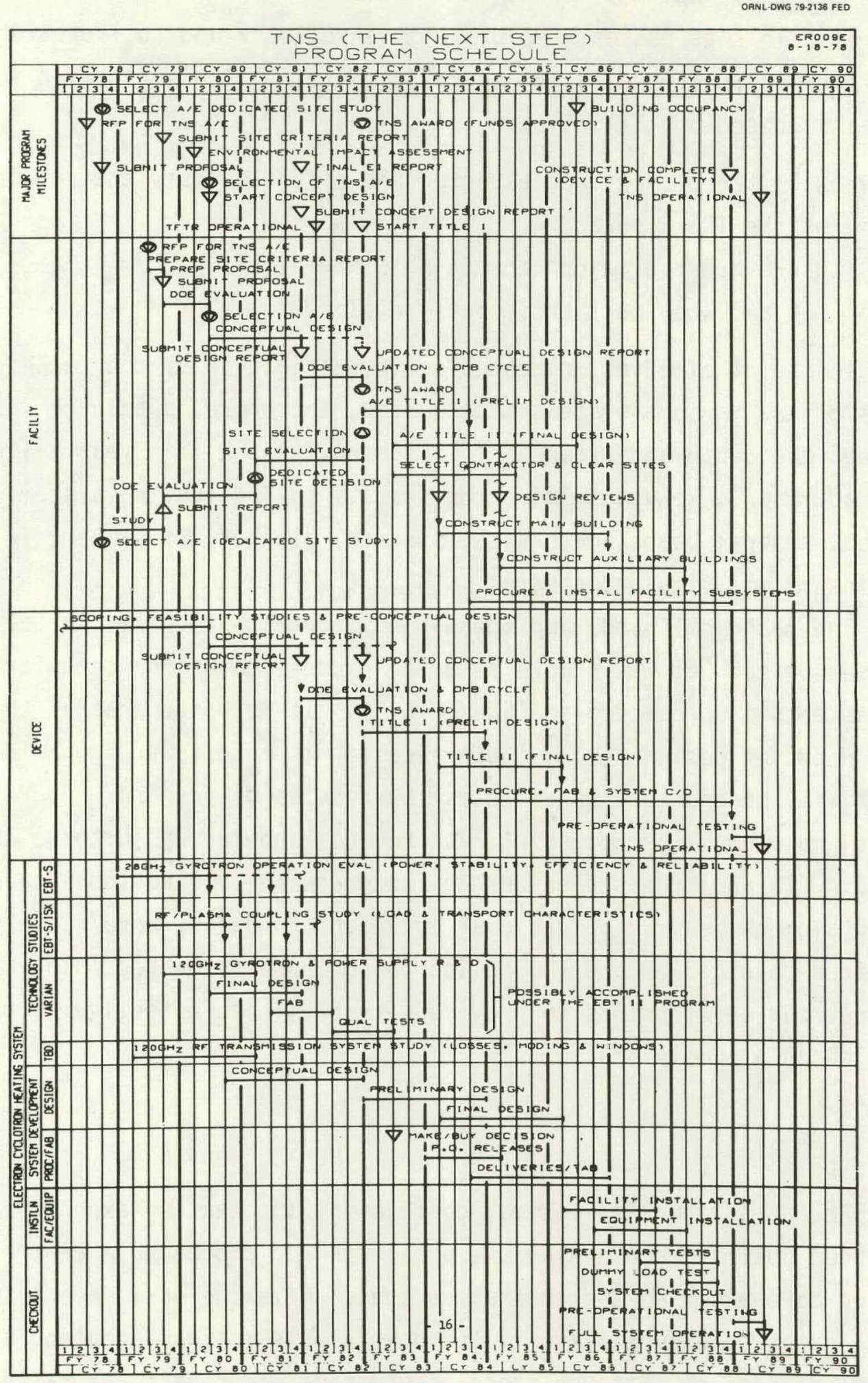

Fig. 3.2. TNS program schedule. 
technical gaps that may imjede the successful implementation of the TNS procram. This assessment employs both a rollback and rollforward approach for determining the needs for specific systems. The evaluation for each system is based on the following questions:

(1) Will the present and expected R\&D effort satisfy the requirements cf the TNS Program?

(2) Where are the major gaps in this R\&D effort?

(3) Low and when must these gaps be closed?

The level of effort directed to the definition of the technical raeds of the various systems was 1 imited; therefore, a Jalance was made between the depth and breadth of consideration for this year. Ten areas were addressed: physics, divertor system, pellet fueling system, PF system, neutral beams, mechanical systems, blanket, rf system, TF system, and instrumentation and ccntrol.

The technical needs and the R\&D advancements required in each area are sumnarized below. A more detailed discussion of the technical needs assessments is presented in ORNL/TM-6722. It is ncted that at this preconceptual design stage, these assessments tend toward generic issues, which will become more sfecific as the studies go forward. There seem to se, however, two continuing requirements showing up in these assessments: (1) ar increased effort to integrate the verious physics results to obtain the desired operational cycle and to define more clearly the required physics R\&D and (2) an increased emphasis on technology and engineerin for TNS on a timely basis.

\subsubsection{Physics}

Recent advances in tokamak confinement and heating experiments have provided optimism concerning the prospects for producing a controllable fusion core based on the tokamak concept. Nevertheless, uncertainties still exist in essentially all the physics assumptions adopted in the Reference Design, althougn these assumptions are considered reasonable. This section briefiy summarizes and discusses the physics R\&D needs as 
suggested by the required improvements in understanding. Highlighted are five physics areas in which even a rudimentary level of understanding is considered seriously lacking. These areas are ordered according to an increasing level of uncertainty: plasma confinement, plasina heating, ignition and burn, operation and control, and impurity control.

\section{Plasma confinement and optimization}

This area deals with the plasma size, the TF strength, the plasma density, and the plasma temperature required for ignition and burn in the Reference Design. These parameters (see Table 2.1) are chosen in the context of their influence on plasma confinement. Substantial understanding in this area is already available, although surprises in future experiments cannot be ruled out. Continued studies to improve tokamak confinement via improved stability by optimizations in the plasma shape, profile, and beta are also being actively pursued. The evolution of high beta plasmas over long pulses is one of the topics on which work is still needed.

\section{Plasma heating}

Heating with 150-keV, 50-MW deuterium beams for $6 \mathrm{sec}$ is assumed in the Reference Design. Recent neutral beam injection in PLT, heating the plasma to near ignition temperatures, has increased confidence in these assumptions. Experimental corroboration is needed for the theoretical calculations showing that ignition can be reached with a neutral beam. energy level of only $150 \mathrm{keV}$ using the low density or smalil radius heating scenario in the Reference Design. The.physics of $r f$ heating is presently less well understood, although vigorous experimental programs are in progress. The optimal combination of $r f$ and neutral beam heating. also needs to be explored experimentally.

\section{Fusion ignition and burn}

Achieving $Q=1-2$ in TFTR will only provide a demonstration of the approach to ignition, while the Reference Design assumes ignition $(Q=5)$ 
and burn $(?>5)$. An experimental understanding of the plasma physics of ignition and burn is needed. The study of the dependence of the burn process on the plasma parameters, the fusion alpha par-icle power depositian profile, the fueling rate, the D-T composition, and the method of fueling will provide the basis for burn control over long pulse times i $\left.210^{2} \mathrm{sec}\right)$. Detailed numerical simulations consistent with the proper corfinemen: assumptions and tie possible improvements in TFTR achievements to $Q>2$ are needed to reduce the gap between present estimates and the actual demonstration of ignition and burn. An experimental test of ignition and burn still sems necessary to verify our assumptions.

\section{Plasma operation and control}

The desired plasma parameters, profiles, and cross sections through the phases of startup, heating, ignition, burn, and shutdown should be elucidated through studies in plasma confinement and cptimization, heating, and ignition and burn. An understanding of the plasma control requirements along the cesired path of operation durirg the pulse is presentiy lacking. Studies of methods to avoid fusior thernal runaway and plasma disruption and to reduce pulsed fields at the TF coils should be actively pursued.

\section{Impurity control}

The plasma and impurity transport processes through the plasma edge/scrape-off region and in the divertors are presently the weakest area af physics understanding. The use of poloidal divertors will be stucied in PDX. However, the physics of the bundle divertors chosen for the Reference Design (because of their potential engineering advantages) and the impact of the divertors on plasma confinement must be studied at a level comparable to that of PDX before a clear choice can be made for the TMS class of device. The impurity production process involves interactions between the plasma and the wall/collector plates under large thermal power loading. The long pulse $\left(210-10^{2} \mathrm{sec}\right)$ behavior of these interactions and their effects on the impurity control processes 
also need to be studied because presently successful methods using titanium gettering may be limited to short pulses ( $\sim \mathrm{sec})$. Other impurity control schemes should also be explored.

\section{Summary of physics needs}

On the basis of these discussions we can identify some critical physics issues for the Reference Design. They include:

(1) Long pulse behavior of impurity production and transport under high thermal power in a diverted plasma.

(2) Long pulse evolution of high beta MHD equilibria through substantial flux diffusion and influenced by fusion alpha particle heating and various fueling sources.

We can also identify areas where understanding can be developed via theoretical analyses and numerical simulations with some confidence (al though experimental studies in these areas would increase our confidence in the fusion plasma operation in the Reference Design). They include:

(1) The physics of fusion ignition and burn $(Q>5)$ for a time scale much longer than the energy confinement time.

(2) The physics of helium ash accumulation and transport in diverted plasmas.

Finally, the physics/engineering studies during FY 1978 have suggested schemes that could favorably impact the reactor engineering and technology requirements. These studies point to the following desirable experimental verifications:

(1) Experiments to optimize the neutral beam injection process (such as the low density and small radius scenarios) that directly or indirectly corroborate the process of heating to ignition with beam energies of $2150 \mathrm{keV}$.

(2) Fueling experiments with partial pellet penetration.

(3) Experiments with a flexible PF coil system and superconducting TF coils to study ways to minimize the pulsed field during startup and disruption. 
(4) Exp:riments with the use of plasma heating sources before and during current sta"tup tc increase tre startup time and to reduce cost.

(5) Experiments with variable field perturbations (such as ripples in the toroidal field) as a method of controlling the runaway electrons and the plasma edge condition and improving access to the plasma core.

\subsubsection{Divertor System}

Ir the Reference Design, a bundle divertor approach was adopted for impurity control. The cancept chosen for continuing study incorporates a liqu'd litioum jet syster to absorb the larje amount of diverted power and particies with a reasonatle cross-sectional area. The assessment of the technical needs for the tundle divertor sho'ws two areas of needed emphas:s:

(1) Bundle divertor cail configurations that address

- the incorporation of larger coils that permit adequate scrapeoff areas and allow room for adequate shielding,

- approaches to equalize the energy variation expected across the face of the lithium collection jets, and

- methods of ceramic insulation of the coils that would ease the shielding requirements.

(2) The 1:quid lithiun "shower" concept for ion, energy collection that aduresses

- the expansion of the temperature range beyond the present $2350^{\circ} \mathrm{C}$ limit where data are available or the collection of hydrogen isotope ions by liquid litnium,

- the ability 0 - the "shower" to retain embedded alpha particles, and

- the ability of liquid lithium to pump nautral hydrogen isotopes. 


\subsubsection{Pellet Fueling System}

The fueling technique adopted in the Reference Design is the injection of pellets of solid deuterium and tritium. The developments being carried out in this area have provided encouraging results both in laboratory experiments and on the ISX-A tokamak. ${ }^{4}$ Continuing physics calculations and experiments are needed to better define the injection requirements. The technical advancements required for TNS implementation are highlighted by three needed actions:

(1) Development of the potentially promising concepts of pellet injection by gas, mechanical, and electromagnetic methods of acceleration.

(2) Expansion of the data base on the physical properties of deuterium and tritium pellets.

(3) Intensification of efforts to achieve equipment design innovations and simplifications that will lead to enhanced equipment reliability, fabricability, and cost effectiveness.

\subsubsection{Neutral Beams}

The demonstrated success of neutral beam heating, in particular the recent PLT results, has provided a growing confidence that such systems can be used in future devices. However, the complexities of current experimental beam lines raise issues concerning cost, reliability, and maintenance in the TNS context. The chief technical needs of neutral beam systems for the Reference Design are as follows:

(1) The capacity for $12.5 \mathrm{MW}$ per beam line for $6 \mathrm{sec}$ at energy levels up to $150 \mathrm{keV}$.

(2) Simple, more reliable systems that can obtain the recessary performance.

(3) Simple means of operating and controlling multiple beam lines.

(4) Design and fabrication concepts that will minimize the difficulties of maintaining the beam 1 ines in a reactor environment. 


\subsubsection{Poloidal Field System}

The PF system consists of seven sets of coils, each requiring separate power supplies. A combination of copper and superconducting coils (inside and outside the TF coils, respectively) is used; the interior copper coils permit a close coupling to the plasma. The key R\&D needs are:

(1) Pulsed superconducting coil technology to meet the Reference Design needs (e.g., $\dot{B} \sim 2 \mathrm{~T} / \mathrm{sec}, B_{\max } \sim 8 \mathrm{~T}$ ).

(2) Simple electrical storage and supply circuitry for cost and reliability improvements.

\subsubsection{Mechanical Systems}

The mechanical systems for the Reference Design include the machine structure, the secondary vacuum enclosure, the remote servicing equipment, and snielding. The technology data base is largely available to meet the mechanical systems requirements of the Reference Design. However, the specific implementation of the design requirements requires significant expansion of the data base, especially in two areas:

(3) Material properties in a high temperature, high neutron flux environment.

(2) Remote servicing equipment and methods for replacement and repair of highly activated device components.

\subsubsection{Blanket}

The Reference Design includes concepts for the first wall and bulk. shield =unctions but does not address the requirements o: a breeding blanket. The blanket that must breed fuel, recover heat, and provide some shielding is being studied in depth in the ORNL Tokamak Reactor Blanket Study, 5 the objective of which is to develop a blanket concept based on near-term technology that satisfies reliability and lifetime needs for a commercial reactor. A promising blanket concept has been advanced, and preliminary analyses support its potential for reactor 
application. This technical area is of particular value to the engineering test phase of the TNS, and a continuing blanket development effort is necessary. The blanket requirements in terms of surface and volumetric heat generation rates coupled with the large number of power on/off cycles are challenging - even if the severe neutron irradiation effects are ignored. The following R\&D activities would be of particular benefit:

(1) Development of an experimental basis for promising bianket concepts via model testing that includes some limited neutron environment. MHD effects can and should be tested for blankets employing liquid lithium.

(2) Characterization of the requirements imposed on the blanket (i.e., particle loading and heat loads) in the event of an abnormal or disruption situation as well as for a normal cycle.

\subsubsection{Toroidal Field System}

The Reference Design specifies an on-axis magnetic field of $5.3 \mathrm{~T}$, which is to be produced by 12 superconducting TF coils with a horizontal bore of $6.2 \mathrm{~m}$ and a vertical bore of $9.8 \mathrm{~m}$. This combination of number of coils and coil size yields a magnetic field ripple of $1.5 \%$ at the plasma edge. The TF coils are assumed to be a pure tension D-shape design with a trapezoidal cross section. The centering forces on the coils are reacted through a bucking cylinder. The major technology needs associated with the TF system may be summarized as follows:

(1) Production of $\mathrm{Nb}_{3} \mathrm{Sn}$ conductor and manufacture of coils without strain degradation of properties.

(2) Designs for coil cooling that will avoid collections of helium bubbles and/or vapor in the liquid helium, which would result in degradation of the heat transfer.

(3) Means of coil protection, including the detection of small normal zones, quench pressure in forced flow channel, or quench voltage in bath-cooled coils and the control of coil currents or fault forces. 


\subsubsection{RF Sys:em}

The use of $r f$ heasing around $120 \mathrm{GHz}$ has been selected to aid plasma breakdown. Experinental substantiation of this assumption is critical and should be yigorously pursued because of the large potential cost benefits. Microwave power on the order of $1 \mathrm{MW}$ is suggested for deposition in the plasma region for $\sim 2 \mathrm{sec}$. Relatively efficient waveguides and flush-mounted arrays can be designed to accomplish the power transmission. The major R\&D areas that should be pursied iriclude:

(1) Development of power tubes to achieve $200 \mathrm{~kW} \mathrm{cW}$ per tube at $120 \mathrm{GHz}$.

(2) Development and component testing of the elements required to transfer the rf power from the sources to the plasma: including oversize waveguides, modal filters, materials tiat cán tolerate the reactor environment, pressurization windows, and antennas.

\subsubsection{Instrumentation and Controls System}

Tris system is required to automatically control the device through all its phases of operation. Instrumentation is provided for controlling functions and for diagnostics. The data from the instrumentation are processed and either displayed or stored for later on-call display. The . ohiloscphy of operation is that of semiautonomous subsystem controls and diagnostics operating under the supervision of a central computerized control. A significant emphasis in the development of this system must be the necessary designs for fail-safe operations and degraded mode options.

Table 3.3 is a list of major parameters that may need $\div 0$ be measured, along with some sensing concepts that should be studied for use in the reactor environment.

Future investigatiors must include more study of the problems of disruptions, aborts, and shutdo'wn and of the difficulties of defining sensors and instrumentation systems that can survive the reactor environment and meet the accuracy and response demands of the controls and diagnostics. Thus, the Frimary R\&D needs include: 
(1) Development of a hybrid computer instrumentation and control (I\&C) simulation, bench marked with experiments and expension to long pulse calculations and experiments.

(2) Development of instrumentation that can operate $i r_{i}$ the expected reactor environment.

Table 3.3. Parameters to be measured and candidate sensing concepts.

\begin{tabular}{lc}
\hline \multicolumn{1}{c}{ Parameters } & Candidate sensing concepts \\
\hline $\begin{array}{l}\text { Plasma density as a function } \\
\text { of time and plasma radius }\end{array}$ & $\begin{array}{c}\text { Thomson scattering, } \\
\text { microwave atsorption }\end{array}$ \\
Plasma location & Inductive pickup loops \\
Average plasma current & Rogowski coils \\
$\begin{array}{l}\text { Plasma ion and electron } \\
\text { temperatures as functions } \\
\text { of time and plasma radius }\end{array}$ & Thomson scattering, \\
Magnetic field strengths & soft x-ray detectors \\
Neutron flux at first wall & Inductive pickup loops \\
\end{tabular}

\subsection{MISSION DESCRIPTION}

The operating plan or mission of the facility is to provide a majcr cost-effective stepping-stone of knowledge and unjerstanding for the development path to a fusion energy option. The facility operation must be carefully planned and conducted on this basis. The early identification of the desired operations provides additional guidance to the evolution from the Reference Design to the Final Design. Therefore, the mission description is an important element in the design process, and the following comments relay the initial issues and suggestions.

\subsubsection{Objectives}

TNS is viewed as the initial core of an Engineering Test Facility (ETF). This initial core may be followed by several modifications and 
upgrädes and also by additional fusion cores based on aliernate concepts. The program objectives of TNS must reflect its position in the ETF and in the overall nagnetic fusion energy development program. TNS is intended to bridge the gap between TFTR and an engineering prctotype reactor (EPF). 6 Toward this end, TNS mus: achieve the necessary advanceme its in boti plasma physics and engineering technology develapment. In tr. a area of Jlasma physics, TNS must produce a controllajle, ignited plasma and demonstrate long pulse, high duty factor, D-T operction. In the area of engineering technology development, TNS must incorporate and test components and systems which are relevant to the EPZ.

\subsubsection{Assumptions}

The progress in physics and technology development prior to the operation of TNS will be significant and must be assessed in such a way that the mission plan is properly based. The following assumptions have been made about the TNS pregram and about the physics and engineering data base which would be available during TNS development.

(1) Operation will begin in late 1989.

(2) TNS will be operaticnal for at least 10 years.

(3) The physics data base available prior to TNS operation will include successful experience in

- particle energy confinement,

- long pulse hydrogen operation,

- ignition and burr dynamics,

- disruption characterizations,

- startup and controlled shutdown,

- fueling and particle control,

- heating,

- divertor operaticn, and

- reactor-relevant diagnostics.

(4) The engineering datc base will include technology developments in

- large superconducting magnets (steady-state and pulsed),

- tritium operatioris, 
- remote maintenance and assembly,

- radiation-compatible controls and sensors, and

- helium/hydrogen separation-pumping.

The proposed TNS operational plan has been divided into the following four phases:

Phase I. Integrated system checkout (0.5 year),

Phase II. Hydrogen (deuterium) phase ( 1.5 years),

Phase III. Ignition test and plasma burn phase (2.5 years),

Phase IV. Engineering test phase ( 5.5 years).

The schedule relationship of these phases is shown in Fig. 3.3.

Phase I. Integrated system checkout

During this phase, the checkout of each system of the device and the step-by-step integration of the systems into the completed operating device will be accomplished. Remote maintenance and assembly procedures are to be evaluated throughout Phases. I and II. The major machine system operation in this phase includes discharge cleaning, diagnostics shakedown, and hydrogen operation to validate the physics regimes observed in previous experiments (approximately 10,000 shots).

The three subphases are:

(1) Debugging to check out all subsystems and integrate them into the device (4 months).

(2) Limited hydrogen operation to correlate with physics regimes of previous machines ( 2 months).

(3) Remote maintenance and assembly checkout (continuous).

Phase II. Hydrogen (deuterium) operation

During this phase, the device will be operated over a broad range of hydrogen plasma parameters. The characterization of the major functions of the device will be to provide the base for "fine-tuning" the machine and its scenarios for the subsequent ignition and burn phase. Long pulse operations will be stressed, with their attendant refueling, 
ORNL DWG 79-24.34 FEU

TINS UPERATIUNALL YEAKS

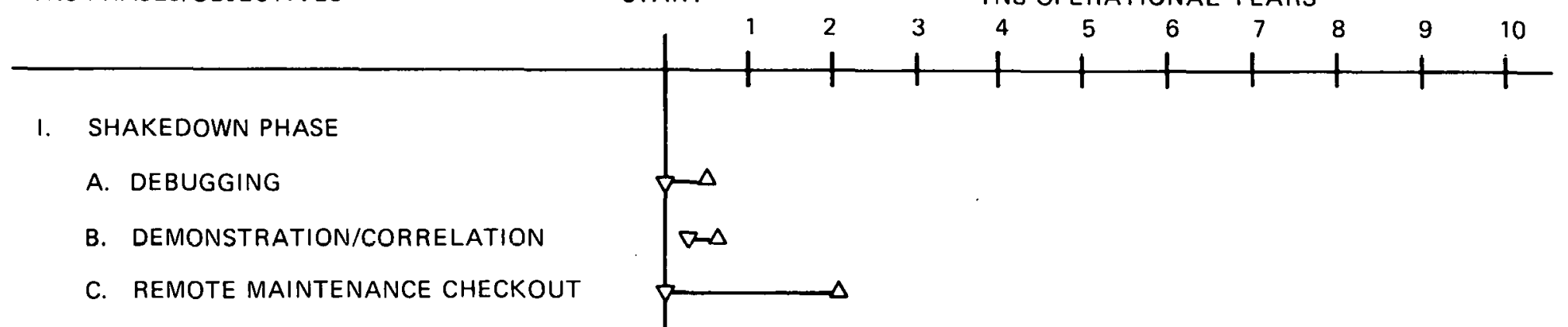

II. IIYDNOGEN (DCUTL MIUM) PIIAGE
A. S.HARACTERIZE MACHINE'S HYDROGEN CAPABILITY
B. LONG PULSE OPERATIONS

III. IGNITION TEST AND PLASMA BURN PHASE
A. NEAR.IGNITION EXPLORATION
B. IGNITION CHARACTERIZATION
c. LONG BURN/HIGH DUTY FEASIBILITY

IV. ENGINEERING TEST PHASE
A. PLASMA ENGINEERING COMPONENTS
B. SHUTDOWN FOR CHANGEOUTS
C. NUCLEAR ENGINEERING COMPONENTS

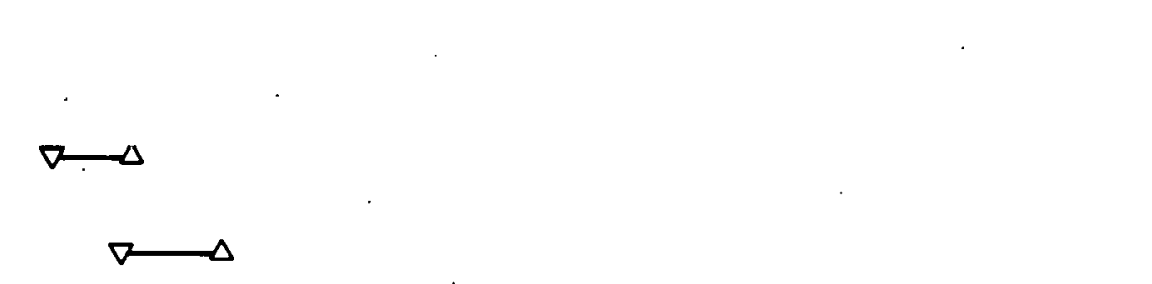

Fig. 3.3. TNS operating plan. 
impurity, and disruption concerns. The severity and frequency of disruptions will be addressed, the techniques for dealing with disruptions having been evaluated in previous experiments. There will be approximately 30,000 hydrogen (deuterium) shots during this operational phase (150 shots per 2-shift day, assuming that an average shot at this stage is about $6 \mathrm{~min}$ ).

The two subphases are:

(1) Characterization of the machine's startup/shutdown, fueling, heating, and magnetic field capability ( 7 months).

(2) Long pulse operation to emphasize refueling, impurity control, divertors, power densities, and disruption characteristics (11 months).

Phase III. Ignition test and plasma burn phase

This most critical phase will begin with an exploration of operation near ignition to define the phenomena expected upon ignition and how excursions may occur and be controlled. Following this subphase, the ignition regime will be explored. After these 2-1/2 years of operation (approximately 100,000 shots at an average of 5 min per shot) have provided the necessary understanding of the ignited plasma and its interaction with the machine variables, extension of the burn times will be undertaken to explore the path to high duty cycles.

The three subphases are:

(1) Exploration of near ignition (12 months).

(2) Characterization of ignition (12 months).

(3) Long burn tests and determination of high duty cycle feasibility (6 months).

\section{Phase IV. Engineering test phase}

The primary objective of this phase is component tesing for the EPR. Here the operations (approximately 400,000 shots at an average of about 5 min per shot) are dictated mainly by the need to fill any gaps in the extrapolatability of the previous test results to the EPR. The 
technology and engireering questions will have become more prominent during the growth of plasma physics knowledge in the previous phases. New heating, fueling, and other plasma engineering technologies developed during the previous 5 years will be introduced and tested. Sensitivity of machine operation to design parameters (especially those that could leaci to reliability and cost improvements) will be studied. It is expected that remote maintenance and changeout procedures developed during earlier phases will be ased extensively during this phase. Candidate blanket modules will be considered for test. The previous extrapolation of the neutronic performance of the prototype designs will be verified.

The three subphases are:

(1) Flasma engineering components/testing of plasma neating, fueling/ refueling, magnet systens, divertors, and controls/diagnostics (24 months).

(2) Shutdown for changeouts (e.g., blanket modules) (12 months).

(3) Nuclear engineering component/testing of heat renoval, remote maintenance and assembly, and upgrade of selected systems (30 months). 
89

REFERENCES

1. D. A. Sink and E. M. Iwinski, A Computer Code for the Costing and Sizing of TNS Tokamaks, WFPS-TME-062, Westinghouse Electric Corporation, Pittsburgh, Pennsylvania (September 1977).

2. W. B. Wood, Draft Program Plan for TNS - The Next Step After the Tokamak Fusion Test Reactor: Part IV - Program Planning, ORNL/TM-5984, . Oak Ridge, Tennessee (September 1978).

3. Oak Ridge TNS Program Staff, Draft Program Plan for TNS - The Next Step After the Tokamak Fusion Test Reactor: Part II - RED Needs Assessment, ORNL/TM-5983, Oak Ridge, Tennessee (December 1977).

4. S. L. Milord et al., Hydrogen Pellet Fueling Experiment on the ISX-A Tokamak, ORNL/TM-6496, Oak Ridge, Tennessee (October 1978).

5. P. B. Mohr et al., Advanced Systems Program: Tokamak Blanket Design Study, ORNL/TM-6847, Oak Ridge, Tennessee (to be published).

6. J. M. Deutsch, The Department of Energy Policy for Fusion Energy, DOE/ER-0018, United States Department of Energy, Washington, D.C. (September 1978). 
THIS PAGE

\section{WAS INTENTIONALLY LEFT BLANK}




\section{CONCLUSIONS}

The major activities of the Oak Ridge TNS Program for FY 1978 are summarized below in the context of engineering feasibility, plasma operating characteristics, and project planning, and conclusions are drawn.

\subsection{ENGINEERING FEASIBILITY}

The activities in the area of engineering feasibility focused on three issues: remote maintenance, the PF system design, and the divertor design.

\section{1:1 Remote Maintenance}

The remote maintenance features of the Reference Design are a significant improvement over those of the Baseline Design as a result of three major design changes:

(1) The number of TF coils was reduced from 20 to 12 in order to create enough room between coils to replace a torus sector without removing the TF coils.

(2) The TF coil bore was increased by about 30\%, which made it possible to relocate the PF coils inside the TF coils during a sector replacement operation and thus eliminate the need for PF coil segmentation.

(3) The use of mechanical torus joints, made possible by the use of an evacuated reactor building has el iminated the need for internal cutting and welding to replace a torus sector.

A 1:40 scale model was constructed to help evaluate the maintenance features of the evolving design.

\subsubsection{Poloidal Field System}

The PF system adopted in the Reference Design represents a significant improvement over that employed in the Baseline Design. The PF system in the Reference Design consists of a superconducting $\mathrm{OH} c 0 i 1$, 
interior ('nside the TF coil bore) copper EF coils, which carry about $35 \%$ of the EF current, and exterior (outside the TF coil bore) superconducting EF.coils, which carry $65 \%$ of the EF current. The PF system in the Daseline Design consisted of a copper $\mathrm{OH}$ coil outside the TF coils and copper EF coils inside the TF coils. The updated PF system design offers a reasonable balance between system cost, coil maintenance, TF coil protection, and power requirements. Moreover, the use of a superconducting central solenoid permits the flux swing for a burn time of around $500 \mathrm{sec} w^{*}$ thout excessive Joule heating losses.

\subsubsection{Divertor System}

A bundle divertor has been adopted for impurity control in the Reference Design, instead of the compact poloidal d-vertar adopted in the Bassline Design. The primary reason for this change in design was to move the divertor sjstem outside the TF coil jore to improve overall access and to provide more space for particle and energy collection. An innovative scheme making use of an array of litnium jets has been proposed as a means of accomplishing the particle and energy collection in the bundle divertor.

\subsection{PL.?.SMA OPERATIMG CHARACTERISTICS}

The activities related to plasma operation focused on the following areas: the reduction of the technology requirements for startup and heating, the maintenance of high beta configurations, and the identification of the key physics issues requiring investigation in order to achieve a controllable, long pulse, ignited tokamak plasma.

\subsubsection{Technology Requirements}

In order to reduce the power supply requirements during startup, a microwave assisted startup procedure has been proposed and evaluated. It is estimated that the peak voltage requirement might be reduced by rouglly an order of magnitude relative to estimates for startup without microwaive breakdown and preheating. Additional experimental evidence is 
required to verify the validity of such an approach. Calculations of neutral beam heating indicate that ignition could be reached with deuterium beam energies as low as $100 \mathrm{keV}$ without excessive demands on power requirements. These calculations, which must still be confirmed by experiments, suggest that reactor heating requirements could be satisfied with positive ion beam systems employing direct recovery and that negative ion beam systems may not be necessary. Beams of $150 \mathrm{keV}$ were adopted in the Reference Design.

\subsubsection{High Beta Maintenance}

The magnetic flux diffusion process in high beta piasmas heated with beams and alpha particles over long time scales is not well understood. The FY 1978 studies have been concerned with the maintenance of high beta equilibria during the heating, ignition, and early burn phases. In this context, the PF system proposed for the Reference Design will allow the control of the D-shaped plasma cross section despite large changes in the plasma profile and beta during, these phases.

\subsubsection{Key Physics Issues}

The control and handling of plasma disruptions is identified as a key physics issue relative to the implementation of TNS. Plasma disruptions would severely limit the useful life of the first wall and would also impose serious design constraints in terms of superconducting magnet protection. The need to characterize, understand, and control disruptions is identified as a major area for further investigation. Overall particle control during the various phases of the plasma operation also represents a key physics area of uncertainty. To date, conceptual solutions based on empirical arguments have been employed to define schemes of particle control, but it is clear that significantly more work needs to be done in this area to define requirements and techniques. A third key physics issue requiring investijation is plasma control during burn, including control of profiles, beta, and impurity. content. 


\subsection{PROJECT PLANNING}

The project planning activi ¿ies considered cost and schedule, R\&D needs assessments, and an operating plan.

\subsubsection{Cost and. Schedule}

The cost estimates performed for the TNS indicate that the direct cost of the facility would be approximately $\$ 500$ million and that the total cast, excluding escalation and interest during construction, would be about $\$ 1$ billion. A cost estimate breakdown on the basis 0 major furictional areas indicates the very large jependence of cost on the TF coil system, followed by the electrical power and controls systems. The TNS scheduling exercise suggests a total project timespan requirement of about ten years, with approximately six years required for device construction.

\subsubsection{3\&D Needs Assessmerits}

The R\&D needs assessments in the general areas of physics and technology identified two major themes: (1) an expansion 0 i efforts is needed to integrate the various physics results in the context of the desired oserational cycle of the plasma in orcer to define more clearly the required $R \& D$ needs for a controllable, lorig pulse, ignition fusion core, and (2) an increased emphasis is recuired in the area of technology and engineering developments to provide reliable, cost-e;fective components for the TWS on a timely basis.

\subsubsection{TNS Mission}

Ar cperating plan or mission was laid out for the TWS facility. This mission consisted of four phases:

Phàse I. Integrated checkout ( 0.5 year $)$.

Phase II. Hydrogen (deuterium) operation ( 1.5 years).

Phase III. Ignition test and plasma burn ( 2.5 years).

Phase IV. Engineering testing ( 5.5 years). 


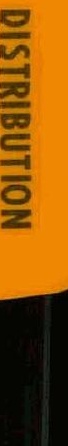


ORNL/TM-6720

Dist. Category UC-20 d

INTERNAL DISTRIBUTION

1. R. G. Alsmiller

2. S. E. Attenberger

3. J. K. Ballou

4. W. R. Becraft

5. L. A. Berry

6. E. E. Bloom

7. A. L. Boch

8. T. G. Brown

9. E. H. Bryant

10. J. D. Callen

11. D. D. Cannon

12. R. J. Colchin

13. R. A. Dory

14. J. L. Dunlap

15. P. N. Haubenreich.

16. J. T. Hogan

17. W. A. Houlberg

18. T. J. Huxford

19. M. S. Lubell

20. J. W. Lue

21. A. T. Mense

22. 0. B. Morgan

23. L. W. Nelms

24. Y-K. M. Peng
25. H. Postma

26. R. L. Reid

27. J. A. Rome

28. M. W. Rosenthál

29. R. T. Santoro

30. C. Sardella

31. J. L. Scott

32. T. E. Shannon

33. J. Sheffield

34-85. D. Steiner

86. N. A. Uckan

87. J. S. Watson

88. W. M. Wells

89. F. W. Wiffen

90. G. W. Wiseman

91. H. T. Yeh

92-93. Central Research Library

94-95. Fusion Energy Division Library

96. Fusion Energy Division Communications Center

97-98. Laboratory Records Department

99. Laboratory Records, ORNL-RC

100. ORNL Patent Office

101. Document Reference Section

\section{EXTERNAL DISTRIBUTION}

102. R. E. Aronstein, Bechtel, P.0. Box 3965, San Francisco, CA 94119

103. D. J. Anthony, General Electric Co., Bldg. 23, Rm. 290, I River Rd., Schenectady, NY 12345

104. J. E. Baublitz, Office of Fusion Energy, Department of Energy, Washington, DC 20545

105. D. S. Beard, Office of Fusion Energy, Department of Energy, Washington, DC 20545

106. G. Benedict, Deaprtment of Energy, Oak Ridge Operations, P.O. Box E, Oak Ridge, TN 37830

107. S. L. Bogart, Science Applications Inc., 8400 Westpark Drive, McLean, VA 22102

108. Roger Boom, University of Wiscons in, Madison, WI 53706

109. R. Botwin, Grumman Aerospace Corp., Bethpage, NY 11714

110. R. N. Cherdack, Burns \& Roe, Inc., 283 Highway 17, Paramus, NJ 07652 
111. J. F. Clarke, Dffice of Fusion Energy, Department of Energy, Washington, DC 20545

112. F. E. Coffman, Office of Fusion Energy, Department of Energy, Washington, DC 20545

113. D. Cohn, Massachusetts Institute of Technology, Cambridge, MA 02139

114. J. W. Coursen, Grumman Aerospäce Corp., Bethpage, NY 11714

115. J. G. Crocker, EG\&G Idaho, Idaho National Engineering Laboratory, P.0. Box 1625, Idaho Falls, ID 8340 I

116. Library, Culhan Laboratory, Abingdon, Oxon, OX14 3DB, United Kingdom

117. N. Anne Davies, Office of Fusion Energy, Department of Energy, Washington, DC 20545

118. H. W. Deckman, Advanced Energy Systems Laboratory, Government Research Laboratories, Exxon Research and Engineering Co., P.O. Box 8, Linden, NJ 07036

119. A. Favale, Grumman Aerospace Corporation, Bethpage, NY 11714

120. J. J. Ferrante, Large Coil Program, B1dg. 2-708, General Electric, Co., 1 River Rd., Schenectady, NY 12345

121. F. Fickett, National Bureau of Standards, Boulder, CO 80302

122. C. A. Flanagan, Westinghouse Electric Corp., Fusion Power Systems, P.0. Box 10864, Pittsburgh, PA 15236

123. H. K. Forsen, Exxon Nuclear Co., Inc., 737 la6th Ave., Bellevue, WA 98009

124. J. W. French, EBASCO Services, Inc., Princeton University, P.0. Box-451, Princeton, NJ 03540

125. G. M. Fuller, M=Donnell-Douglas, Dept. E-450, B1dg. 10613, Rm. 370, St. Louis, MO 53166

126. H. P. Furth, Princeton Plasma Physics Laboratory, Princeton University, P.0. Box 451, Princeton, NJ 08540

127. A. Gaines, Combustion Engineering, 100 Prospect Hill Rd., Windsor, CT 06095

128. A. Gibson, Culham Laboratory, Abingdon, Oxon, OX14 3DB, United Kingdom

129. R. W. Gould, Mail Stop 116-81, California Institute of Technology, Pasadena, CA 91125

130. E. Gregory, Airco Inc., Murray H111, NJ 07974

131. D. S. Hackley, Large Coil Program, General Dynamics-Convair Division, P.0. Box 80847, San Diego, CA 92138

132. R. Hancox, Cu ham Laboratory, Abingdon, Oxon, OX14 3DB, United Kingdom

133. C. R. Head, Office of Fusion Energy, Department of Energy, Washington, DC 20545

134. C. Henning, Läwrence Livermore Laboratory, P.0. Box 808, Livermore, CA 94550

135. R. L. Hirsch, Exxon Research and Engineering Co., P.0. Box 101, Florham Park, NJ 07932

136. Anthony Hsu, Office of Fusion Energy, Department of Energy, Washington, DC 20545

137. D. L. Jassby, Princeton Plasma Physics Laboratory, Princeton University, P.O. Box 451, Princeton, Ni 0854C 
138. D. L. Kummer, McDonnel1-Douglas Astronautics Co., East, P.0. Box 516, St. Louis, MO 63166

139. D. G. McAlees, Manager, ETF Systems Interface, Exxon Nuclear Co., Inc., Research and Technical Center, 2955 George Washington Way, Richland, WA 99352

140. V. A. Maroni, Argonne National Laboratory, 9700 South Cass Ave., Argonne, IL 60439

141. D. M. Meade, Princeton Plasma Physics Laboratory, Princeton University, P.0. Box 451, Princeton, NJ 08540

142. R, L. Miller, General Atomic Co., P.0. Box 81608, San Diego, CA 92138

143. M. R. Murphy, Office of Fusion Energy, Department of Energy, Washington, DC 20545

144. J. G. Murray, Princeton Plasma Physics Laboratory, Princeton University, P.0. Box 451, Princeton, NJ 08540

145. L. K. Price, Department of Energy, Oak Ridge Operations, P.0. Box E, Oak Ridge, TN 37830

146. J. M. Rawls, General Atomic Co., P.0. Box 81608, San Diego, CA 92138

147. P. Reardon, Princeton Plasma Physics Laboratory, Princeton University, P.0. Box 451, Princeton, NJ 08540

148. T. Reuther, Office of Fusion Energy, Department of Energy, Washington, DC 20545

149. M. Roberts, Office of Fusion Energy, Department of Energy, Washington, DC 20545

150. D. J. Rose, Department of Nuclear Engineering, Massachusetts Institute of Technology, Cambridge, MA 02139

151. M. N. Rosenbluth, School of Natural Sciences, Princeton University, P.0. Box 451, Princeton, NJ 08540

152. C. Rosner, Intermagnetics General Corp., Charles Industrial Park, New Karner Rd., Guilderland, NY 12084

153. P. H. Sager, Jr., General Atomic Co., P.0. Box 87608, San Diego, CA 92138

154. G. Schilling, Princeton Plasma Physics Laboratory, Princeton University, P.0. Box 451, Princeton, NJ 08540

155. Z. M. Shapiro, Westinghouse Electric Corp., Fusion Power Systems Department, P.0. Box 10864, Pittsburgh, PA 15236

156. G. Siegel, Tennessee Vally Authority, 1360 Commerce Union Bank Bldg., Chattanooga, TN 37401

157. A. Simon, University of Rochester, Rochester, NY 14627

158. W. M. Stacey, Jr., School of Nuclear Engineering, Georgia Institute of Technology, Atlanta, GA 30332

159. J. Stekly, Magnetic Corp. of America, 179 Bear Hill Rd., Waltham, MA 02154

160. L. D. Stewart, Princeton Plasma Physics Laboratory, Princeton University, P.0. Box 451, Princeton, NJ 08540

161. C. Taylor, Controlled Thermonuclear Research, Nail Code L-382, Lawrence Livermore Laboratory, P.0. Box 808, Livermore, CA 94550

162. F. Thomas, Grumman Aerospace Corp., Bethpage, NY 11714

163. T. C. Varljen, Westinghouse Electric Corp., Fusion Power Systems, P.0. Box 10864, Pittsburgh, PA 15236 
164. S. S. Waddle, Department of Energy, Oak Ridge Operations, P.O. Box E, Oak Ridge, TN 37830

165. J. Willis, Office of Fusion Energy, Department of Energy, Washington, DC 20545

166. W. Wilkes, Mound Laboratories, Miamisburg, $\mathrm{OH} 45432$

167. H. H. Woodson, Department of Electrical Engineering, University of Texas, Austin, TX 78712

168. W. W. Wi thee, Energy Systems, General Dynamics-Convair Division, P.0. Box 80847, San Diego, CA 92138

169. S. Yoshikawê, Princeton Plasma Physics Laboratory, Princeton University, P.0. Box 451, Princeton, NJ 08540

170. J. L. Young, Large Coil Program, Westinghouse Electric Corp., 1310 Beulah Road, Pi.ttsburgh, PA 15235

171. E. Ziurys, Cffice of Fusion Energy, Department of Energy, Washington, DC 20545

172. K. Zwilsky, Office of Fusion Energy, Departmen: of Energy, Washington, DC 20545

173. Office of Assistant Manager, Energy Research and Development, Department of Energy, Oak Ridge Operations, P.0. Box E, Oak Ridge, TN 37830

174-324. Given distrioution as shown in TID-4500, Magnetic Fusion Energy (Distribution Category UC-20 d, Fusion Systems) 